\title{
AGR-2 Irradiation Test Final As-Run Report
}

\author{
Blaise P. Collin
}

February 2018

The INL is a

U.S. Department of Energy

National Laboratory

operated by

Battelle Energy Alliance

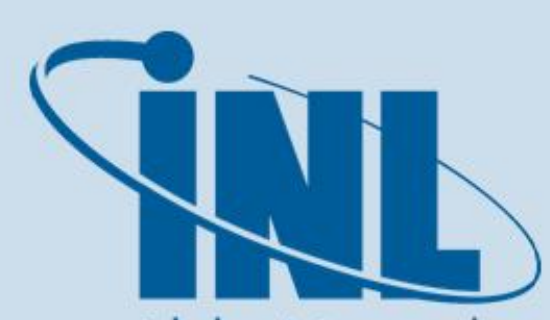

Idaho National Laboratory 


\section{DISCLAIMER}

This information was prepared as an account of work sponsored by an agency of the U.S. Government. Neither the U.S. Government nor any agency thereof, nor any of their employees, makes any warranty, expressed or implied, or assumes any legal liability or responsibility for the accuracy, completeness, or usefulness, of any information, apparatus, product, or process disclosed, or represents that its use would not infringe privately owned rights. References herein to any specific commercial product, process, or service by trade name, trade mark, manufacturer, or otherwise, does not necessarily constitute or imply its endorsement, recommendation, or favoring by the U.S. Government or any agency thereof. The views and opinions of authors expressed herein do not necessarily state or reflect those of the U.S. Government or any agency thereof. 


\title{
AGR-2 Irradiation Test Final As-Run Report
}

\author{
Blaise P. Collin
}

February 2018

\begin{abstract}
Idaho National Laboratory
INL ART Program

Idaho Falls, Idaho 83415
\end{abstract}

http://www.inl.gov

Prepared for the

U.S. Department of Energy

Assistant Secretary for the Office of Nuclear Energy

Under DOE Idaho Operations Office

Contract DE-AC07-05ID14517 

INL ART Program

AGR-2 Irradiation Test Final As-Run Report

INL/EXT-14-32277

Revision 3

February 2018

Prepared by:

13laise Collin

Blaine P. Collin

Approved by:

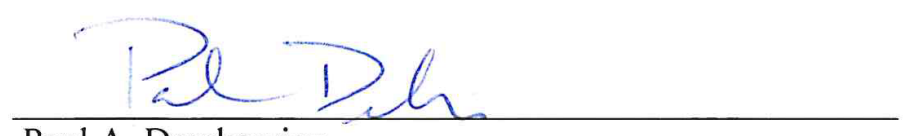

Paul A. Demkowicz

Director AGR Fuel Program

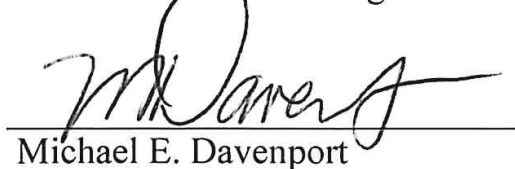

Irradiation Technical Lead

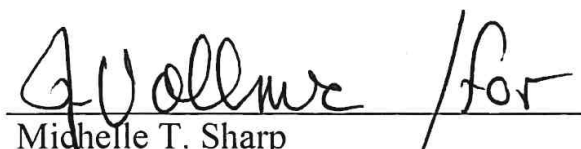

Michelle T. Sharp INL Quality Assurance

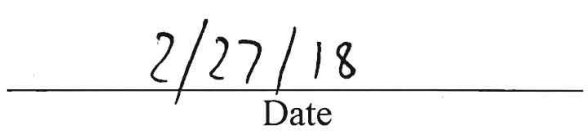

$\frac{2 / 27 / 18}{\text { Date }}$
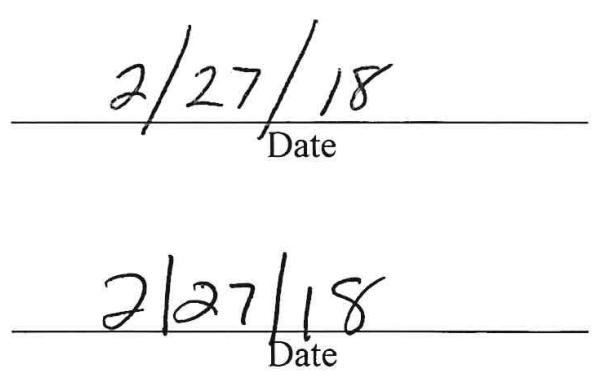

vii 


\section{REVISION LOG}

\begin{tabular}{|c|c|c|c|}
\hline Rev. & Date & Affected Pages & Revision Description \\
\hline 0 & $7 / 16 / 14$ & All & $\begin{array}{l}\text { Initial issue of the AGR-2 Irradiation Test Final As- } \\
\text { Run Report }\end{array}$ \\
\hline 1 & $8 / 6 / 14$ & Page $6,11,20$ & $\begin{array}{l}\text { Typos on pages } 6 \text { and } 11 \text {. Corrected call out of } \\
\text { Figures } 8 \text { and } 9 \text {. Boron content corrected. }\end{array}$ \\
\hline 2 & $8 / 21 / 2014$ & Pages $25-27$ & Updated results in Tables 6 and 7. \\
\hline 3 & $2 / 27 / 2018$ & Appendix A & Fuel properties (Tables A-2 and A- 3 ) \\
\hline & & & \\
\hline & & & \\
\hline & & & \\
\hline & & & \\
\hline & & & \\
\hline & & & \\
\hline
\end{tabular}




\section{SUMMARY}

This document presents the as-run analysis of the AGR-2 irradiation experiment. AGR-2 is the second of the planned irradiations for the U.S. Department of Energy Advanced Gas Reactor (AGR) Fuel Development and Qualification Program. The objectives of the AGR-2 experiment are to:

1. Irradiate $\mathrm{UCO}$ (uranium oxycarbide) and $\mathrm{UO}_{2}$ (uranium dioxide) tristructural isotropic (TRISO) coated particle fuel produced in a large coater. Fuel attributes are based on results obtained from the AGR-1 test and other project activities.

2. Provide irradiated fuel samples for post-irradiation experiment and safety testing.

3. Support the development of an understanding of the relationship between fuel fabrication processes, fuel product properties, and irradiation performance.

The primary objective of the test was to irradiate both $\mathrm{UCO}$ and $\mathrm{UO}_{2}$ TRISO fuel produced from prototypic scale equipment to obtain normal operation and accident condition fuel performance data. The UCO compacts were subjected to a range of burnups and temperatures typical of anticipated prismatic reactor service conditions in three capsules. The test train also includes compacts containing $\mathrm{UO}_{2}$ particles produced independently by the U. S., South Africa, and France in three separate capsules. The range of burnups and temperatures in these capsules were typical of anticipated pebble bed reactor service conditions. The results discussed in this report pertain only to U.S.-produced fuel.

In order to achieve the test objectives, the AGR-2 experiment was irradiated in the B-12 position of the Advanced Test Reactor (ATR) at Idaho National Laboratory for a total irradiation duration of 559.2 effective full power days. Irradiation began on June 22, 2010, and ended on October 16, 2013, spanning 12 ATR power cycles and approximately three-and-a-half calendar years. The test contained six independently controlled and monitored capsules. Each U.S. capsule contained 12 compacts of either $\mathrm{UCO}$ or $\mathrm{UO}_{2}$ AGR coated fuel.

No definite evidence of fuel particle failure was observed during the AGR-2 irradiation. Final burnup values on a per compact basis ranged from 7.26 to $13.15 \%$ FIMA (fissions per initial heavy-metal atom) for UCO fuel, and 9.01 to $10.69 \%$ FIMA for $\mathrm{UO}_{2}$ fuel, while fast fluence values ranged from 1.94 to $3.47 \times 10^{25} \mathrm{n} / \mathrm{m}^{2}(\mathrm{E}>0.18 \mathrm{MeV})$ for UCO fuel, and from 3.05 to $3.53 \times 10^{25} \mathrm{n} / \mathrm{m}^{2}(\mathrm{E}>0.18 \mathrm{MeV})$ for $\mathrm{UO}_{2}$ fuel. Time-average volume-average (TAVA) temperatures on a capsule basis at the end of irradiation ranged from $987^{\circ} \mathrm{C}$ in Capsule 6 to $1296^{\circ} \mathrm{C}$ in Capsule 2 for $\mathrm{UCO}$, and from 996 to $1062^{\circ} \mathrm{C}$ in $\mathrm{UO}_{2}$-fueled Capsule 3. By the end of the irradiation, all of the installed thermocouples had failed. Fission product release-to-birth (R/B) ratios were quite low. In the UCO capsules, R/B values during the first three cycles were below $10^{-6}$ with the exception of the hotter Capsule 2 , in which the R/Bs reached $2 \times 10^{-6}$. In the $\mathrm{UO}_{2}$ capsule (e.g., Capsule 3), the R/B values during the first three cycles were below $10^{-7}$. R/B values for all following cycles are not reliable due to gas flow and cross-talk issues. 
This page intentionally left blank. 


\section{CONTENTS}

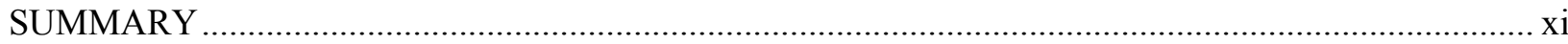

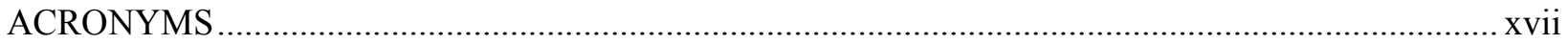

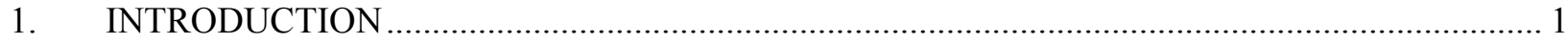

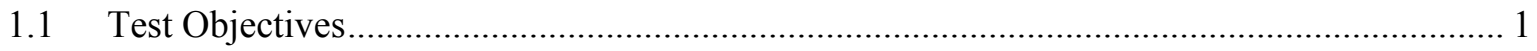

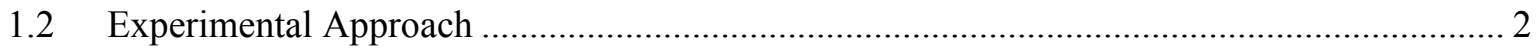

1.3 Management and Qualification of AGR-2 Data .......................................................... 6

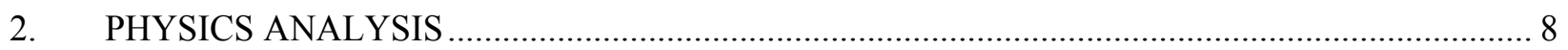

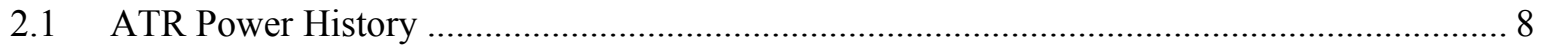

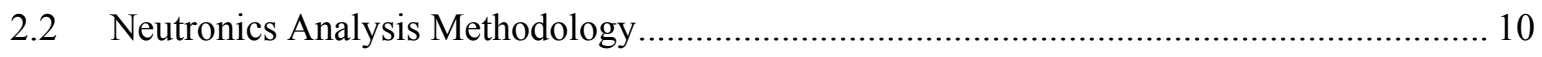

2.3 As-Run Neutronics Analysis Results ............................................................................ 10

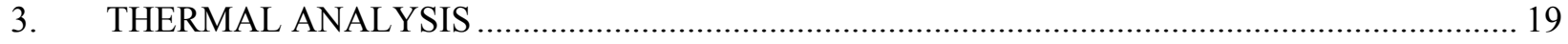

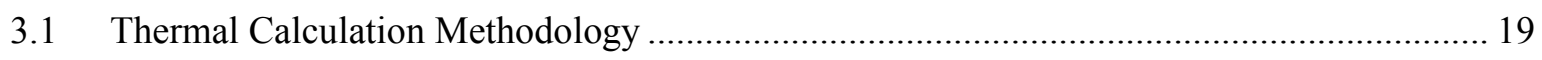

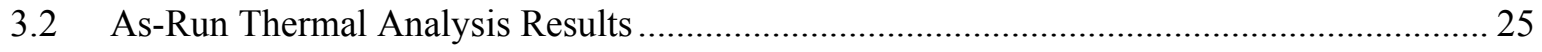

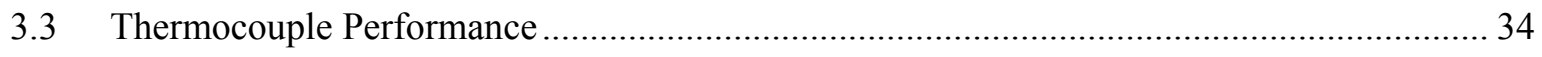

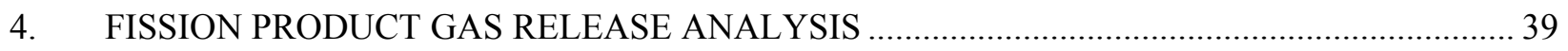

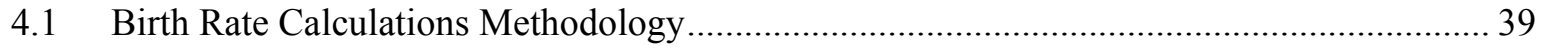

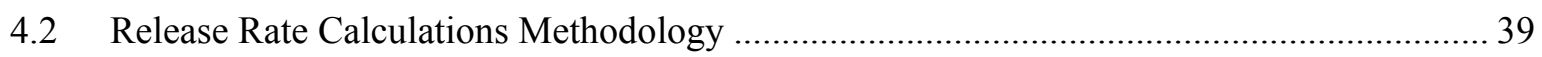

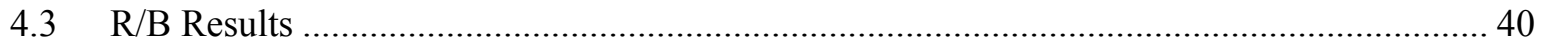

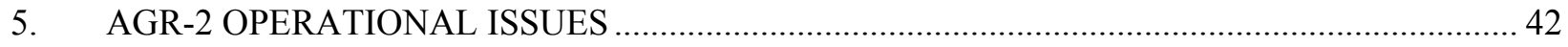

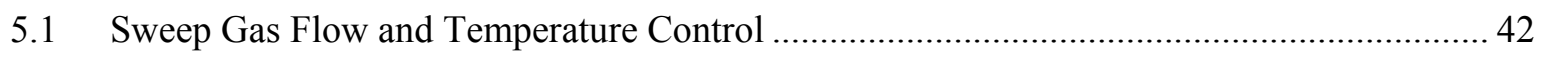

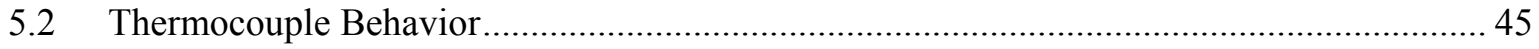

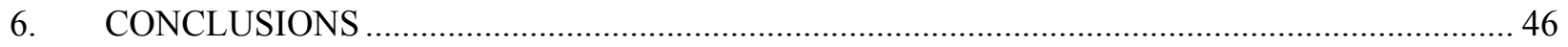

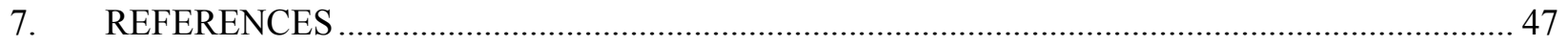

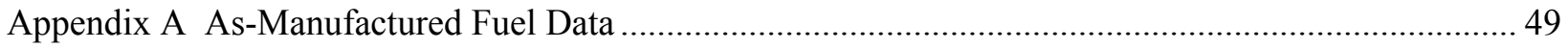

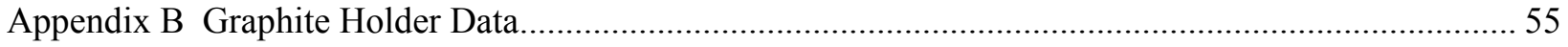

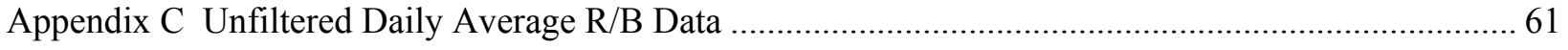

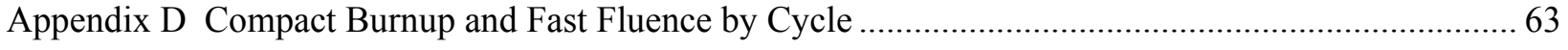




\section{FIGURES}

Figure 1. ATR core cross-section displaying the B-12 position. ............................................................ 2

Figure 2. Axial schematic of the AGR-2 capsules.................................................................................... 3

Figure 3. Schematic of a radial cut of an AGR-2 capsule ......................................................................... 3

Figure 4. Three-dimensional cutaway rendering of single AGR-2 capsule............................................... 4

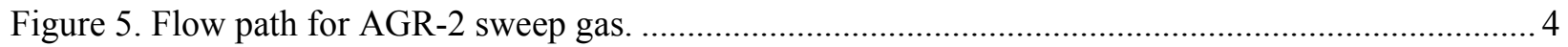

Figure 6. Capsule average power density versus irradiation time in EFPD.......................................... 11

Figure 7. Maximum instantaneous peak particle power versus irradiation time in EFPD for

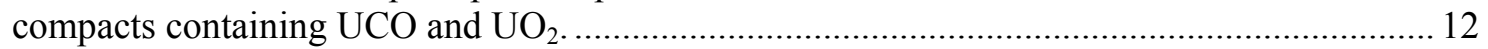

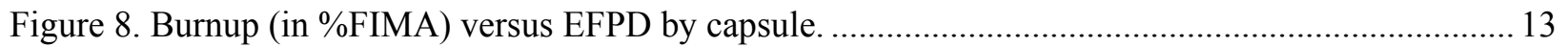

Figure 9. Fast neutron fluence $(\mathrm{E}>0.18 \mathrm{MeV})$ versus EFPD by capsule. ............................................. 14

Figure 10. Fast neutron fluence $(\mathrm{E}>0.18 \mathrm{MeV})$ vs. Burnup for AGR-2 compacts................................ 15

Figure 11. Rendering of ABAQUS finite element mesh of a single AGR-2 capsule.............................. 19

Figure 12. Thermal conductivity of unirradiated, boronated graphite holders (Thompson 2006,

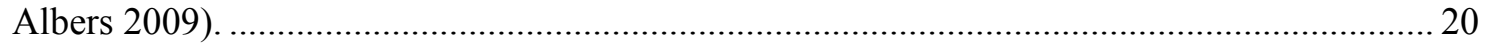

Figure 13. Sweep gas thermal conductivity versus temperature and mole fraction helium...................... 21

Figure 14. Temperature $\left({ }^{\circ} \mathrm{C}\right)$ contour plot cutaway view of the three fuel stacks. ..................................22

Figure 15. Calculated daily minimum, maximum, and volume-average temperatures. ….......................23

Figure 16. Calculated time-average minimum, time-average maximum, and time-average

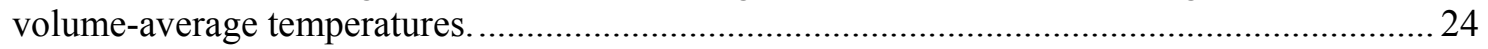

Figure 17. AGR-2 time at temperature for Capsules 5 and 6 (UCO fuel)...........................................28

Figure 18. AGR-2 time at temperature for Capsule 2 (UCO fuel) .........................................................29

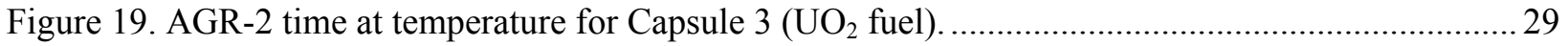

Figure 20. Time-average fuel temperature distribution for AGR-2 UCO fuel and GA SC-MHR.............. 30

Figure 21. Time-average fuel temperature distribution for AGR-2 UCO fuel and GA SC-MHR

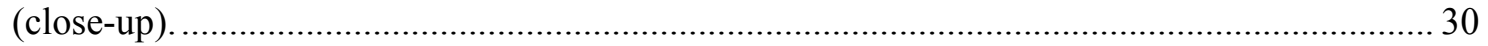

Figure 22. 3-D scatter plots of the irradiation characteristics of the AGR-2 compacts............................ 31

Figure 23. Time-average volume-average temperature $\left({ }^{\circ} \mathrm{C}\right)$ vs. Burnup (\%FIMA) for AGR-2

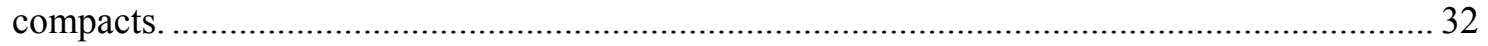

Figure 24. Time-average volume-average temperature $\left({ }^{\circ} \mathrm{C}\right)$ vs. Fast neutron fluence $(\mathrm{E}>0.18$

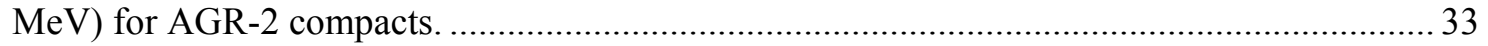

Figure 25. Cutaway view of each capsule showing type and position of TCs (ATR core center to

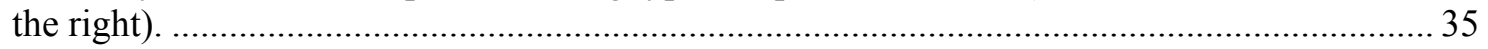

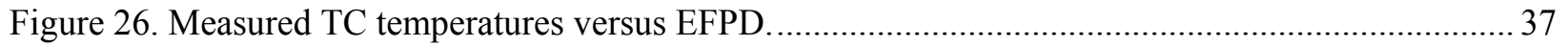

Figure 27. Difference between measured and calculated TC temperatures versus EFPD........................ 38 
Figure 28. R/B ratios from daily birthrates for $\mathrm{Kr}-85 \mathrm{~m}, \mathrm{Kr}-88$, and $\mathrm{Xe}-138$ versus time in EFPD. Data from Cycle 149A and following cycles are not deemed reliable because of gas flow and cross-talk issues.

Figure C-1. Unfiltered R/B ratios from daily birthrates for $\mathrm{Kr}-85 \mathrm{~m}, \mathrm{Kr}-88$, and $\mathrm{Xe}-138$ versus time in EFPD. Data from Cycle 149A and following cycles are not deemed reliable because of gas flow and cross-talk issues.

\section{TABLES}

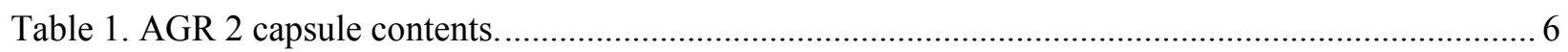

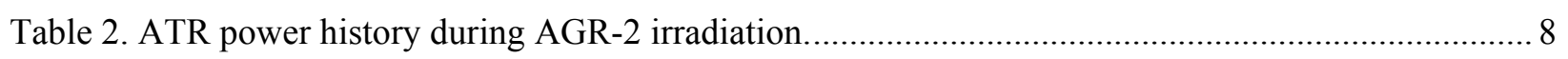

Table 3. Burnup and fast neutron fluence for Capsules 6 and 5 at the end of irradiation......................... 16

Table 4. Burnup and fast neutron fluence for Capsules 3 and 2 at the end of irradiation.......................... 17

Table 5. Minimum, average, and peak compact burnup, and fast fluence at the end of irradiation. ........... 17

Table 6. Compact temperature data for Capsules 6 and 5 at end of irradiation......................................26

Table 7. Compact temperature data for Capsules 3 and 2 at end of irradiation......................................2 27

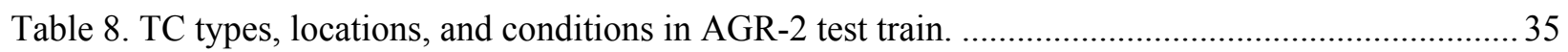

Table A-1. Selected properties for kernel Lot G73I-14-69307 (UCO) and Lot G73AA-10-69308

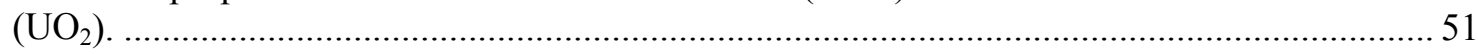

Table A-2. Selected properties for AGR-2 coated particle composites................................................. 52

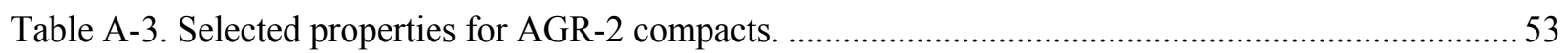

Table D-1. Compact burnup and fast fluence for Capsules 6 and 5 after cycle 147A (AGR-2 cycle 1$)$.

Table D-2. Compact burnup and fast fluence for Capsules 3 and 2 after cycle 147A (AGR-2 cycle 1).

Table D-3. Compact burnup and fast fluence for Capsules 6 and 5 after cycle 148A (AGR-2 cycle 2).

Table D-4. Compact burnup and fast fluence for Capsules 3 and 2 after cycle 148A (AGR-2 cycle 2).

Table D-5. Compact burnup and fast fluence for Capsules 6 and 5 after cycle 148B (AGR-2 cycle 3$)$.

Table D-6. Compact burnup and fast fluence for Capsules 3 and 2 after cycle 148B (AGR-2 cycle 3 ).

Table D-7. Compact burnup and fast fluence for Capsules 6 and 5 after cycle 149A (AGR-2 cycle 4).

Table D-8. Compact burnup and fast fluence for Capsules 3 and 2 after cycle 149A (AGR-2 cycle 4).

Table D-9. Compact burnup and fast fluence for Capsules 6 and 5 after cycle 149B (AGR-2 cycle 5). 
Table D-10. Compact burnup and fast fluence for Capsules 3 and 2 after cycle 149B (AGR-2 cycle 5).

Table D-11. Compact burnup and fast fluence for Capsules 6 and 5 after cycle 150B (AGR-2 cycle 6).

Table D-12. Compact burnup and fast fluence for Capsules 3 and 2 after cycle 150B (AGR-2 cycle 6).

Table D-13. Compact burnup and fast fluence for Capsules 6 and 5 after cycle 151A (AGR-2 cycle 7).

Table D-14. Compact burnup and fast fluence for Capsules 3 and 2 after cycle 151A (AGR-2 cycle 7).

Table D-15. Compact burnup and fast fluence for Capsules 6 and 5 after cycle 151B (AGR-2 cycle 8).

Table D-16. Compact burnup and fast fluence for Capsules 3 and 2 after cycle 151B (AGR-2 cycle 8).

Table D-17. Compact burnup and fast fluence for Capsules 6 and 5 after cycle 152B (AGR-2 cycle 9).

Table D-18. Compact burnup and fast fluence for Capsules 3 and 2 after cycle 152B (AGR-2 cycle 9).

Table D-19. Compact burnup and fast fluence for Capsules 6 and 5 after cycle 153B (AGR-2 cycle 10).

Table D-20. Compact burnup and fast fluence for Capsules 3 and 2 after cycle 153B (AGR-2 cycle 10).

Table D-21. Compact burnup and fast fluence for Capsules 6 and 5 after cycle 154A (AGR-2 cycle 11).

Table D-22. Compact burnup and fast fluence for Capsules 3 and 2 after cycle 154A (AGR-2 cycle 11).

Table D-23. Compact burnup and fast fluence for Capsules 6 and 5 after cycle 154B (AGR-2 cycle 12). 86

Table D-24. Compact burnup and fast fluence for Capsules 3 and 2 after cycle 154B (AGR-2 cycle 12). 


\section{ACRONYMS}

2-D two-dimensional

3-D three-dimensional

AG against grain

AGR Advanced Gas Reactor

ASME American Society of Mechanical Engineers

ATR Advanced Test Reactor

BWXT BWX Technologies

DNE DIDO Nickel Equivalent

EFPD effective full-power days

FIMA fissions per initial heavy-metal atom

FPM fission product monitor

FPMS fission product monitoring system

GA General Atomics

GT-MHR Gas-Turbine Modular Helium Reactor

HPGe high-purity germanium

HTGR High-Temperature Gas-cooled Reactor

INL Idaho National Laboratory

IPyC inner pyrolytic carbon

LEU low-enriched uranium

MCNP Monte Carlo N-Particle transport code

NDMAS Nuclear Data Management and Analysis System

NQA Nuclear Quality Assurance

OPyC outer pyrolytic carbon

ORNL Oak Ridge National Laboratory

PALM powered axial locator mechanism

PIE post-irradiation examination

$\mathrm{R} / \mathrm{B} \quad$ release rate to birth rate ratio

SC-MHR Steam Cycle - Modular Helium Reactor

$\mathrm{SiC} \quad$ silicon carbide

TAVA time-average volume-average

TC thermocouple

TRISO tristructural isotropic

UCO uranium oxycarbide 
$\mathrm{UO}_{2} \quad$ uranium dioxide 


\section{AGR-2 Irradiation Test Final As-Run Report}

\section{INTRODUCTION}

Several fuel and material irradiation experiments have been planned for the U.S. Department of Energy Advanced Gas Reactor (AGR) Fuel Development and Qualification Program, which supports the development of the high temperature gas-cooled reactors (HTGRs). The goals of these experiments are to provide irradiation performance data to support fuel process development, qualify fuel for normal operating conditions, support development and validation of fuel performance and fission product transport models and codes, and provide irradiated fuel and materials for post-irradiation examination (PIE) and safety testing (INL 06/2017). AGR-2 is the second in this series of planned experiments to test tristructural isotropic (TRISO)-coated fuel particles containing low-enriched uranium fuel in a uranium oxycarbide and uranium dioxide forms.

The primary objective of the test was to irradiate both uranium oxycarbide (UCO) and uranium dioxide $\left(\mathrm{UO}_{2}\right)$ TRISO fuel produced from prototypic scale equipment to obtain normal operation and accident condition fuel performance data. If substantial failures had occurred during irradiation, such as leakage or malfunctions with temperature control, gas monitoring, or instrumentation, the test train could have been removed from the reactor before the planned completion of irradiation. Test components would have then been examined to determine what modifications would be required for subsequent test trains.

In conjunction with the fuel process development effort, AGR-2 irradiated fuel that was produced in an industrial scale coater. The AGR-2 fuel design serves as the final design for the AGR fuel development program although subsequent tests in the AGR program will irradiate fuel produced in a larger coater to better reproduce fuel fabrication at an industrial level.

The AGR-2 fuel test was successful in irradiating the fuel compacts to the burnup and fast fluence target ranges. All compacts achieved, as specified, a burnup of at least $7 \%$ fissions per initial heavy-metal atom (FIMA), and 36 of the 48 compacts ( $28 \mathrm{UCO}$ compacts and $8 \mathrm{UO}_{2}$ compacts) reached a burnup higher than $10 \%$ FIMA, which is better than the goal of 24 compacts. Fast neutron fluence fell in the expected range of 1.5 to $5 \times 10^{25} \mathrm{n} / \mathrm{m}^{2}(\mathrm{E}>0.18 \mathrm{MeV})$ for all compacts. Finally, no definite evidence of particle failure was observed during the test. Once the PIE is completed, this test will provide irradiated fuel performance data and safety testing performance fuel data to support the development of a fundamental understanding of the relationship between the fuel fabrication process, as-fabricated fuel properties, and normal operation and accident condition performance.

This document presents the AGR-2 data collected and the analysis results of the as-run fuel irradiation conditions, including a summary of the experimental approach, as-run reactor physics and thermal analysis, fission product release-to-birthrate ratio calculations and measurements, issues encountered during the test, and a summary of data qualification work.

At the time this report was released, the AGR-2 test train had been unloaded from the reactor and some post-irradiation observations had been made, but the full PIE had not occurred, so it will be documented in a later report.

\section{$1.1 \quad$ Test Objectives}

As defined in the Technical Program Plan for the AGR fuel program (INL 06/2017), the objectives of the AGR-2 experiment are to:

1. Irradiate $\mathrm{UCO}$ and $\mathrm{UO}_{2}$ TRISO fuel produced in a large coater. Fuel attributes are based on results obtained from the AGR-1 test and other project activities. 
2. Provide irradiated fuel samples for post-irradiation experiment and safety testing.

3. Support the development of an understanding of the relationship between fuel fabrication processes, fuel product properties, and irradiation performance.

\subsection{Experimental Approach}

To achieve the test objectives outlined above, in accordance with requirements from the Technical Program Plan (INL 06/2017) and the Irradiation Test Specification (Maki 2010), AGR-2 was irradiated in the B-12 position of the Advanced Test Reactor (ATR) at Idaho National Laboratory (INL). A cross-sectional view of the ATR core indicating this location is displayed in Figure 1. A priori physics calculations (Chang 2002) showed that anticipated HTGR end-of-irradiation conditions (burnup to about $20 \%$ FIMA and maximum fast neutron fluence of $5 \times 10^{25} \mathrm{n} / \mathrm{m}^{2}, \mathrm{E}>0.18 \mathrm{MeV}$ ) were best matched by the conditions obtained from irradiation in these large B positions.

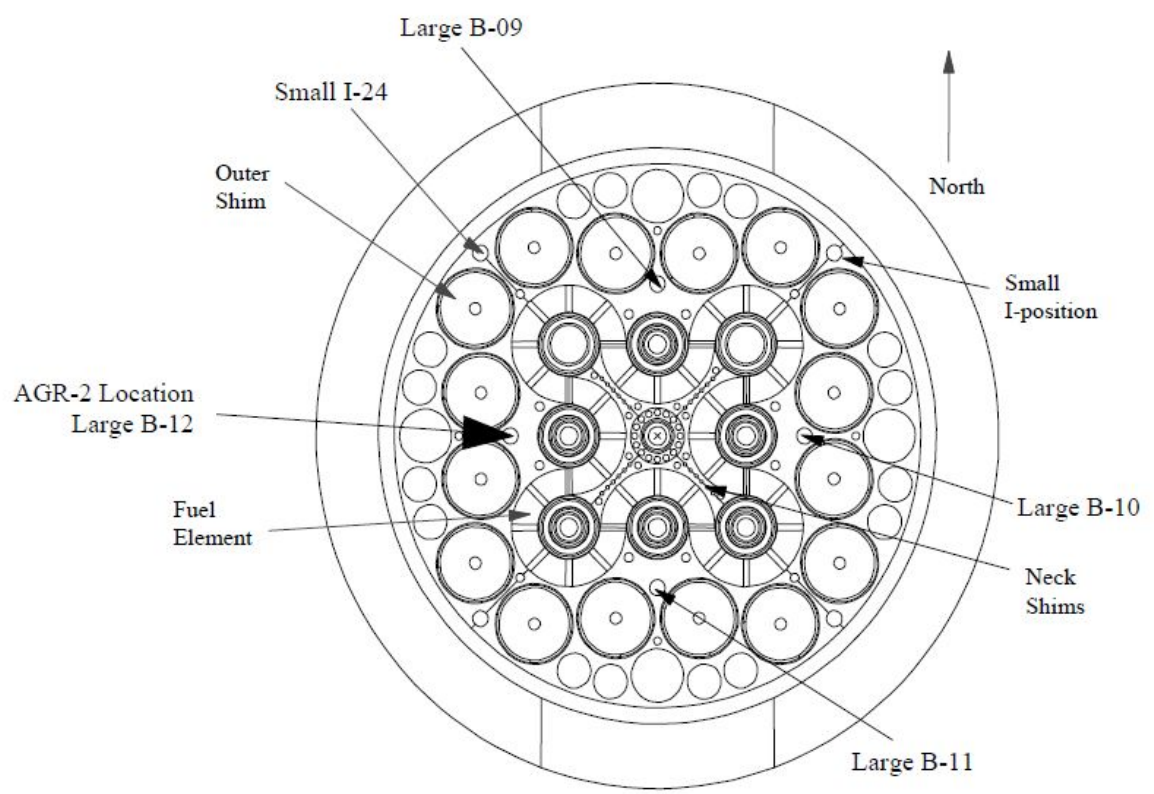

Figure 1. ATR core cross-section displaying the B-12 position.

The AGR-2 test train is a multi-capsule, instrumented lead experiment, designed for irradiation in the $38.1 \mathrm{~mm}$ (1.5 in.) diameter B-12 position of the ATR. The test train contains six capsules, each independently controlled for temperature and independently monitored for fission product gas release. An axial view of the test train is illustrated in Figure 2. Each AGR-2 capsule is $152.4 \mathrm{~mm}$ (6 in.) long and contains 12 fuel compacts arranged in three vertical stacks with each stack containing four compacts. Figure 3 shows a radial cutaway view of a capsule illustrating the arrangement of the three compact stacks and showing the hafnium shroud used to suppress flux on the east side of the capsule. 


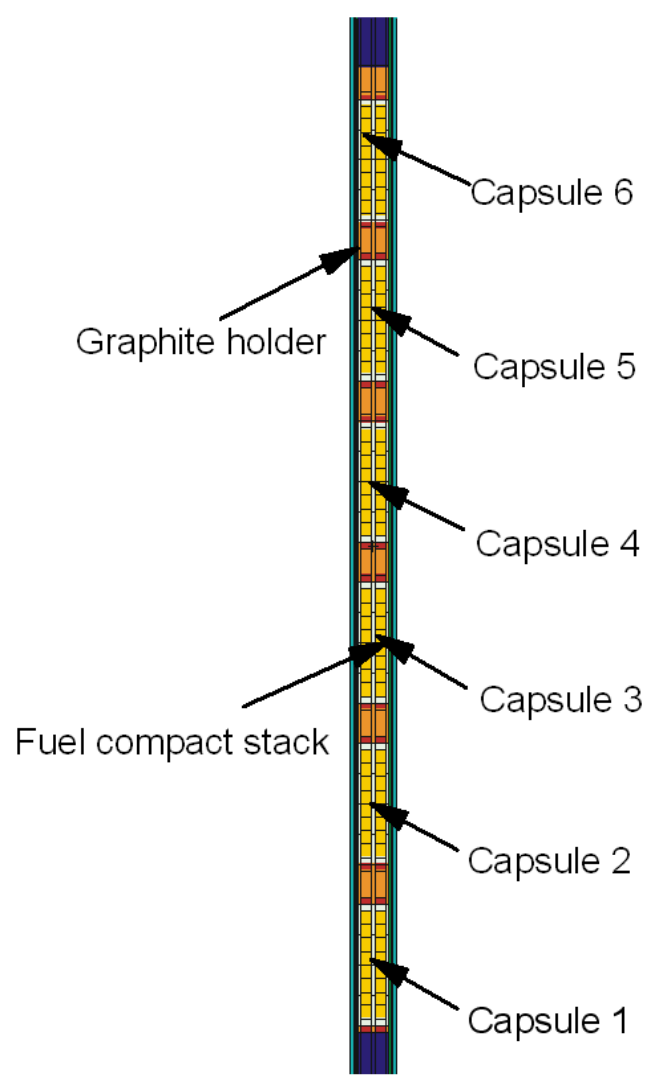

Figure 2. Axial schematic of the AGR-2 capsules.

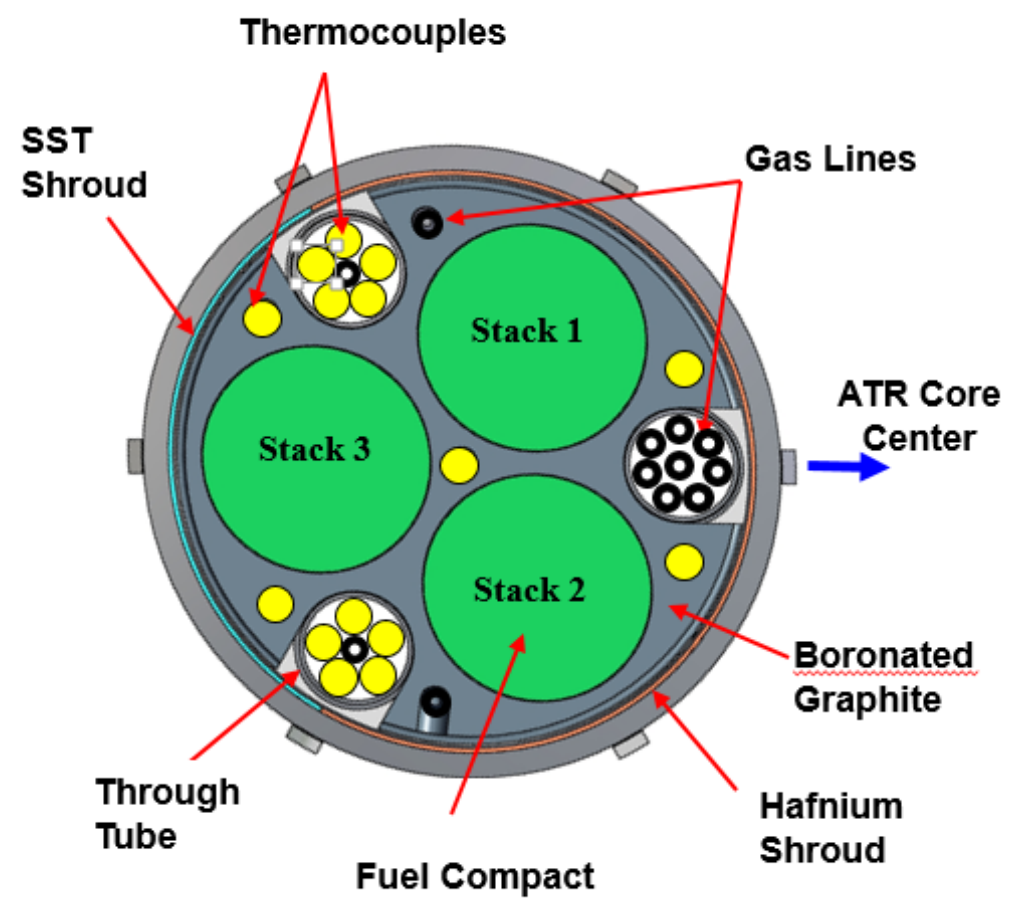

Figure 3. Schematic of a radial cut of an AGR-2 capsule. 
Independent gas lines route a mixture of helium and neon gases through each of the six capsules to provide temperature control and to sweep released fission product gases to the fission product monitoring system (FPMS). Temperature control is based upon temperature feedback from the thermocouples in each capsule and is performed by varying the sweep gas composition (between $100 \%$ helium for high conductivity and $100 \%$ neon for low conductivity). This blending of sweep gases is accomplished by a computerized mass flow controller before the gas enters the test train. The arrangement of the gas lines can be seen in the three-dimensional (3-D) rendering of a test capsule shown in Figure 4. Figure 5 shows a schematic diagram of the FPMS.

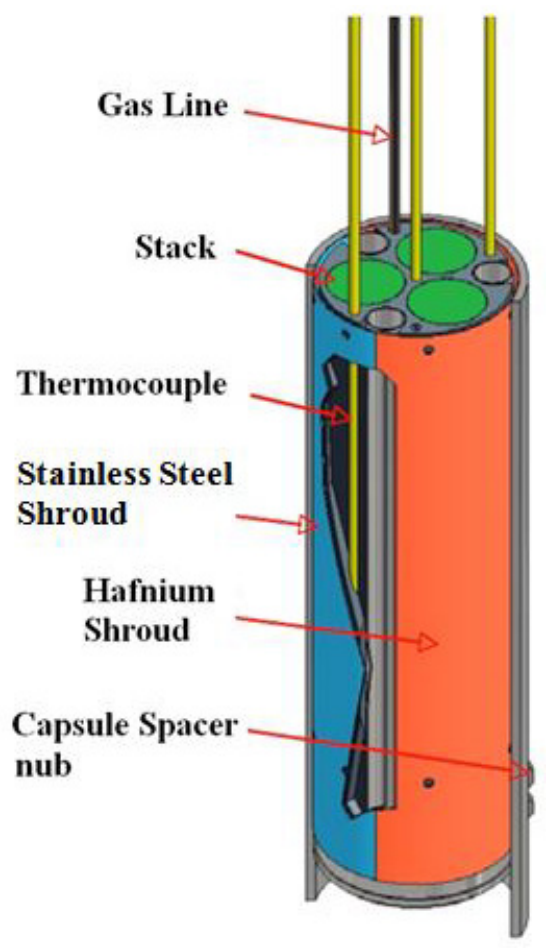

Figure 4. Three-dimensional cutaway rendering of single AGR-2 capsule.

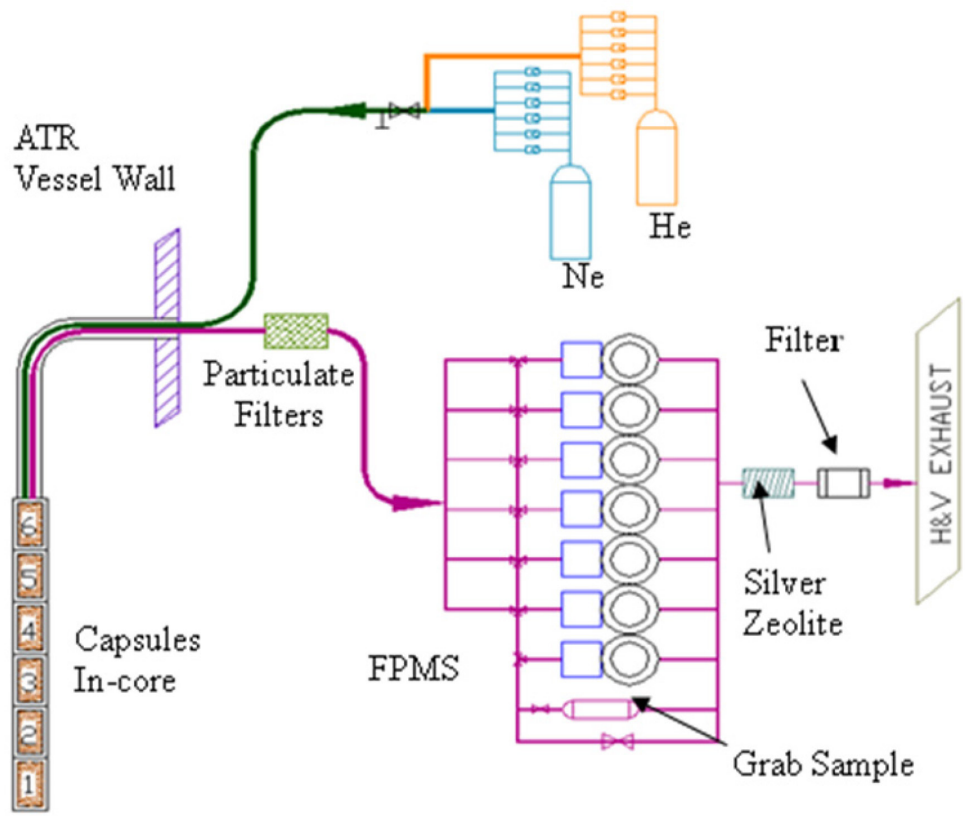

Figure 5. Flow path for AGR-2 sweep gas.

A detailed description of the FPMS can be found in Hartwell (2005). This system continuously measures the sweep gas from each AGR-2 capsule to provide an indicator of fuel irradiation performance. Spectrometer detector systems measure the concentrations of various krypton and xenon isotopes in the sweep gas from each capsule. Eight-hour counting intervals were used to measure the concentrations of $\mathrm{Kr}-85 \mathrm{~m}, \mathrm{Kr}-87, \mathrm{Kr}-88, \mathrm{Kr}-89, \mathrm{Kr}-90, \mathrm{Xe}-131 \mathrm{~m}, \mathrm{Xe}-133$, Xe-135, Xe-135m, Xe-137, Xe-138, and Xe-139.

The FPMS incorporates seven individual monitoring systems, one for each of the individual capsule effluent lines, and one unit that can monitor any individual effluent line or any combination of the six lines. The seventh monitor is primarily provided as a backup unit capable of providing effluent line monitoring should any of the primary monitoring systems fail. Each monitor consists of a high purity germanium (HPGe), detector-based, gamma-ray spectrometer and a sodium iodide [ $\mathrm{NaI}(\mathrm{Tl})]$ scintillation detector-based total radiation detector (often termed the "gross" radiation detector). The gross detectors are able to detect the failure of individual TRISO particles, while the gamma-ray spectroscopy is used for isotopic quantification of the noble gas release. These detector units are located in the ATR 2C Secondary cubicle. 
The sweep gas from each test capsule is routed via sampling lines to the monitoring station associated with that capsule. The sample lines, valves, and filters are predominately contained in the $2 \mathrm{C}$ primary cubicle. The sample lines have only two short, shielded segments in the $2 \mathrm{C}$ secondary cubicle. These short segments run through the gross detector monitoring station and into the HPGe spectrometer shield.

Each gross detector monitoring station (seven stations implemented) incorporates a $\varnothing 25 \times 25 \mathrm{~mm}$ thallium-activated $\mathrm{NaI}(\mathrm{Tl})$ scintillation detector viewing a $25 \mathrm{~mm}$ long segment of the capsule effluent line just before its entry into the HPGe spectrometer shield. The scintillation detector-counting rate is monitored using a computer-controlled multi-channel scaler.

Fuel for AGR-2 consists of TRISO-coated particles that are slightly less than $1 \mathrm{~mm}$ in diameter. Each particle has a central kernel containing the fissile material, a porous carbon buffer layer, an inner pyrolytic carbon (IPyC) layer, a silicon carbide ( $\mathrm{SiC}$ ) barrier coating, and an outer pyrolytic carbon (OPyC) layer. Kernels for AGR-2 consist of low-enriched uranium (LEU) UCO and LEU $\mathrm{UO}_{2}$ fuels. The U.S. kernels were fabricated by BWX Technologies (BWXT) in accordance with the AGR-2 Fuel Product Specification (Barnes 2009). The UCO and $\mathrm{UO}_{2}$ kernels were coated and characterized by BWXT (BWXT, 09/2008 and 2009). In addition, Oak Ridge National Laboratory (ORNL) characterized composite particles for anisotropy, sphericity, mass, and diameter measurements (Hunn 2008, 07/2010, 02/2010, 03/2010 and 11/2010). AGR fuel was originally based on the Gas-Turbine Modular Helium Reactor (GT-MHR) fissile particle of a fissile/fertile two-particle design. This fuel form (UCO) was used as a starting point in defining a baseline fuel for AGR-1 (Barnes 2006). Further development for fuel to be produced in a large coater has resulted in the AGR-2 fuel specification (Barnes 2009). Similarly to AGR-1, AGR-2 uses UCO kernels with slightly increased diameters that can be used in a single particle design. AGR-2 fuel also contains $\mathrm{UO}_{2}$ kernels typical of the fuel from German and South African pebble bed designs. Both types are included as one variant in separate capsules. In addition to U.S.-produced fuel, $\mathrm{UO}_{2}$ fuels produced in France and South Africa were included in AGR-2, but these foreign fuels are not discussed in this document.

After coating, AGR-2 fuel was formed into right cylindrical compacts. The compact matrix material is composed of a thermosetting carbonaceous material. Prior to compacting, the fuel particles were overcoated with approximately 215 - and 390- $\mu$ m-thick layers of the compact matrix material for UCO and $\mathrm{UO}_{2}$ fuels, respectively. This overcoat is intended to prevent particle-to-particle contact and help achieve the desired packing fraction of fuel particles. AGR-2 compacts are nominally $25.1 \mathrm{~mm}$ in length and $12.3 \mathrm{~mm}$ in diameter. The compacts are fabricated with fuel-free end caps of matrix material less than 0.5-mm-thick. These end caps ensure smooth, protected surfaces that help to prevent fuel particle damage during handling. The same compacting process was used for both $\mathrm{UCO}$ and $\mathrm{UO}_{2}$ fuels.

Each AGR-2 capsule contains only one fuel type. U.S. UCO fuel was irradiated in Capsules 2, 5, and 6; U.S. $\mathrm{UO}_{2}$ fuel in Capsule 3; French $\mathrm{UO}_{2}$ fuel in Capsule 1; and South African $\mathrm{UO}_{2}$ fuel in Capsule 4. These assignments are listed in Table 1 where the capsules are numbered consecutively from the top, (e.g., Capsule 6) to the bottom (e.g., Capsule 1). Appendix A contains as-manufactured data for the fuel. Characterization data for the fuel particles and compacts is detailed in the AGR-2 Irradiation Experiment Test Plan (Collin 2018). 
Table 1. AGR 2 capsule contents.

\begin{tabular}{|c|c|c|}
\hline Location & Coated Particle Composite & Fuel Designation \\
\hline Capsule 6 & G73J-14-93073A & $\mathrm{UCO}$ \\
\hline Capsule 5 & G73J-14-93073A & $\mathrm{UCO}$ \\
\hline Capsule 4 & - & South African $\mathrm{UO}_{2}$ \\
\hline Capsule 3 & G73H-10-93085B & $\mathrm{UO}_{2}$ \\
\hline Capsule 2 & G73J-14-93073A & $\mathrm{UCO}$ \\
\hline Capsule 1 & - & French $\mathrm{UO}_{2}$ \\
\hline
\end{tabular}

\subsection{Management and Qualification of AGR-2 Data}

The AGR-2 test spanned 15 cycles of ATR operation (including 12 power cycles) and generated five major streams of data. At the outset, detailed data provided a description of the fuel fabrication process and the contents of each compact. Data streams resulting from neutronics and thermal modeling of the experiment as run in the ATR were created both during the experiment and more recently during the post-experiment evaluation. Particularly, the most accurate post-experiment calculations, summarized in the remainder of this document, are important for future reference. Finally, during the entire course of the irradiation, the following three trains of data were generated on an ongoing basis:

- Fuel irradiation data, which include thermocouple (TC) readings, sweep gas compositions, flow rates and pressures, and moisture monitor readings

- FPMS data, which include both isotopic release data and gross gamma counts

- ATR operating conditions data, which include lobe powers, control cylinder positions, neck shim positions, and control rod positions.

AGR-2 data also include calculated quantities during the experiment such as fission product isotope birth rates and effective full-power days (EFPD) at the start of each ATR cycle.

The preservation and management of these data is a critical contribution to the experiment's ability to meet its objectives. The Nuclear Data Management and Analysis System (NDMAS) was established to ensure that data are qualified for use, stored in a readily accessible electronic form, and analyzed to extract useful results. The system is described in Hull (2016).

The NDMAS provides a single controlled repository for all of the AGR-2 data and makes the data available to users on an easily accessible website. During the experiment, the website showed the progress of the irradiation in almost real-time after the data were generated. The gross gamma data were displayed almost daily, while other irradiation, FPMS, and ATR operational data were displayed within a week or so of real-time.

In addition to displays of the data as it accrues in time, summaries of the data are provided by the NDMAS. Many of the plots in this document are examples of the displays that this system provides.

Another important function of the NDMAS is that it facilitates data qualification and stores the associated documentation. Specific data qualification activities within NDMAS depend on the data qualification category for each data entity as assigned by the data generator. Activities include:

(1) capture testing to confirm that the data stored within NDMAS are identical to the raw data supplied;

(2) accuracy testing to confirm that the data are an accurate representation of the system or object being measured; and (3) documentation that the data were collected under a Nuclear Quality Assurance (NQA)-1 or equivalent quality assurance program. Within the AGR fuel program, the NQA-1 requirements are implemented through the INL ART TDO Quality Assurance Program Plan (INL 08/2017). "Capture tested" data are data whose capture has been verified by showing that data pushed to 
the database match the raw data provided by the generator. Data captured using approved and controlled code are considered verified (i.e., "capture passed") data. Data loaded into the system using an approved code are verified through manual inspection. If data fail capture verification, the capture process is reviewed and modified until the captured data are correct. "Capture failed" is a short-lived data state.

The status of these data streams is summarized below (Pham 2014):

1. Fuel fabrication data - All data have been processed into the NDMAS database and qualified (4,395 records).

2. Fuel irradiation data - Data from all fifteen AGR-2 reactor cycles have been processed into the NDMAS database and tested. Of these, $56.8 \%$ have been qualified, $9.1 \%$ were considered "trend," and $34.1 \%$ have failed NDMAS accuracy testing.

3. FPMS data - Data from all fifteen AGR-2 reactor cycles have been processed into the database and capture tested. Qualification of these data (Scates 2014) has been recorded in NDMAS.

4. ATR Operating Conditions Data - Data for all AGR-2 cycles have been stored and capture tested. These data, which come from outside the AGR fuel program, are assumed to be qualified by ATR quality control procedures.

5. Neutronics and Thermal Modeling Data - All data have been stored in NDMAS and capture passed. Qualification of these data (Sterbentz 2014, Hawkes 2014) has been recorded in NDMAS. 


\section{PHYSICS ANALYSIS}

This section summarizes the physics analyses used to characterize the neutron flux environment and burnup of the fuel compacts. It gives the operational history of the ATR during the AGR-2 irradiation, followed by a description of the methodology used to analyze the test train. Key parameters, such as burnup and fast fluence of the fuel compacts, are included.

\subsection{ATR Power History}

The AGR-2 irradiation experiment lasted for fifteen ATR cycles, including eleven normal cycles, two power axial locator mechanism (PALM) cycles, one low-power cycle, and one unplanned outage cycle. The AGR-2 test train was irradiated for twelve power cycles, from June 2010 until October 2013. The test train was located in the B-12 location during eleven of the power cycles and was moved to the I-24 location during PALM cycle 153B to prevent over-heating of the fuel compacts. Cycle 150A was also a PALM cycle, during which the AGR-2 test train was moved to the ATR canal, and cycles 152A and 153A were low-power testing cycles. No burnup was accumulated during these three cycles; therefore, they are not discussed in this report.

Table 2 shows the irradiation history, including start and stop times and dates for each cycle, and unplanned outages. Times of reactor events are given to the nearest hour, while the total irradiation time in EFPD is based on ATR power history data. The total irradiation time of the AGR-2 test train was 559.2 EFPD.

Table 2. ATR power history during AGR-2 irradiation.

\begin{tabular}{|c|c|c|c|c|c|c|}
\hline $\begin{array}{c}\text { AGR-2 } \\
\text { Cycle }\end{array}$ & $\begin{array}{l}\text { ATR } \\
\text { Cycle }\end{array}$ & $\begin{array}{l}\text { Cycle } \\
\text { EFPD } \\
\end{array}$ & $\begin{array}{c}\text { Cumulative } \\
\text { EFPD }\end{array}$ & $\begin{array}{c}\text { Date } \\
\text { (M-D-Y) }\end{array}$ & Time* & Reactor Event \\
\hline \multirow{6}{*}{1} & \multirow{6}{*}{$147 \mathrm{~A}$} & \multirow{6}{*}{50.2} & 0.0 & $06-22-10$ & 1600 & Reactor start-up \\
\hline & & & 0.1 & $06-23-10$ & 0400 & Full power reached \\
\hline & & & 30.2 & $07-23-10$ & 0600 & Unplanned reactor scram \\
\hline & & & 30.2 & $07-25-10$ & 0800 & Reactor re-start \\
\hline & & & 30.3 & $07-25-10$ & 1300 & Full power reached \\
\hline & & & 50.2 & 08-14-10 & 1100 & Reactor down \\
\hline \multirow{6}{*}{2} & \multirow{6}{*}{$148 \mathrm{~A}$} & \multirow{6}{*}{47.5} & 50.2 & 08-31-10 & 1900 & Reactor start-up \\
\hline & & & 50.3 & 09-01-10 & 0400 & Full power reached \\
\hline & & & 92.1 & $10-12-10$ & 2100 & Unplanned reactor scram \\
\hline & & & 92.1 & $10-17-10$ & 1500 & Reactor re-start \\
\hline & & & 92.2 & $10-17-10$ & 2200 & Full power reached \\
\hline & & & 97.7 & $10-23-10$ & 1100 & Reactor down \\
\hline \multirow{3}{*}{3} & \multirow{3}{*}{ 148B } & \multirow{3}{*}{51.5} & 97.7 & $11-17-10$ & 1500 & Reactor start-up \\
\hline & & & 98.2 & $11-18-10$ & 1100 & Full power reached \\
\hline & & & 149.2 & 01-08-11 & 1100 & Reactor down \\
\hline \multirow{3}{*}{4} & \multirow{3}{*}{$149 \mathrm{~A}$} & \multirow{3}{*}{36.8} & 149.2 & 04-14-11 & 0200 & Reactor start-up \\
\hline & & & 149.3 & 04-14-11 & 1900 & Full power reached \\
\hline & & & 186.0 & $05-21-11$ & 1100 & Reactor down \\
\hline \multirow{3}{*}{5} & \multirow{3}{*}{ 149B } & \multirow{3}{*}{53.6} & 186.0 & 06-06-11 & 1200 & Reactor start-up \\
\hline & & & 186.3 & $06-07-11$ & 0300 & Full power reached \\
\hline & & & 239.6 & $07-30-11$ & 1100 & Reactor down \\
\hline
\end{tabular}


Table 2. (continued).

\begin{tabular}{|c|c|c|c|c|c|c|}
\hline $\begin{array}{l}\text { AGR-2 } \\
\text { Cycle }\end{array}$ & $\begin{array}{l}\text { ATR } \\
\text { Cycle }\end{array}$ & $\begin{array}{l}\text { Cycle } \\
\text { EFPD }\end{array}$ & $\begin{array}{c}\text { Cumulative } \\
\text { EFPD }\end{array}$ & $\begin{array}{c}\text { Date } \\
\text { (M-D-Y) }\end{array}$ & Time* & Reactor Event \\
\hline \multirow{3}{*}{6} & \multirow{3}{*}{$150 \mathrm{~B}$} & \multirow{3}{*}{41.9} & 239.6 & $10-15-11$ & 0100 & Reactor start-up \\
\hline & & & 239.8 & $10-15-11$ & 1800 & Full power reached \\
\hline & & & 281.5 & $11-26-11$ & 1100 & Reactor down \\
\hline \multirow{6}{*}{7} & \multirow{6}{*}{$151 \mathrm{~A}$} & \multirow{6}{*}{56.1} & 281.5 & $12-14-11$ & 0100 & Reactor start-up \\
\hline & & & 281.9 & $12-14-11$ & 1700 & Full power reached \\
\hline & & & 292.6 & $12-25-11$ & 1000 & Unplanned reactor scram \\
\hline & & & 292.6 & $12-28-11$ & 0400 & Reactor re-start \\
\hline & & & 293.0 & $12-28-11$ & 2000 & Full power reached \\
\hline & & & 337.6 & $02-11-12$ & 1100 & Reactor down \\
\hline \multirow{9}{*}{8} & \multirow{9}{*}{$151 \mathrm{~B}$} & \multirow{9}{*}{51.3} & 337.6 & 03-01-12 & 0600 & Reactor start-up \\
\hline & & & 337.8 & 03-01-12 & 1600 & Full power reached \\
\hline & & & 358.8 & $03-22-12$ & 1700 & Unplanned reactor scram \\
\hline & & & 358.8 & $03-25-12$ & 0900 & Reactor restart \\
\hline & & & 359.0 & $03-25-12$ & 2100 & Full power reached \\
\hline & & & 360.8 & $03-27-12$ & 1500 & Unplanned reactor scram \\
\hline & & & 360.8 & 04-07-12 & 0000 & Reactor restart \\
\hline & & & 361.0 & 04-07-12 & 1400 & Full power reached \\
\hline & & & 388.9 & $05-05-12$ & 1100 & Reactor down \\
\hline \multirow{3}{*}{9} & \multirow{3}{*}{$152 \mathrm{~B}$} & \multirow{3}{*}{51.0} & 388.9 & $11-27-12$ & 0400 & Reactor start-up \\
\hline & & & 389.3 & $11-28-12$ & 2100 & Full power reached \\
\hline & & & 439.9 & 01-18-13 & 1100 & Reactor down \\
\hline \multirow{3}{*}{$\begin{array}{c}10 \\
(\mathrm{I}-24)\end{array}$} & \multirow{3}{*}{$153 \mathrm{~B}$} & \multirow{3}{*}{13.5} & 439.9 & $03-29-13$ & 1300 & Reactor start-up \\
\hline & & & 440.5 & 03-30-13 & 2300 & Full power reached \\
\hline & & & 453.4 & $04-12-13$ & 1900 & Reactor down \\
\hline \multirow{6}{*}{11} & \multirow{6}{*}{$154 \mathrm{~A}$} & \multirow{6}{*}{52.3} & 453.4 & 05-19-13 & 0300 & Reactor start-up \\
\hline & & & 453.6 & $05-19-13$ & 1500 & Full power reached \\
\hline & & & 455.2 & $05-21-13$ & 0600 & Unplanned reactor scram \\
\hline & & & 455.2 & $05-23-13$ & 2000 & Reactor re-start \\
\hline & & & 455.3 & $05-24-13$ & 0300 & Full power reached \\
\hline & & & 505.7 & $07-13-13$ & 1100 & Reactor down \\
\hline \multirow{3}{*}{12} & \multirow{3}{*}{$154 \mathrm{~B}$} & \multirow{3}{*}{53.5} & 505.7 & $08-23-13$ & 1500 & Reactor start-up \\
\hline & & & 506.0 & $08-24-13$ & 0600 & Full power reached \\
\hline & & & 559.2 & $10-16-13$ & 1100 & Reactor down \\
\hline
\end{tabular}

* Reactor event time was obtained from hourly ATR Surveillance Data Reports. Events are observed at the nearest full hour increment. 


\subsection{Neutronics Analysis Methodology}

Neutronics analysis of the AGR-2 test train was performed using JMOCUP, a coupling developed at INL combining the continuous energy Monte Carlo N-Particle (MCNP) transport code (LANL 2004) and the depletion code ORIGEN (Croff 1983). The JMOCUP depletion methodology was used to model and deplete the AGR-2 TRISO fuel compacts in the B-12 and I-24 test positions of ATR. The AGR-2 calculations here use the same JMOCUP Monte Carlo depletion methodology and software modules previously used in the AGR-1 physics calculations (Sterbentz 2011). Verification that the calculation executed properly was done through both technical checkers and post-processing of calculated data. A detailed description of the JMOCUP system, along with the Verification and Validation of the JMOCUP depletion calculation is documented in (Sterbentz 2014).

The AGR-2 JMOCUP depletion calculation involves multiple depletion zones: (1) the ATR driver core; (2) the AGR-2 TRISO compacts; (3) the AGR-2 hafnium capsule shroud; and (4) the AGR-2 borated graphite holder. The ATR driver core consists of 840 depletion cells in the MCNP model, or three radial and seven axial cells per each of the 40 driver elements in the serpentine ATR core. The 72 fuel compacts of the AGR-2 experiment are split in half for a total of 144 depletion cells - the hafnium shroud has 24 depletion cells, while the borated graphite holder has 23 depletion cells. Therefore, there are a total of 1,031 depletion cells that JMOCUP operates on and keeps track of during each time-step of each cycle.

The ATR driver fuel depletion cells each contain nine actinides and 24 fission product isotopes that are tracked along with their fission and radiative capture cross-sections, which must be updated at each time-step. Similarly, the compacts have 19 tracked actinides and 71 fission products. In the hafnium shroud cells, the six naturally occurring hafnium isotopes are tracked, as is the Boron- 10 in the 23 borated graphite cells that compose the AGR-2 graphite compact holder. The MCNP code in each case calculates the cell flux and specified reaction rate(s) for each isotope in each depletion cell at each time-step and calculates an updated one-group cross-section. These updated cross-sections are then part of the next ORIGEN depletion calculation.

The neutron transport problem in the JMOCUP method is solved using the KCODE option in the MCNP code. In order for the KCODE option to be effective, the reactor core (in this case, the ATR driver fuel) must be simultaneously depleted along with the AGR-2 experiment depletions. Modeling the depletion of the entire ATR core provides a realistic neutron and gamma source for analyzing the AGR-2 experiment's radiation environment. Effects of important operational details can be taken into account on a daily-averaged basis using this methodology, such as the positions of the outer shim cylinders.

\subsection{As-Run Neutronics Analysis Results}

Figure 6 shows the capsule-average heat generation in the fuel compacts of the AGR-2 test train versus time in EFPD plotted using NDMAS. The general trend shared by each capsule is an increase over the first several cycles as the boron in the graphite is depleted, followed by a leveling-off over the remaining cycles. In many of the individual irradiation cycles, an increase in power density can be observed towards the end. This is because late in the cycle, the northwest outer shim cylinders, as shown in Figure 1, are often rotated such that the hafnium absorbers are oriented further away from the core. This is done in order to balance the lobe powers in the ATR and tends to substantially increase the thermal flux in the region of the B-12 position. This increase at the end of the cycle is not observed during Cycle 153B (the $10^{\text {th }}$ AGR-2 power cycle) because the test train was located in the I- 24 position of the ATR where the effect of the rotation of the outer shims is opposite. Figure 7 displays the maximum instantaneous peak power per particle for compacts containing $\mathrm{UCO}$ and $\mathrm{UO}_{2}$. For each type of fuel, the location of the maximum instantaneous peak can move from one compact to another, so the curves show the maximum values reached at each time-step. 
Burnups of the AGR-2 fuel compacts versus EFPDs are shown in Figure 8. These are in units of percent FIMA, and AGR-2 irradiation intervals are numbered across the bottom. Capsule average burnup is shown for each capsule, along with the values for the peak and minimum compact in each capsule. The capsule at the top of the reactor (e.g., Capsule 6) has the lowest burnup, with higher values found towards the center. Capsule-average burnups ranged from 9.30\% FIMA in Capsule 6 to 12.17\% FIMA in Capsule 2 for UCO, and was $10.10 \%$ FIMA for $\mathrm{UO}_{2}$ in Capsule 3. Figure 9 shows fast neutron fluence $(\mathrm{E}>0.18 \mathrm{MeV})$ versus time in EFPD, again with AGR-2 irradiation intervals shown across the bottom. As would be expected, the trends of fast fluence follow closely those of FIMA. The UCO capsule with the lowest average fluence at the end of the irradiation was Capsule 6 with a value of $2.39 \times 10^{25} \mathrm{n} / \mathrm{m}^{2}$, and the UCO capsule with the highest was Capsule 2 at $3.25 \times 10^{25} \mathrm{n} / \mathrm{m}^{2}$. The $\mathrm{UO}_{2}$ capsule had an average fluence of $3.35 \times 10^{25} \mathrm{n} / \mathrm{m}^{2}$ at the end of irradiation.

In addition, Figure 10 shows the correlation between burnup and fast fluence for the 48 AGR-2 compacts. A 3-D scatter plot of the irradiation characteristics of the 48 AGR-2 compacts is presented in Figure 22 (see Section 3.1). All plots show $\mathrm{UCO}$ and $\mathrm{UO}_{2}$ results separately.

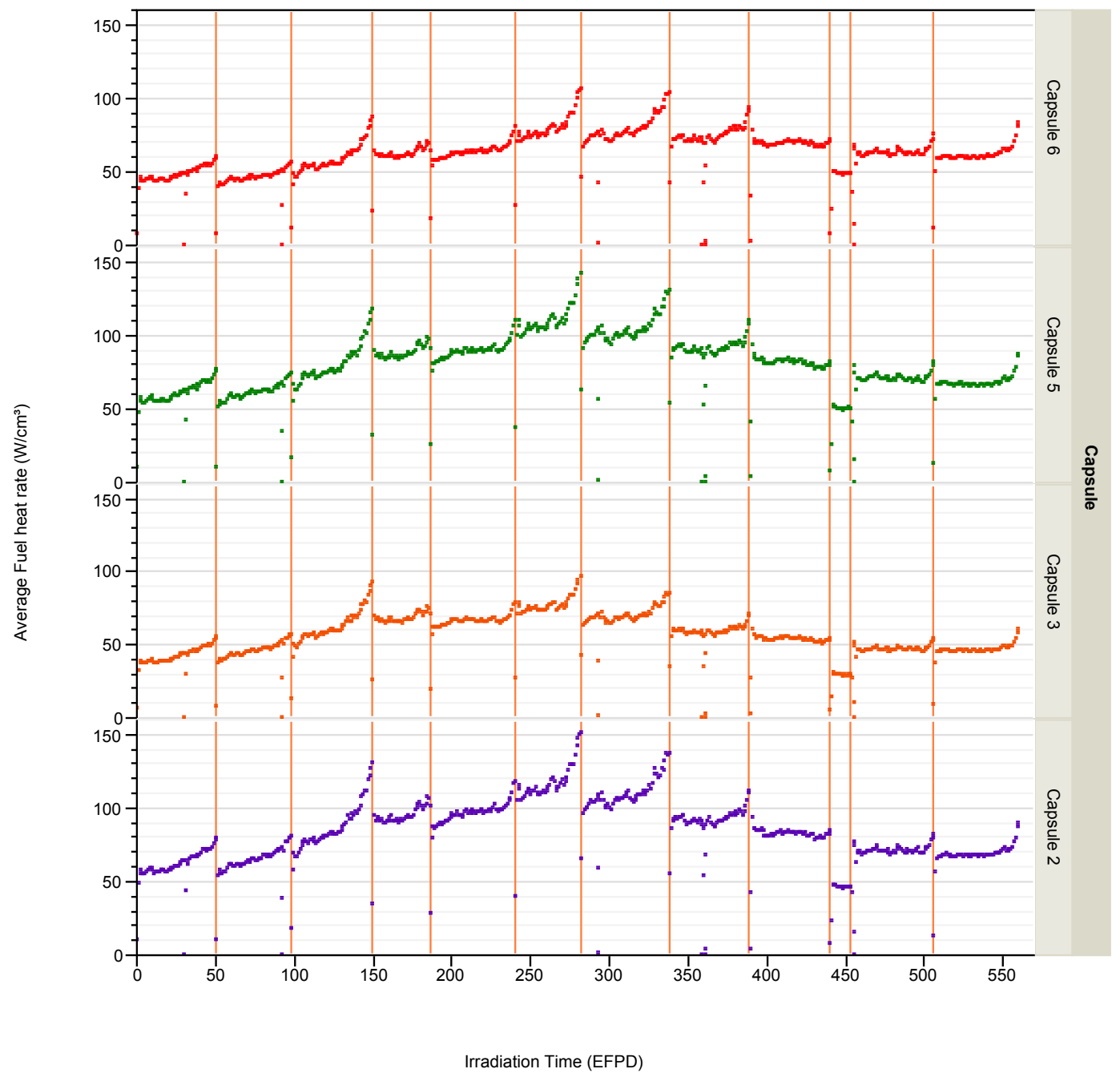

Figure 6. Capsule average power density versus irradiation time in EFPD. 


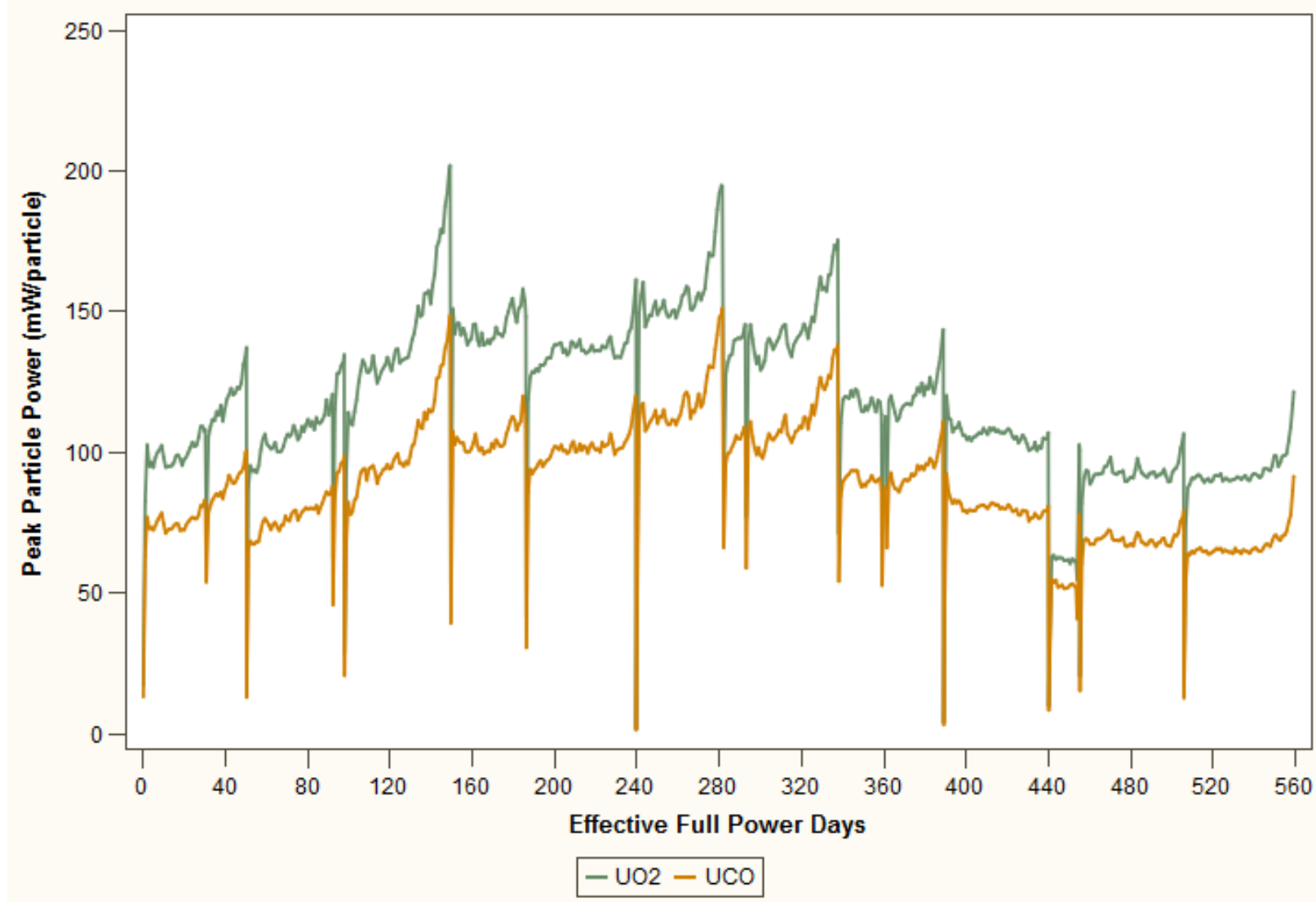

Figure 7. Maximum instantaneous peak particle power versus irradiation time in EFPD for compacts containing $\mathrm{UCO}$ and $\mathrm{UO}_{2}$. 


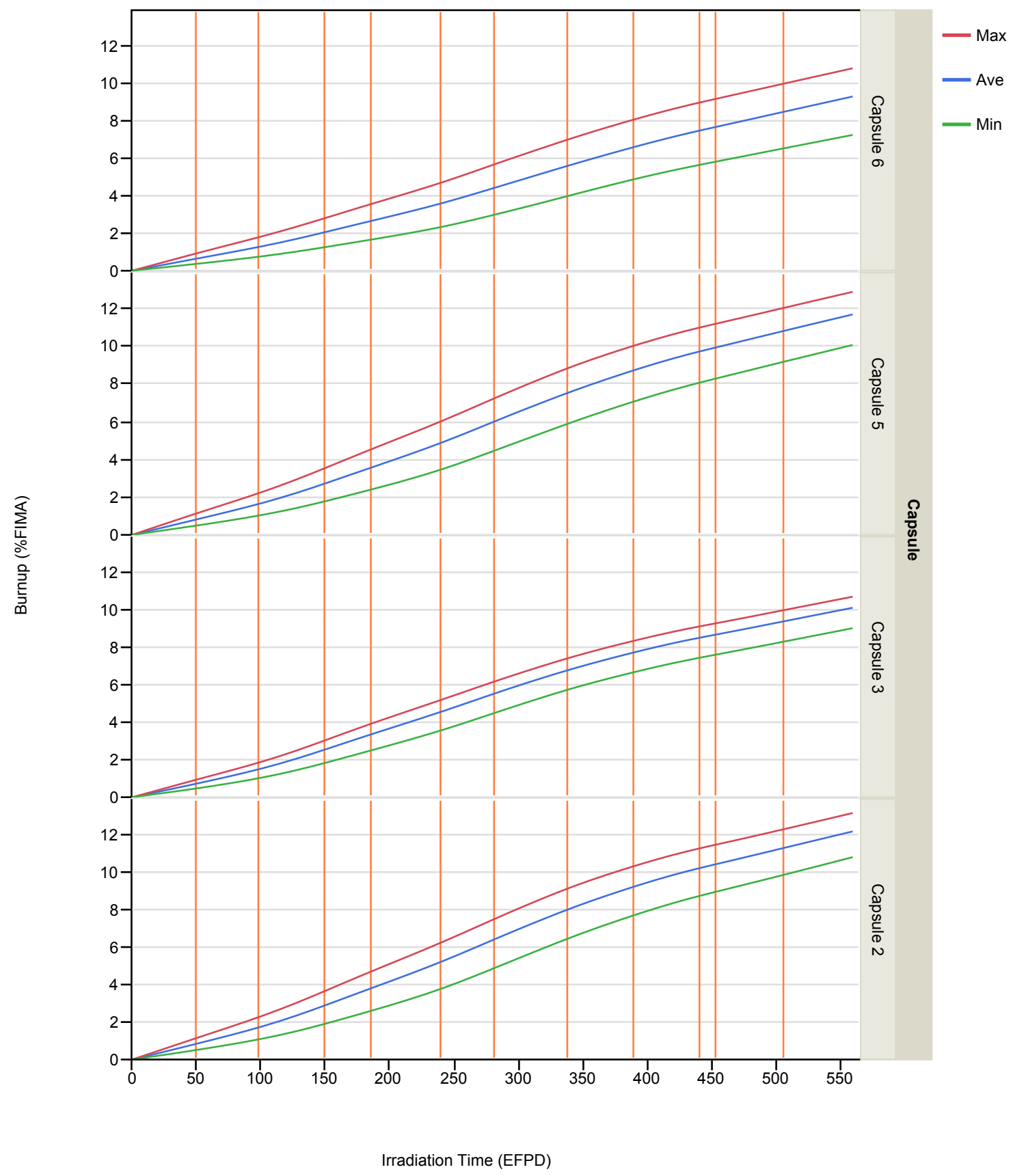

Figure 8. Burnup (in \%FIMA) versus EFPD by capsule. 


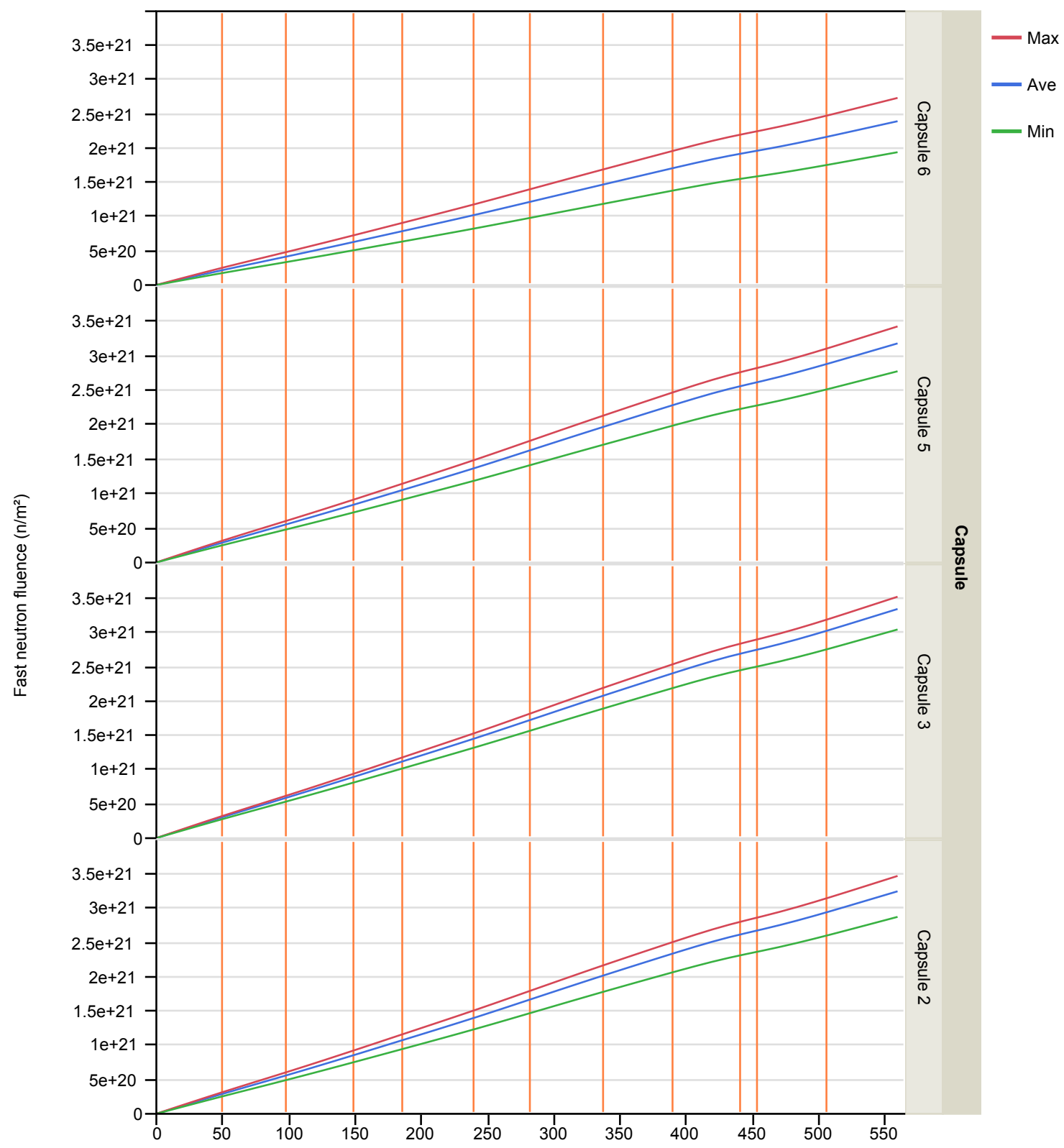

Irradiation Time (EFPD)

Figure 9. Fast neutron fluence $(\mathrm{E}>0.18 \mathrm{MeV})$ versus EFPD by capsule. 

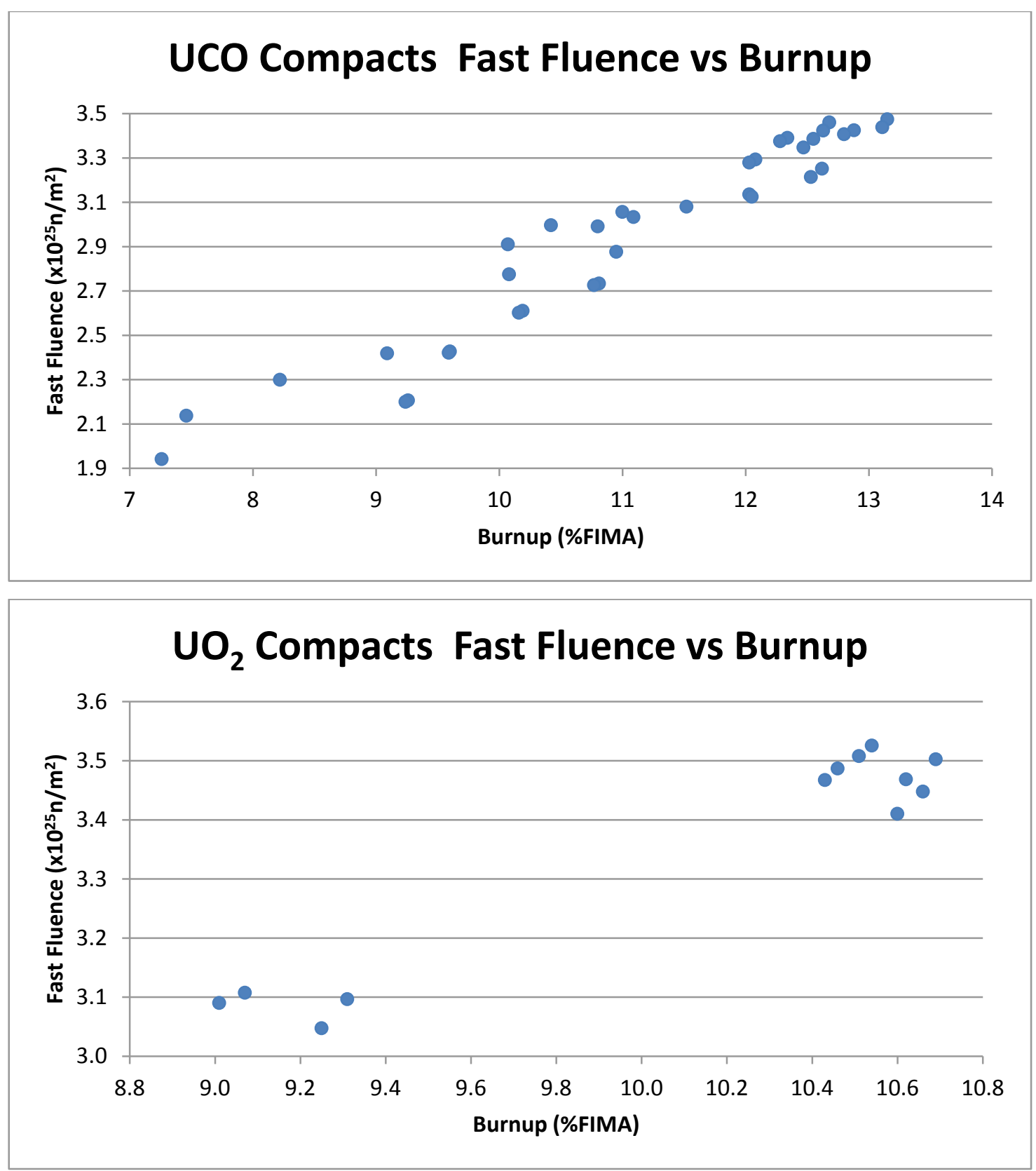

Figure 10. Fast neutron fluence $(\mathrm{E}>0.18 \mathrm{MeV})$ vs. Burnup for AGR-2 compacts.

Tables 3 and 4 show burnup and fast fluence at the end of irradiation for all of the compacts in the test train - capsule averages are also included. From these tables, one can see that burnup on a compact basis ranged from 7.26 to $13.15 \%$ FIMA for UCO and from 9.01 to $10.69 \%$ FIMA for $\mathrm{UO}_{2}$ and the compact fast fluence ranged from $1.94 \times 10^{25}$ to $3.47 \times 10^{25} \mathrm{n} / \mathrm{m}^{2}$ for UCO and from $3.05 \times 10^{25}$ to $3.53 \times 10^{25} \mathrm{n} / \mathrm{m}^{2}$ for $\mathrm{UO}_{2}$. According to these results, all compacts reached the minimum required burnup of 7\% FIMA, and 36 of the 48 compacts ( $28 \mathrm{UCO}$ compacts and $8 \mathrm{UO}_{2}$ compacts) reached a burnup higher than 10\% FIMA. Separation by stack also shows that Stacks 1 and 2 consistently received greater neutron flux than Stack 3 as a result of their orientation towards the core as shown in Figure 3. These data are also summarized in Table 5 with peak, minimum, and capsule average values given for fast fluence and burnup. 
Table 3. Burnup and fast neutron fluence for Capsules 6 and 5 at the end of irradiation.

\begin{tabular}{|c|c|c|c|c|}
\hline Capsule & Stack & Compact & $\begin{array}{l}\text { Burnup } \\
\text { (\% FIMA) }\end{array}$ & $\begin{array}{c}\text { Fast Neutron Fluence } \\
\left(10^{25} \mathrm{n} / \mathrm{m}^{2} \mathrm{E}>0.18 \mathrm{MeV}\right)\end{array}$ \\
\hline \multirow{12}{*}{$\begin{array}{c}6 \\
\text { (UCO) }\end{array}$} & \multirow{4}{*}{1} & 4 & 9.24 & 2.20 \\
\hline & & 3 & 9.59 & 2.42 \\
\hline & & 2 & 10.16 & 2.60 \\
\hline & & 1 & 10.77 & 2.73 \\
\hline & \multirow{4}{*}{2} & 4 & 9.26 & 2.21 \\
\hline & & 3 & 9.60 & 2.43 \\
\hline & & 2 & 10.19 & 2.61 \\
\hline & & 1 & 10.81 & 2.73 \\
\hline & \multirow{4}{*}{3} & 4 & 7.26 & 1.94 \\
\hline & & 3 & 7.46 & 2.14 \\
\hline & & 2 & 8.22 & 2.30 \\
\hline & & 1 & 9.09 & 2.42 \\
\hline \multicolumn{3}{|c|}{ Capsule 6 Average } & 9.30 & 2.39 \\
\hline \multirow{12}{*}{$\begin{array}{c}5 \\
(\mathrm{UCO})\end{array}$} & \multirow{4}{*}{1} & 4 & 12.05 & 3.12 \\
\hline & & 3 & 12.03 & 3.28 \\
\hline & & 2 & 12.28 & 3.38 \\
\hline & & 1 & 12.80 & 3.41 \\
\hline & \multirow{4}{*}{2} & 4 & 12.03 & 3.14 \\
\hline & & 3 & 12.08 & 3.29 \\
\hline & & 2 & 12.34 & 3.39 \\
\hline & & 1 & 12.88 & 3.42 \\
\hline & \multirow{4}{*}{3} & 4 & 10.08 & 2.77 \\
\hline & & 3 & 10.07 & 2.91 \\
\hline & & 2 & 10.42 & 3.00 \\
\hline & & 1 & 11.09 & 3.03 \\
\hline \multicolumn{3}{|c|}{ Capsule 5 Average } & 11.68 & 3.18 \\
\hline
\end{tabular}


Table 4. Burnup and fast neutron fluence for Capsules 3 and 2 at the end of irradiation.

\begin{tabular}{|c|c|c|c|c|}
\hline Capsule & Stack & Compact & $\begin{array}{l}\text { Burnup } \\
\text { (\% FIMA) }\end{array}$ & $\begin{array}{c}\text { Fast Neutron Fluence } \\
\left(10^{25} \mathrm{n} / \mathrm{m}^{2} \mathrm{E}>0.18 \mathrm{MeV}\right)\end{array}$ \\
\hline \multirow{12}{*}{$\begin{array}{c}3 \\
\left(\mathrm{UO}_{2}\right)\end{array}$} & \multirow{4}{*}{1} & 4 & 10.62 & 3.47 \\
\hline & & 3 & 10.46 & 3.49 \\
\hline & & 2 & 10.43 & 3.47 \\
\hline & & 1 & 10.60 & 3.41 \\
\hline & \multirow{4}{*}{2} & 4 & 10.69 & 3.50 \\
\hline & & 3 & 10.54 & 3.53 \\
\hline & & 2 & 10.51 & 3.51 \\
\hline & & 1 & 10.66 & 3.45 \\
\hline & \multirow{4}{*}{3} & 4 & 9.31 & 3.10 \\
\hline & & 3 & 9.07 & 3.11 \\
\hline & & 2 & 9.01 & 3.09 \\
\hline & & 1 & 9.25 & 3.05 \\
\hline \multicolumn{3}{|c|}{ Capsule 3 Average } & 10.10 & 3.35 \\
\hline \multirow{12}{*}{$\begin{array}{c}2 \\
\text { (UCO) }\end{array}$} & \multirow{4}{*}{1} & 4 & 13.11 & 3.44 \\
\hline & & 3 & 12.63 & 3.42 \\
\hline & & 2 & 12.47 & 3.35 \\
\hline & & 1 & 12.53 & 3.21 \\
\hline & \multirow{4}{*}{2} & 4 & 13.15 & 3.47 \\
\hline & & 3 & 12.68 & 3.46 \\
\hline & & 2 & 12.55 & 3.39 \\
\hline & & 1 & 12.62 & 3.25 \\
\hline & \multirow{4}{*}{3} & 4 & 11.52 & 3.08 \\
\hline & & 3 & 11.00 & 3.06 \\
\hline & & 2 & 10.80 & 2.99 \\
\hline & & 1 & 10.95 & 2.88 \\
\hline \multicolumn{3}{|c|}{ Capsule 2 Average } & 12.17 & 3.25 \\
\hline
\end{tabular}

Table 5. Minimum, average, and peak compact burnup, and fast fluence at the end of irradiation.

\begin{tabular}{|c|c|c|c|c|c|c|}
\hline \multirow{2}{*}{ Capsule } & \multicolumn{3}{|c|}{$\begin{array}{c}\text { Compact Burnup } \\
\text { (\% FIMA) }\end{array}$} & \multicolumn{3}{c|}{$\begin{array}{c}\text { Compact Fast Neutron Fluence } \\
\left(\mathbf{1 0}^{\mathbf{2 5}} \mathbf{n} / \mathbf{m}^{\mathbf{2}} \mathbf{E}>\mathbf{0 . 1 8} \text { MeV) }\right.\end{array}$} \\
\cline { 2 - 7 } & $\begin{array}{c}\text { Minimum } \\
\text { Compact }\end{array}$ & $\begin{array}{c}\text { Capsule } \\
\text { Average }\end{array}$ & $\begin{array}{c}\text { Peak } \\
\text { Compact }\end{array}$ & $\begin{array}{c}\text { Minimum } \\
\text { Compact }\end{array}$ & $\begin{array}{c}\text { Capsule } \\
\text { Average }\end{array}$ & $\begin{array}{c}\text { Peak } \\
\text { Compact }\end{array}$ \\
\hline 6 & 7.26 & 9.30 & 10.81 & 1.94 & 2.39 & 2.73 \\
\hline 5 & 10.07 & 11.68 & 12.88 & 2.77 & 3.18 & 3.42 \\
\hline 3 & 9.01 & 10.10 & 10.69 & 3.05 & 3.35 & 3.53 \\
\hline 2 & 10.80 & 12.17 & 13.15 & 2.88 & 3.25 & 3.47 \\
\hline
\end{tabular}


The neutronic specifications of the irradiation as enumerated in the AGR-2 Irradiation Test Specification (Maki 2010) are listed below with comments on the performance of the experiment with respect to each:

- $\quad$ The minimum compact average burnup for UCO and $\mathrm{UO}_{2}$ fuel shall be $>7 \%$ FIMA.

On a compact basis, all 48 compacts exceeded an average burnup of 7\% FIMA.

- The compact average burnup goal for the majority of the UCO and $\mathrm{UO}_{2}$ fuel compacts should be $>10$ $\%$ FIMA.

On a compact basis, 36 of the 48 compacts reached a burnup of 10\% FIMA. Twenty-eight of the 36 UCO compacts and 8 of the $12 \mathrm{UO}_{2}$ compacts reached a burnup of more than $10 \%$ FIMA. The burnup ranged from 7.26 to $13.15 \%$ FIMA for UCO compacts and from 9.01 to $10.69 \%$ FIMA for $\mathrm{UO}_{2}$ compacts.

- The maximum peak fast neutron fluence for each fuel compact shall be $<5 \times 10^{25} \mathrm{n} / \mathrm{m}^{2}, E>0.18 \mathrm{MeV}$.

The fast neutron fluence reached a maximum peak of $3.47 \times 10^{25} \mathrm{n} / \mathrm{m}^{2}, \mathrm{E}>0.18 \mathrm{MeV}$ for UCO compacts and $3.53 \times 10^{25} \mathrm{n} / \mathrm{m}^{2}$, and $\mathrm{E}>0.18 \mathrm{MeV}$ for $\mathrm{UO}_{2}$ compacts.

- The minimum peak fast neutron fluence for each fuel compact shall be $>1.5 \times 10^{25} \mathrm{n} / \mathrm{m}^{2}, E>0.18 \mathrm{MeV}$. The compact fast neutron fluence had a minimum peak of $1.94 \times 10^{25} \mathrm{n} / \mathrm{m}^{2}, \mathrm{E}>0.18 \mathrm{MeV}$ for UCO compacts and $3.05 \times 10^{25} \mathrm{n} / \mathrm{m}^{2}$, and $\mathrm{E}>0.18 \mathrm{MeV}$ for $\mathrm{UO}_{2}$ compacts.

- The instantaneous peak power per particle shall be $<400 \mathrm{~mW} /$ particle.

The instantaneous peak power was limited to $150 \mathrm{~mW} /$ particle for UCO compacts and to $200 \mathrm{~mW} /$ particle for $\mathrm{UO}_{2}$ compacts. 


\section{THERMAL ANALYSIS}

The temperature at which the fuel compacts were irradiated is an essential component of assessing the performance of the fuel. This section describes the methodology and the results of the finite element thermal analysis used to provide fuel temperatures and to generate predicted TC temperatures for use in calibration of the gas flow control system.

\subsection{Thermal Calculation Methodology}

3-D finite element thermal calculations were performed on a daily basis using ABAQUS. The methods used in the thermal analysis summarized here are described in more detail in a separate report (Hawkes 2014). These calculations were performed using compact and graphite heat generation rates provided by the as-run neutronics analysis described in Sections 2.2 and 2.3 and with additional operational input for sweep gas composition versus time. Figure 11 shows a 3-D rendering of the finite element mesh formed from $100 \%$ eight-node hexahedral bricks, which contains approximately 350,000 nodes per AGR-2 capsule.

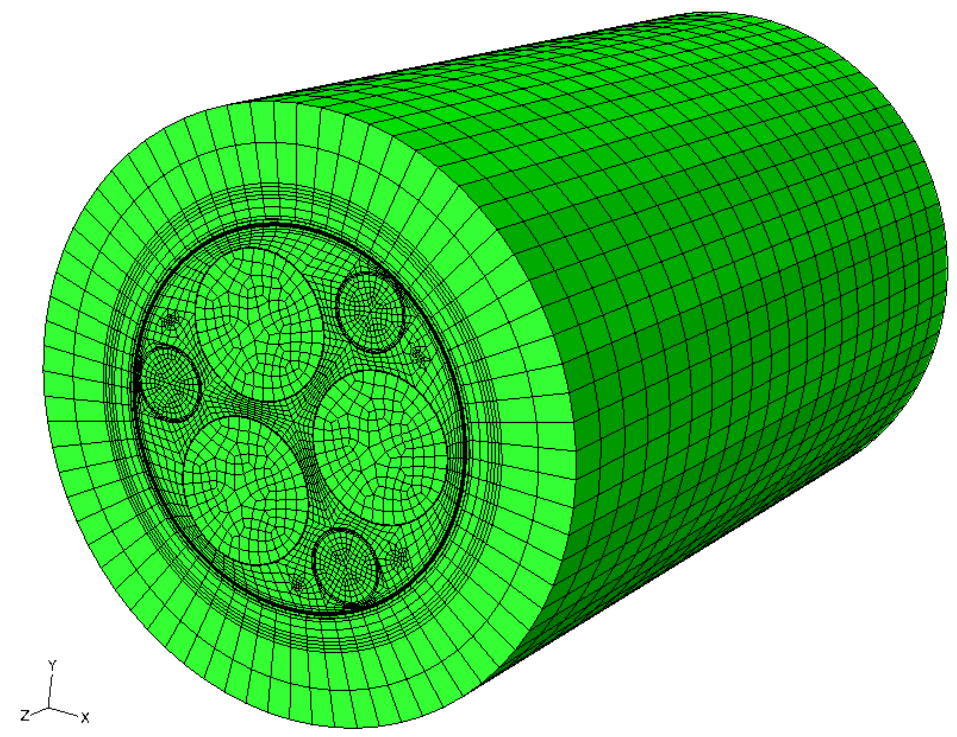

Figure 11. Rendering of ABAQUS finite element mesh of a single AGR-2 capsule.

Fuel compact thermal conductivity was taken from correlations presented in Gontard (1990), which gives correlations for conductivity, taking into account temperature, temperature of heat treatment, neutron fluence, and TRISO-packing fraction. In this work, the convention used to quantify neutron damage to a material is fast fluence $\mathrm{E}>0.18 \mathrm{MeV}$, yet in Gontard (1990), the unit used was the DIDO nickel equivalent (DNE). The following equation conversion was used to convert from the DNE convention to the $>0.18 \mathrm{MeV}$ fast fluence:

$\Gamma_{>0.18 \mathrm{MeV}}=1.52 \Gamma_{\mathrm{DNE}}$

where $\Gamma$ is neutron fluence in either the $>0.18 \mathrm{MeV}$ unit or DNE. The correlations in the report by Gontard (1990) were further adjusted to account for differences in fuel compact density. The correlations were developed for a fuel compact matrix density of $1.75 \mathrm{~g} / \mathrm{cm}^{3}$, whereas the compact matrix used in AGR-2 had a density of approximately 1.59 and $1.68 \mathrm{~g} / \mathrm{cm}^{3}$ for $\mathrm{UCO}$ and $\mathrm{UO}_{2}$ compacts, respectively. The thermal conductivities were scaled according to the ratio of densities (e.g., 0.91 for UCO and 0.96 for $\mathrm{UO}_{2}$ ) in order to correct for this difference. 
Unirradiated graphite thermal conductivity data for the holders were provided by GrafTech (Thompson 2006, Albers 2009). Figure 12 shows unirradiated thermal conductivity of different types of boronated graphite. The percentages indicate the weight percent ( $\mathrm{wt} \%$ ) boron present in the material. A boron content of 5.75\% against grain (AG) was used in the holders of Capsules 5 and 2, while $4.92 \%$ AG and $4.83 \%$ AG were used in Capsules 3 and 6, respectively. Corresponding thermal conductivities can be obtained by interpolation from the plots in Figure 12. The selection of a specific boron content for a given capsule was based upon meeting the capsule specific temperature targets. The higher boron content provided a flatter compact heating profile through the irradiation when compared with no boron.
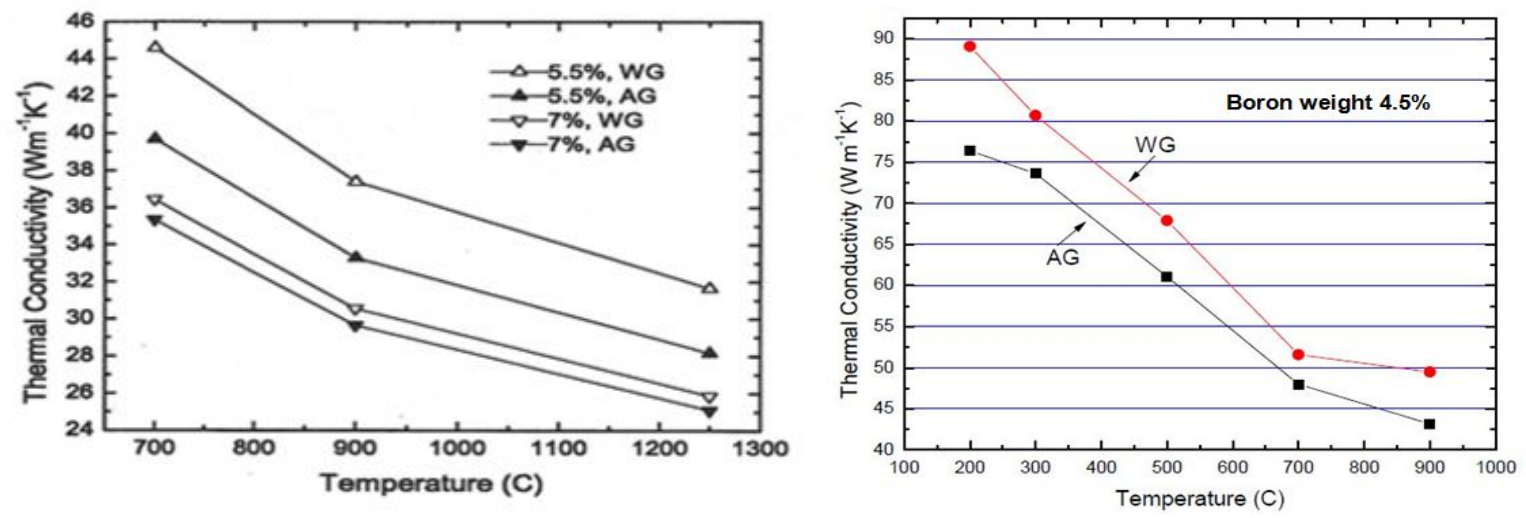

Figure 12. Thermal conductivity of unirradiated, boronated graphite holders (Thompson 2006, Albers 2009).

The effect of irradiation on the thermal conductivity of the graphite was accounted for in this analysis using the following correlation by Snead (1995):

$$
\begin{aligned}
& \frac{k_{i r r}}{k_{0}}=\left(0.25-0.00017 * T_{i r r}\right) * A^{*} \log (d p a)+0.000683 * T_{i r r} \\
& A=-1.0
\end{aligned}
$$

where $k_{0}$ and $k_{i r r}$ are thermal conductivity of unirradiated and irradiated graphite, respectively; $T_{i r r}$ is the irradiation temperature; and $d p a$ is displacements per atom. The multiplier used to convert fast fluence $(\mathrm{E}>0.18 \mathrm{MeV})$ to dpa is $8.23 \times 10^{-26}$ and has units of $\mathrm{dpa} /\left(\mathrm{n} / \mathrm{m}^{2}\right)$ (Sterbentz 2009).

Heat produced in the fuel compacts is transferred through the gaps surrounding the compacts into the graphite holder via a gap conductance model using the gap width and the conductivity of the sweep gas, as is discussed later in this report. Heat is transferred across the outer sweep gas flow region between the outside of the graphite holder and the inside of the steel liner via radiation between the two surfaces and conduction through the helium/neon sweep gas. Because the velocity of the sweep gas is very low in this gap, convection is not considered. The thermal conductivity of the sweep gas was determined using the kinetic theory of gases, which gives conductivity $k$ of a gas mixture as a function of the gas constituents $i$ and $j$ according to:

$$
k=\sum_{i} \frac{X_{i} k_{i}}{\sum_{j} X_{j} \phi_{i j}}
$$


where $X_{i}$ is the mole fraction of gas $i$, and $k_{i}$ is the thermal conductivity of pure gas $i$ (Fluent, Inc. 2006). The parameter $\Phi_{i j}$ in Equation 3 is given by:

$$
\phi_{i j}=\frac{\left[1+\left(\frac{\mu_{i}}{\mu_{j}}\right)^{1 / 2}\left(\frac{M_{w, j}}{M_{w, i}}\right)^{1 / 4}\right]^{2}}{\left[8\left(1+\frac{M_{w, i}}{M_{w, j}}\right)\right]^{1 / 2}}
$$

where $\mu_{i}$ is the viscosity of pure gas $i$ and $M_{w, i}$ is the molecular weight of pure gas $i$. Figure 13 shows a plot of the resulting helium/neon sweep gas thermal conductivity versus temperature and mole fraction of helium.

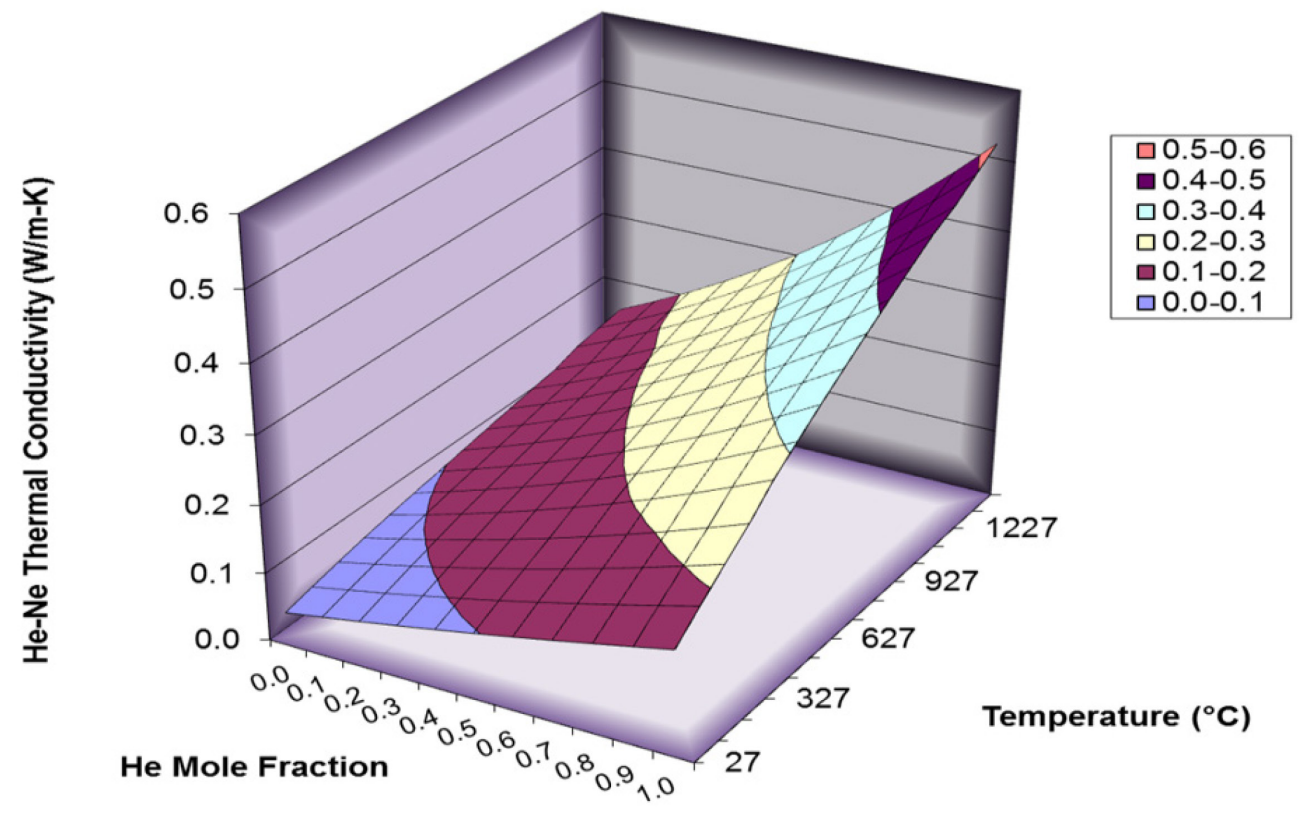

Figure 13. Sweep gas thermal conductivity versus temperature and mole fraction helium.

The radiation heat transfer of the sweep gas gap between the graphite holder and the stainless steel sleeve was modeled assuming radiation and conduction heat transfer. It was implemented with emissivity of all graphite surfaces being 1.0 and stainless steel at 0.4 . The flow rate of the sweep gas in this gap is low enough that forced convection need not be considered.

The daily gas mixtures were taken from NDMAS data. Data in the NDMAS system provides a separate flow rate for helium and neon for each capsule. Data were taken every 5 minutes and averaged by NDMAS to get a daily average.

Gamma heating for the non-fuel structural components were taken from Sterbentz (2014) and taken into account in the finite element thermal calculations.

Figure 14 shows a temperature contour plot cutaway view of the three stacks calculated by ABAQUS. Stacks 1 and 2 are oriented to the right, and higher temperatures can be observed in these as a result of their orientation towards the ATR core center. Figure 15 shows the daily calculated fuel temperatures (capsule-average, capsule maximum, and capsule minimum) for each of the four U.S. capsules of the AGR-2 test train versus time in EFPD plotted using NDMAS. Figure 16 shows the time averages of these temperatures versus time for the four capsules. 


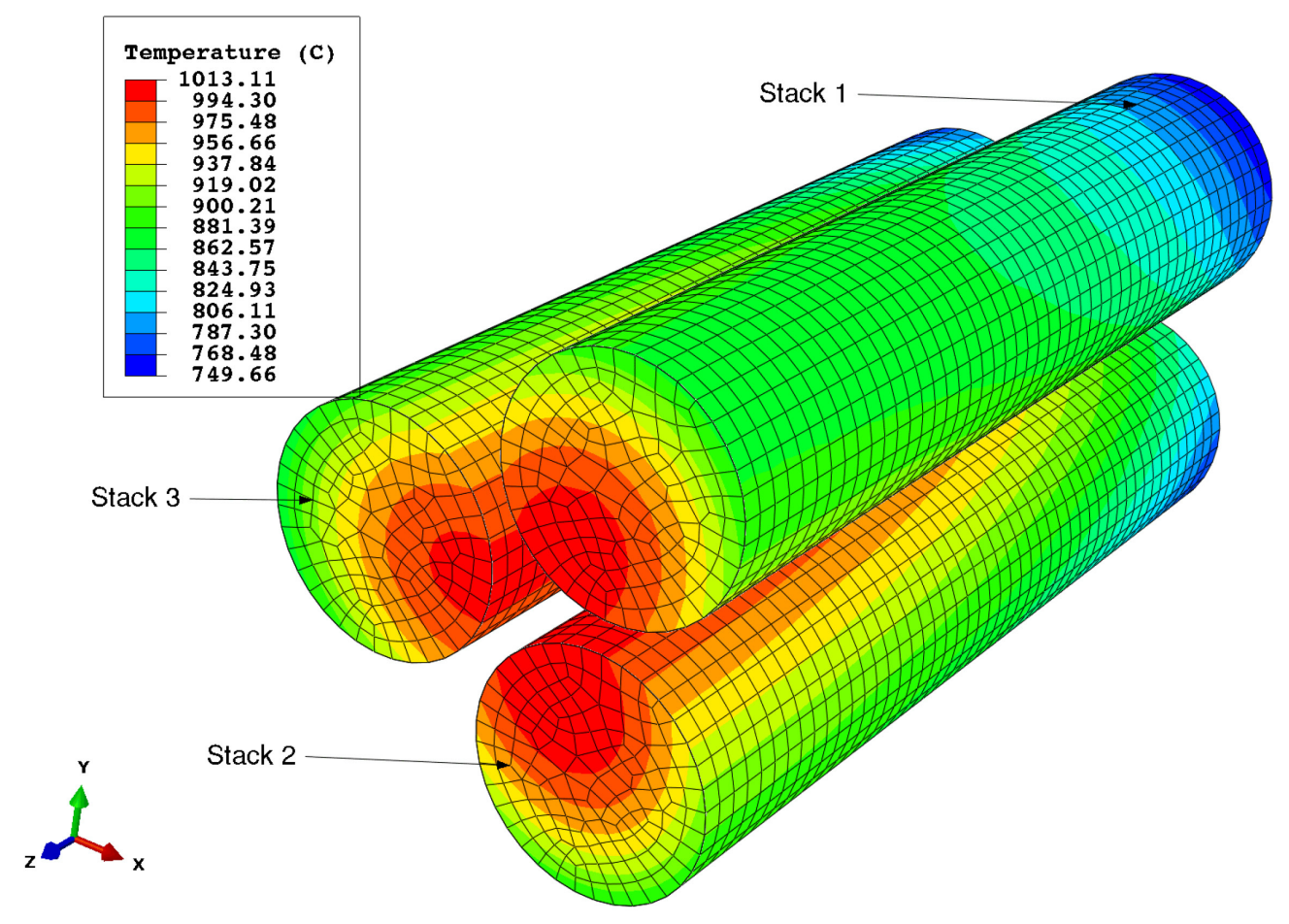

Figure 14. Temperature $\left({ }^{\circ} \mathrm{C}\right)$ contour plot cutaway view of the three fuel stacks. 


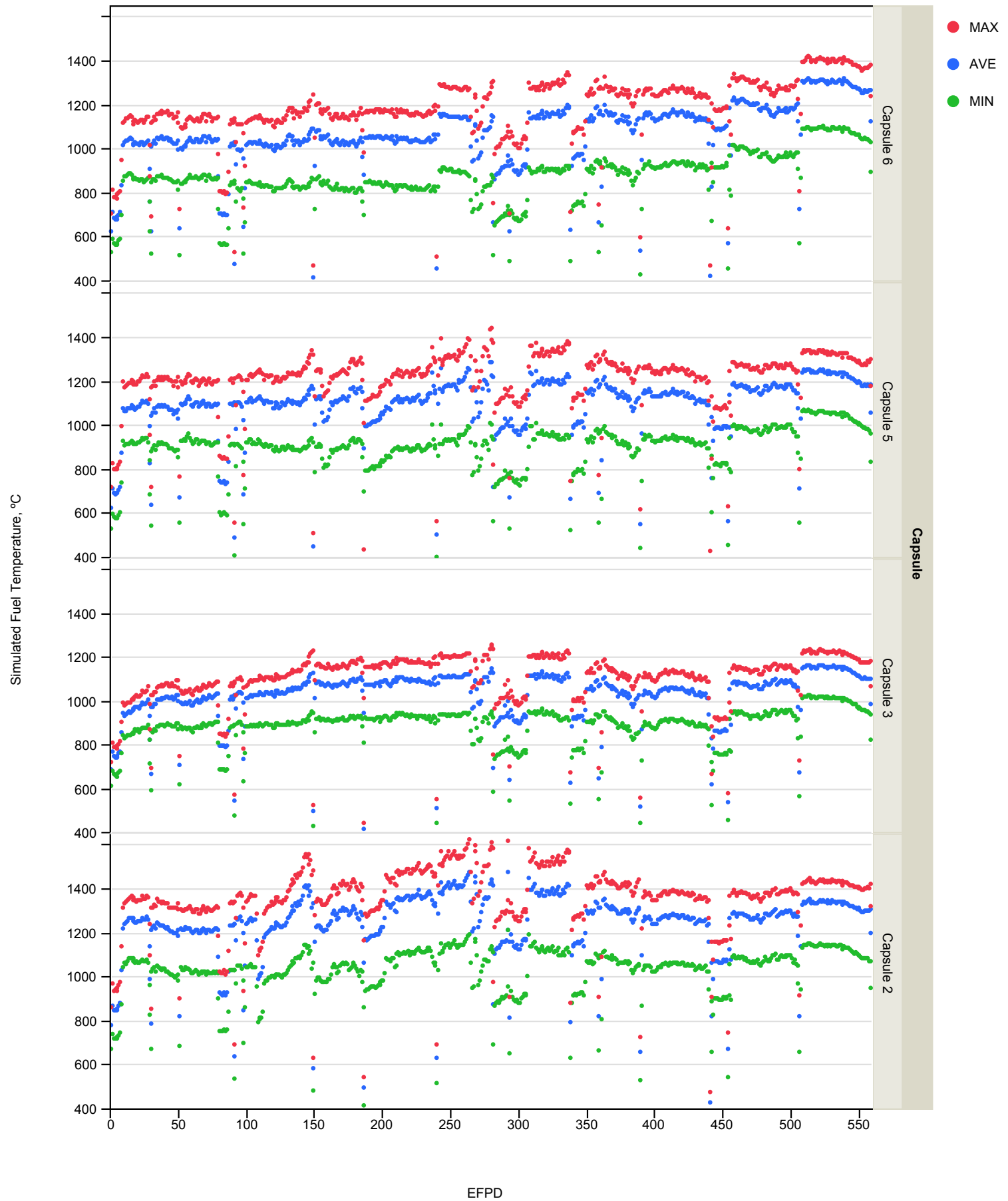

Figure 15. Calculated daily minimum, maximum, and volume-average temperatures. 


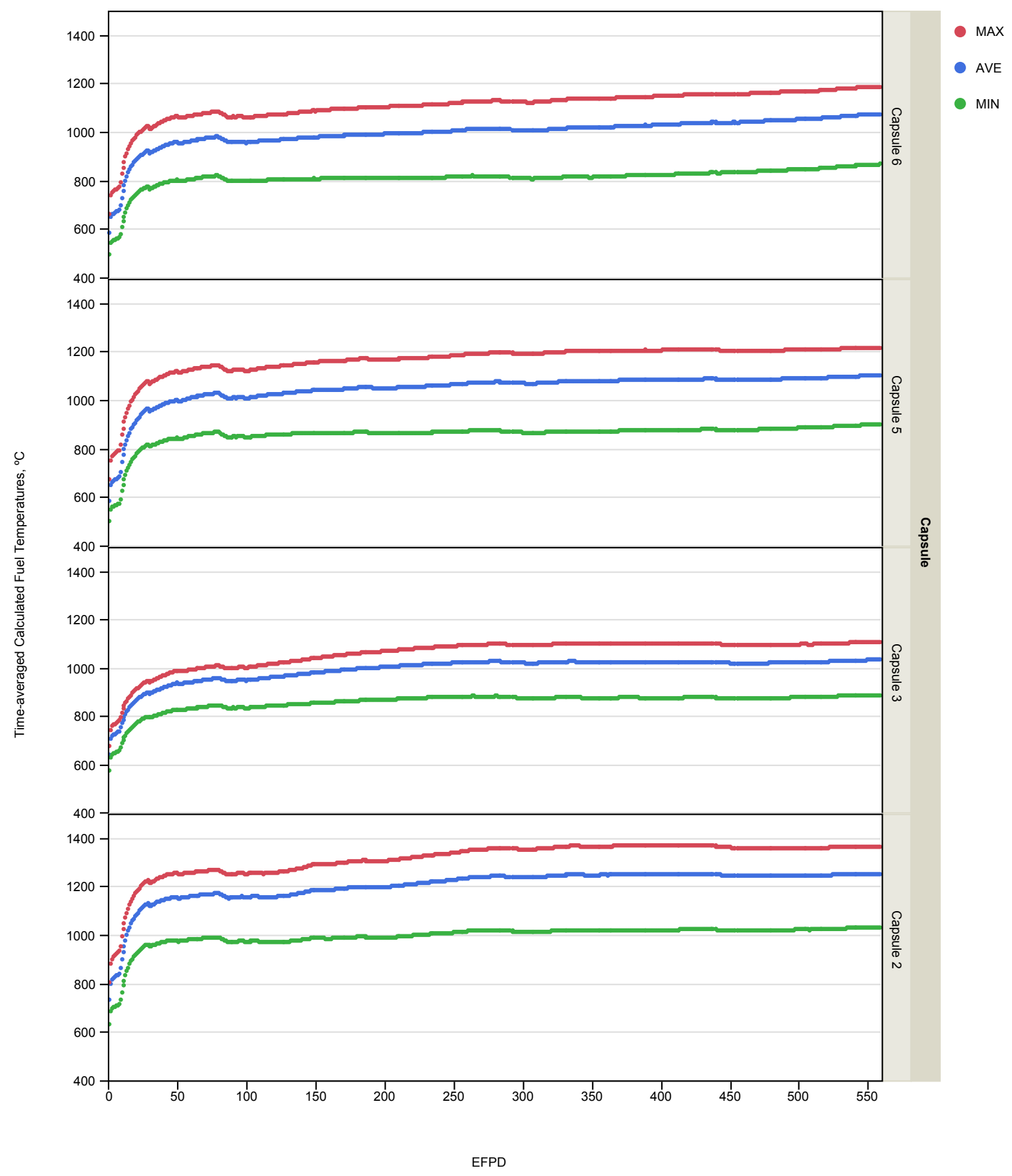

Figure 16. Calculated time-average minimum, time-average maximum, and time-average volume-average temperatures. 


\subsection{As-Run Thermal Analysis Results}

Table 6 and Table 7 show the time-average minimum, time-average volume-average (TAVA), and time-average peak temperatures on a compact basis for all 48 U.S. compacts in the AGR-2 test. TAVA temperatures on a capsule basis at the end of irradiation ranged from $1074^{\circ} \mathrm{C}$ in Capsule 6 to $1252^{\circ} \mathrm{C}$ in Capsule 2 for UCO fuel, while the TAVA temperature for $\mathrm{UO}_{2}$ in Capsule 3 was $1032^{\circ} \mathrm{C}$. In the AGR-2 Irradiation Test Specification (Maki 2010), three goals of the experiment were specified related to the thermal conditions of the fuel during irradiation. These are listed below with comments on the performance of the experiment with respect to each:

- $\quad$ The instantaneous peak temperature for each capsule shall be $\leq 1800^{\circ} \mathrm{C}$.

As can be seen in Figure 15, this constraint was met in all capsules.

- The time-average peak temperature shall be $\leq 1400^{\circ} \mathrm{C}$ for one capsule containing UCO fuel, $\leq 1250^{\circ} \mathrm{C}$ for each remaining capsule containing $U C O$, and $\leq 1150^{\circ} \mathrm{C}$ for the capsule containing $U_{2}$ fuel.

As can be seen in Figure 16, this constraint was met. For UCO fuel, Capsule 2 had the highest time-average peak temperature with $1360^{\circ} \mathrm{C}$, thus lower than $1400^{\circ} \mathrm{C}$, followed by Capsule 5 with $1210^{\circ} \mathrm{C}$ and Capsule 6 with $1183^{\circ} \mathrm{C}$, both lower than $1250^{\circ} \mathrm{C}$. For $\mathrm{UO}_{2}$, Capsule 3 had a time-average peak temperature of $1105^{\circ} \mathrm{C}$, lower than the specified limit of $1150^{\circ} \mathrm{C}$.

- The TAVA temperature goal should be $\geq 1150^{\circ} \mathrm{C}$ for the highest temperature capsule containing UCO fuel, $\geq 1000^{\circ} \mathrm{C}$ for each remaining capsule containing UCO fuel, and $\geq 900^{\circ} \mathrm{C}$ for the capsule containing $\mathrm{UO}_{2}$ fuel.

As can be seen in Figure 16, this constraint was met. For UCO fuel, Capsule 2 had the highest TAVA temperature with $1252^{\circ} \mathrm{C}$, thus higher than $1150^{\circ} \mathrm{C}$, followed by Capsule 5 with $1101^{\circ} \mathrm{C}$ and Capsule 6 with $1074^{\circ} \mathrm{C}$, both higher than $1000^{\circ} \mathrm{C}$. For $\mathrm{UO}_{2}$, Capsule 3 had a TAVA temperature of $1032^{\circ} \mathrm{C}$, higher than the specified limit of $900^{\circ} \mathrm{C}$. 
Table 6. Compact temperature data for Capsules 6 and 5 at end of irradiation.

\begin{tabular}{|c|c|c|c|c|c|}
\hline Capsule & Stack & Compact & $\begin{array}{c}\text { Time-Average } \\
\text { Minimum Temp. } \\
\left({ }^{\circ} \mathrm{C}\right)\end{array}$ & $\begin{array}{c}\text { Time-Average } \\
\text { Volume-Average } \\
\text { Temp. } \\
\left({ }^{\circ} \mathrm{C}\right) \\
\end{array}$ & $\begin{array}{c}\text { Time-Average } \\
\text { Peak Temp. } \\
\left({ }^{\circ} \mathrm{C}\right) \\
\end{array}$ \\
\hline \multirow{12}{*}{$\begin{array}{c}6 \\
(\mathrm{UCO})\end{array}$} & \multirow{4}{*}{1} & 4 & 891 & 1018 & 1106 \\
\hline & & 3 & 1003 & 1094 & 1160 \\
\hline & & 2 & 1044 & 1129 & 1183 \\
\hline & & 1 & 964 & 1100 & 1178 \\
\hline & \multirow{4}{*}{2} & 4 & 894 & 1018 & 1106 \\
\hline & & 3 & 1006 & 1094 & 1160 \\
\hline & & 2 & 1047 & 1129 & 1183 \\
\hline & & 1 & 968 & 1100 & 1178 \\
\hline & \multirow{4}{*}{3} & 4 & 868 & 987 & 1080 \\
\hline & & 3 & 970 & 1060 & 1134 \\
\hline & & 2 & 1012 & 1095 & 1157 \\
\hline & & 1 & 941 & 1069 & 1152 \\
\hline \multicolumn{3}{|c|}{ All Capsule 6 compacts } & 868 & 1074 & 1183 \\
\hline \multirow{12}{*}{$\begin{array}{c}5 \\
(\mathrm{UCO})\end{array}$} & \multirow{4}{*}{1} & 4 & 923 & 1071 & 1168 \\
\hline & & 3 & 1016 & 1126 & 1197 \\
\hline & & 2 & 1032 & 1141 & 1209 \\
\hline & & 1 & 956 & 1108 & 1202 \\
\hline & \multirow{4}{*}{2} & 4 & 927 & 1071 & 1168 \\
\hline & & 3 & 1021 & 1126 & 1197 \\
\hline & & 2 & 1037 & 1141 & 1210 \\
\hline & & 1 & 962 & 1109 & 1203 \\
\hline & \multirow{4}{*}{3} & 4 & 901 & 1040 & 1143 \\
\hline & & 3 & 986 & 1093 & 1172 \\
\hline & & 2 & 1003 & 1108 & 1184 \\
\hline & & 1 & 936 & 1078 & 1177 \\
\hline \multicolumn{3}{|c|}{ All Capsule 5 compacts } & 923 & 1101 & 1210 \\
\hline
\end{tabular}


Table 7. Compact temperature data for Capsules 3 and 2 at end of irradiation.

\begin{tabular}{|c|c|c|c|c|c|}
\hline Capsule & Stack & Compact & $\begin{array}{c}\text { Time-Average } \\
\text { Minimum Temp. } \\
\left({ }^{\circ} \mathrm{C}\right)\end{array}$ & $\begin{array}{c}\text { Time-Average } \\
\text { Volume-Average } \\
\text { Temp. } \\
\left({ }^{\circ} \mathrm{C}\right) \\
\end{array}$ & $\begin{array}{c}\text { Time-Average Peak } \\
\text { Temp. } \\
\left({ }^{\circ} \mathrm{C}\right) \\
\end{array}$ \\
\hline \multirow{12}{*}{$\begin{array}{c}3 \\
\left(\mathrm{UO}_{2}\right)\end{array}$} & \multirow{4}{*}{1} & 4 & 901 & 1013 & 1085 \\
\hline & & 3 & 997 & 1062 & 1104 \\
\hline & & 2 & 995 & 1061 & 1104 \\
\hline & & 1 & 900 & 1011 & 1083 \\
\hline & \multirow{4}{*}{2} & 4 & 904 & 1013 & 1085 \\
\hline & & 3 & 999 & 1062 & 1105 \\
\hline & & 2 & 998 & 1062 & 1104 \\
\hline & & 1 & 903 & 1012 & 1084 \\
\hline & \multirow{4}{*}{3} & 4 & 891 & 998 & 1073 \\
\hline & & 3 & 981 & 1046 & 1092 \\
\hline & & 2 & 980 & 1045 & 1092 \\
\hline & & 1 & 889 & 996 & 1072 \\
\hline \multicolumn{3}{|c|}{ All Capsule 3 compacts } & 889 & 1032 & 1105 \\
\hline \multirow{12}{*}{$\begin{array}{c}2 \\
\text { (UCO) }\end{array}$} & \multirow{4}{*}{1} & 4 & 1069 & 1240 & 1343 \\
\hline & & 3 & 1195 & 1296 & 1360 \\
\hline & & 2 & 1185 & 1287 & 1353 \\
\hline & & 1 & 1050 & 1218 & 1324 \\
\hline & \multirow{4}{*}{2} & 4 & 1074 & 1240 & 1343 \\
\hline & & 3 & 1199 & 1296 & 1360 \\
\hline & & 2 & 1189 & 1287 & 1354 \\
\hline & & 1 & 1055 & 1219 & 1324 \\
\hline & \multirow{4}{*}{3} & 4 & 1054 & 1216 & 1324 \\
\hline & & 3 & 1171 & 1270 & 1342 \\
\hline & & 2 & 1161 & 1261 & 1335 \\
\hline & & 1 & 1034 & 1194 & 1305 \\
\hline \multicolumn{3}{|c|}{ All Capsule 2 compacts } & 1034 & 1252 & 1360 \\
\hline
\end{tabular}


Figures 17 and 18 show plots of the time at temperature for AGR-2 Capsules 5 and 6, and Capsule 2, respectively. By combining the results from the plots, it can be seen that $10 \%$ of the AGR-2 UCO fuel experienced temperatures of $1400^{\circ} \mathrm{C}$ for about 100 days, and that a few percent experienced temperatures in excess of $1500^{\circ} \mathrm{C}$ for about 50 days. Figure 19 shows a similar plot for Capsule 3. It shows that $10 \%$ of the AGR-2 $\mathrm{UO}_{2}$ fuel experienced temperatures of $1150^{\circ} \mathrm{C}$ for about 150 days, and that about $5 \%$ experienced temperatures in excess of $1200^{\circ} \mathrm{C}$ for about 50 days.

Figures 20 and 21 compare the time-average fuel temperature distributions of the AGR-2 capsules with those of the General Atomics (GA) Steam Cycle - Modular Helium Reactor (SC-MHR) demonstration plant conceptual design. The GA SC-MHR is a 350-MWt, high-temperature, gas-cooled, graphite-moderated reactor utilizing a prismatic graphite block fuel form. It operates with an outlet helium temperature of $725^{\circ} \mathrm{C}$ and it is designed to maintain the maximum time-average fuel temperature at less than $1250^{\circ} \mathrm{C}$ (GA 2010). Figure 20 shows the volume distribution of fuel temperature averaged over the residence time for two SC-MHR equilibrium cycles. Only a small fraction of the SC-MHR core $(<5 \%)$ is expected to experience time-average temperatures above $1000^{\circ} \mathrm{C}$, and its fuel temperature distribution is well-bounded by AGR-2, as at least $85 \%$ of the AGR-2 UCO fuel experienced temperatures higher than $1000^{\circ} \mathrm{C}$, and $30 \%$ experienced temperatures higher than $1100^{\circ} \mathrm{C}$. Figure 21 provides a close-up of the AGR-2 data.

In addition, Figure 22 displays 3-D scatter plots of the irradiation characteristics of the U.S. AGR-2 compacts (black dots), along with their two-dimensional (2-D) projections on the "Burnup - Fast Fluence" (blue dots), "Burnup - TAVA Temperature" (green dots), and "Fast Fluence - TAVA Temperature" (red dots) plans. Figures 23 and 24 show the distribution of burnup and TAVA temperature (see Figure 23) and the distribution of fast fluence and TAVA temperature (see Figure 24) for the AGR-2 compacts. The plots show that AGR-2 covers a broad range of burnup, fast fluence, and irradiation temperatures in an effort to bound expected reactor irradiation characteristics.

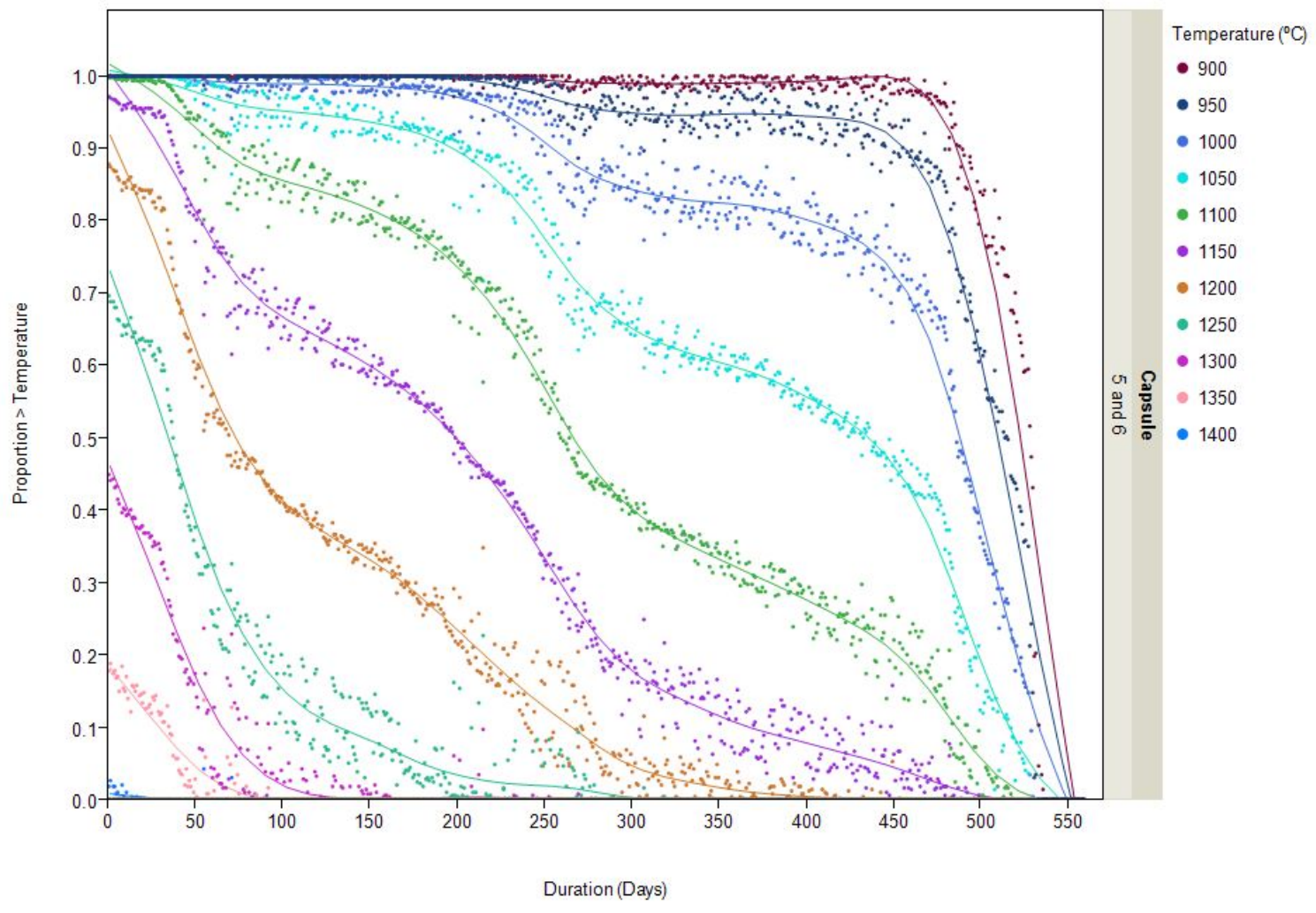

Figure 17. AGR-2 time at temperature for Capsules 5 and 6 (UCO fuel). 


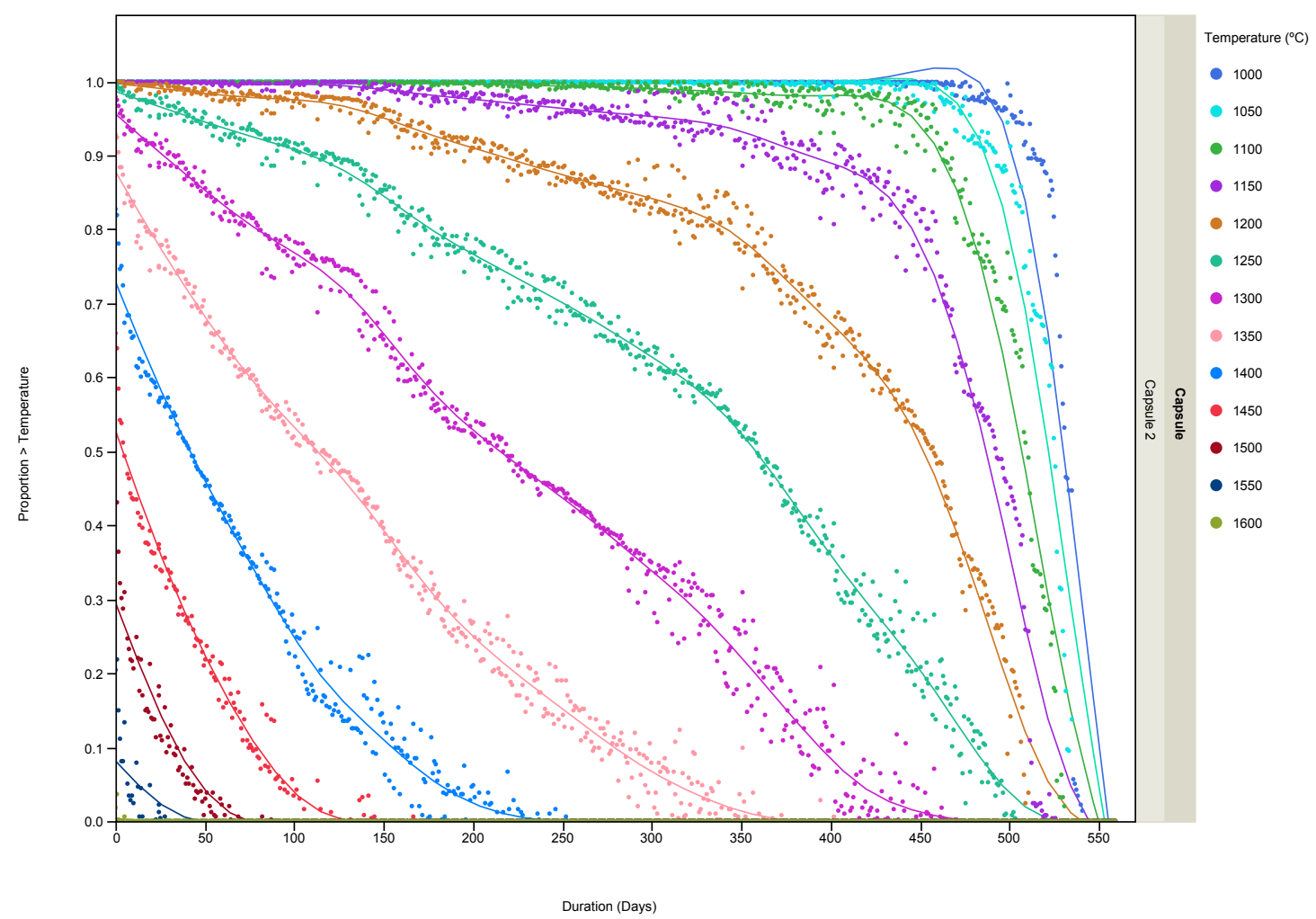

Figure 18. AGR-2 time at temperature for Capsule 2 (UCO fuel).

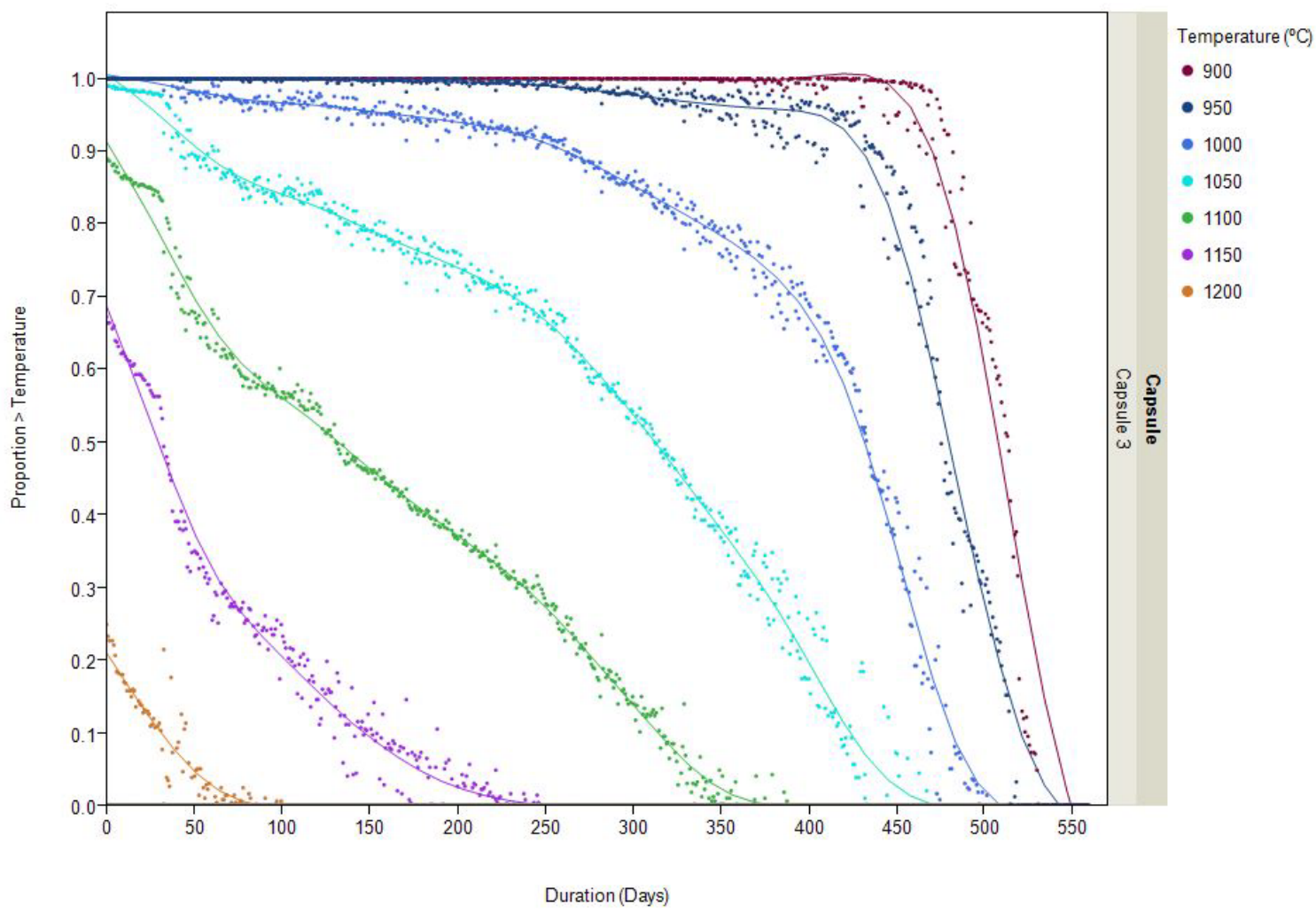

Figure 19. AGR-2 time at temperature for Capsule $3\left(\mathrm{UO}_{2}\right.$ fuel). 


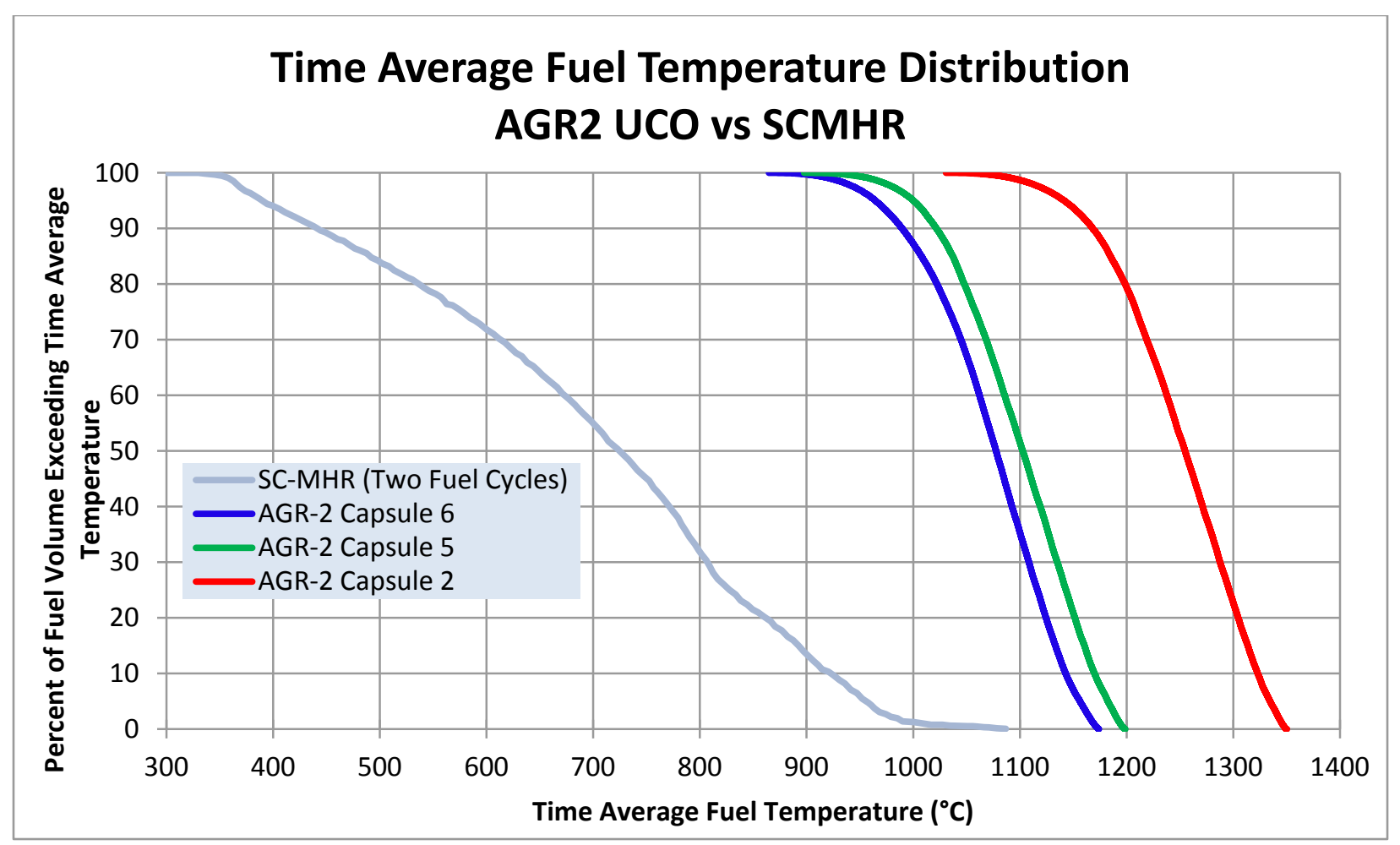

Figure 20. Time-average fuel temperature distribution for AGR-2 UCO fuel and GA SC-MHR.

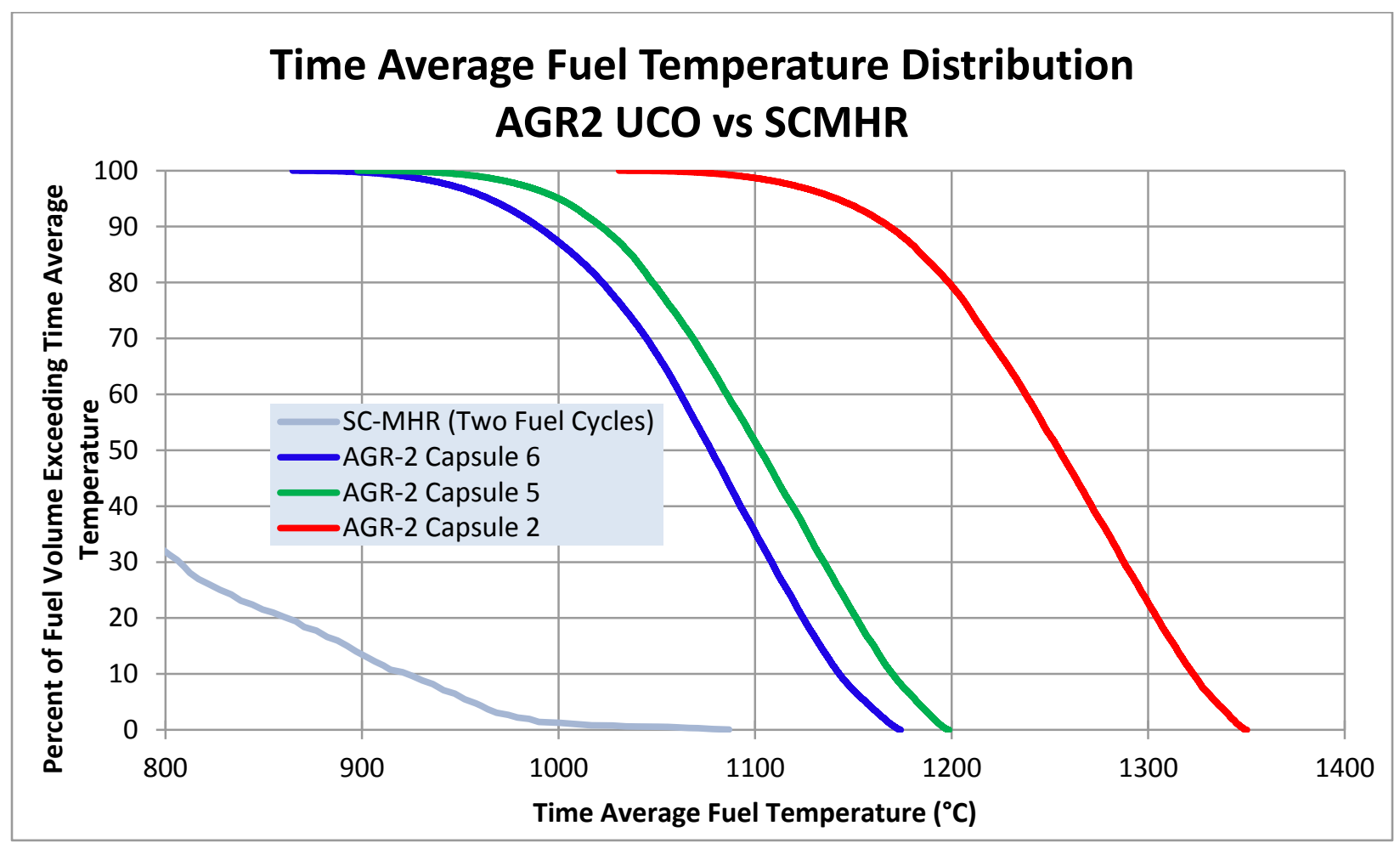

Figure 21. Time-average fuel temperature distribution for AGR-2 UCO fuel and GA SC-MHR (close-up). 


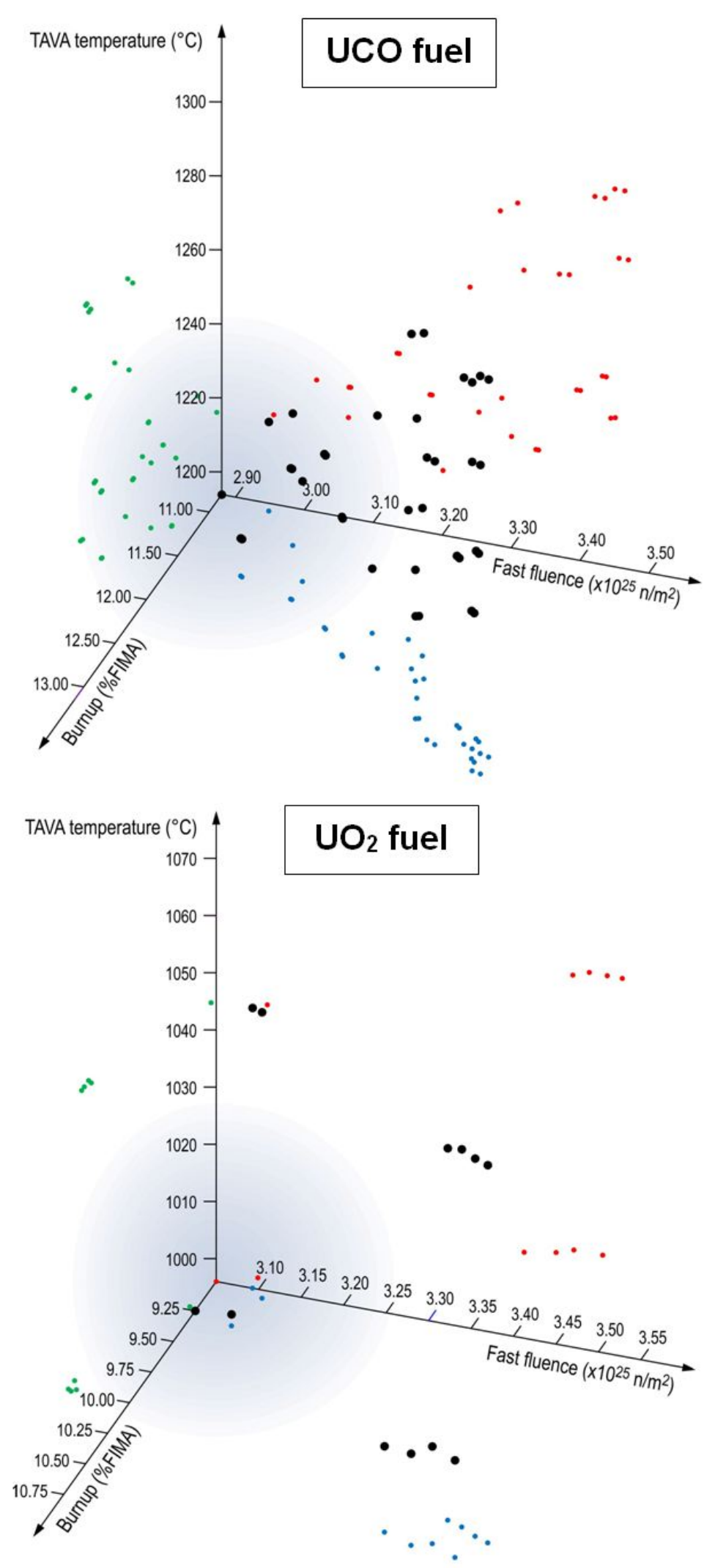

Figure 22. 3-D scatter plots of the irradiation characteristics of the AGR-2 compacts. 

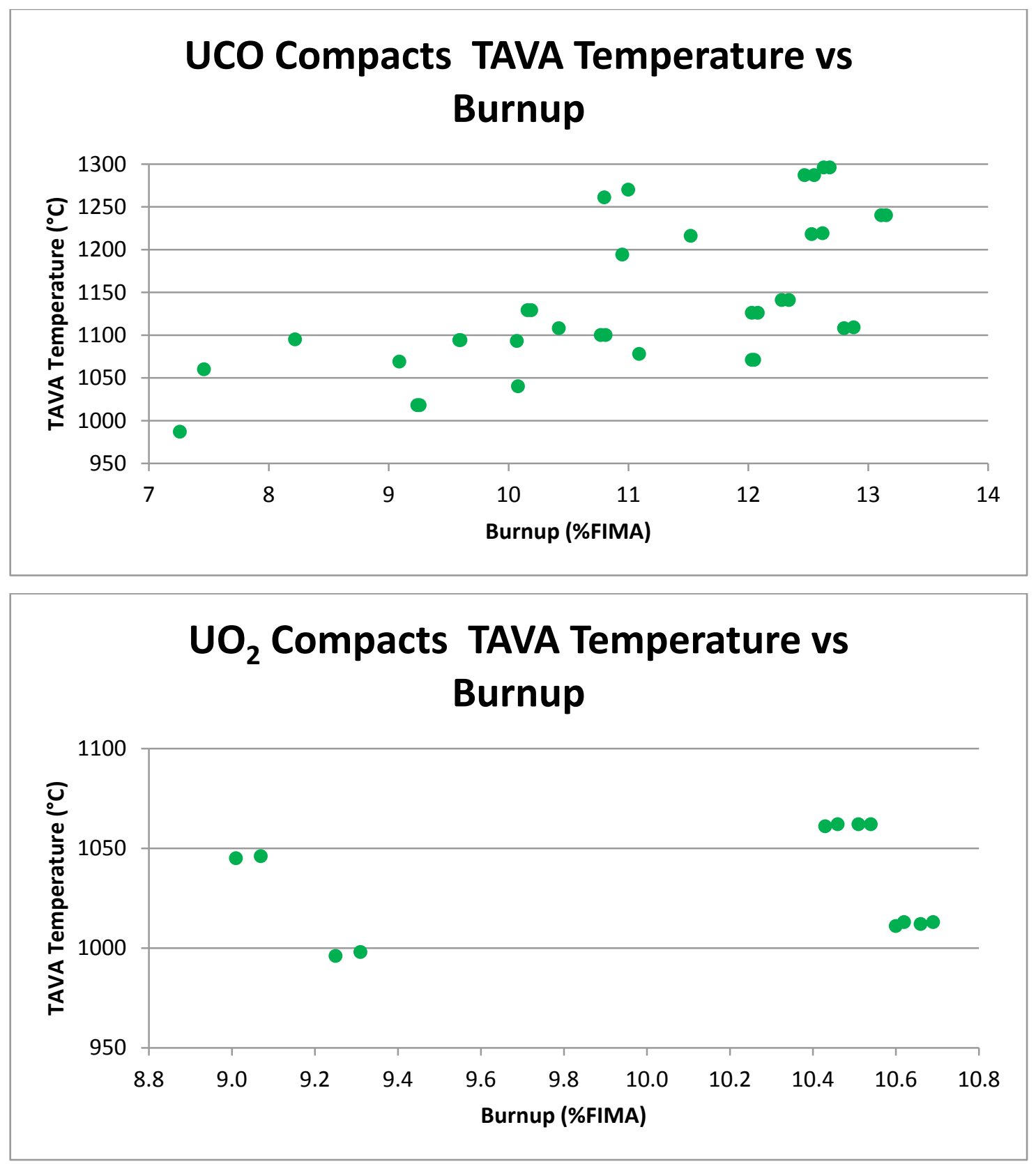

Figure 23. Time-average volume-average temperature $\left({ }^{\circ} \mathrm{C}\right)$ vs. Burnup (\%FIMA) for AGR-2 compacts. 

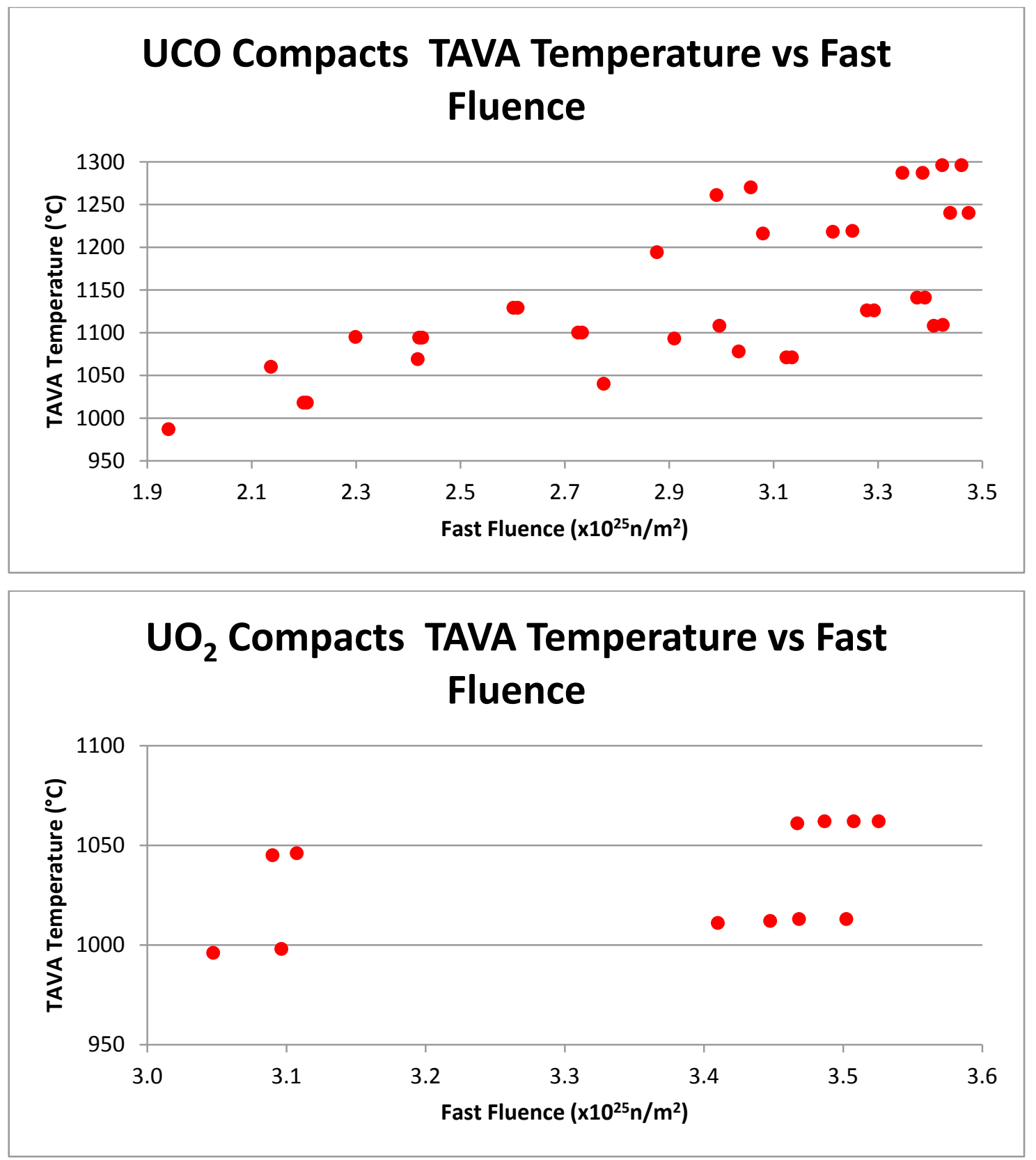

Figure 24. Time-average volume-average temperature $\left({ }^{\circ} \mathrm{C}\right)$ vs. Fast neutron fluence $(\mathrm{E}>0.18 \mathrm{MeV})$ for AGR-2 compacts. 


\subsection{Thermocouple Performance}

AGR-2 temperature measurements were performed by TCs terminating within the graphite sample holders of each capsule. These measurements support temperature control of the experiment where designated control TCs provide feedback to the automated sweep gas control system, which adjusts gas blends to maintain reference temperatures. TC measurements are also used to support thermal analyses of the test train, which ultimately determine fuel temperatures.

When a control TC failed during the irradiation, a previously selected back-up TC within the same capsule was used as the control TC and the reference control temperature reset based on thermal analysis calculations. When all TCs failed within a capsule, results from physics and thermal analyses, and operating history of adjacent capsules were used to manually set the gas blends of the affected capsule. Early in Cycle 150B, after the AGR-2 test was re-installed back from the canal into the reactor following PALM cycle 150A, significant capsule gas line cross-talk and leakage to the leadout started to occur. These cross-talk and leakage problems made it impossible to individually control the temperature in each capsule by independent gas mixture composition as designed. On January 17, 2012 (e.g., the middle of Cycle 151A), AGR operational staff implemented a procedure to set all capsules to the same helium/neon gas mixture ratio (uniform neon fraction) for overall experiment temperature control. TC-2 in Capsule 4 was then used as the control TC for all six capsules. When all TCs failed during Cycle 154B, the neon fraction was held constant for two-thirds of the cycle based on the neon fraction of the previous cycle, while for the last third of the cycle, it was determined by its estimated relationship to the projected fuel fission power assessed from the position of the outer shim cylinders.

Figure 25 gives a diagram of the locations and types of the various TCs in each capsule. Of the 11 planned TCs, one failed during fabrication, while the other ten failed during operation. AGR-2 TCs deteriorate and sometimes fail because of the high irradiation and temperature conditions that occur during test reactor cycles. The two common failure mechanisms for TCs are the formation of virtual junctions and open circuit failures where the signal ceases altogether. Open circuit failures occur when the entire TC breaks in two, causing a break of the thermo-elements, and hence an open circuit. Failures from virtual junctions are caused by deterioration or damage to the TC sheath and/or dielectric insulating material that separates the TC thermal elements. This produces an electrical path ("virtual junction") at some location along the TC wire other than at the terminal tip. Virtual junctions are detected by perturbing the temperature in a single capsule using gas flow, then observing the TC readings from capsules below this one to see if they respond. If a capsule TC responds to temperature changes in a capsule above it, it is likely that a virtual junction has formed and the TC can be considered failed. No evidence of virtual junctions was found during the operating lifetime of the AGR-2 TCs, so all TC failures were attributed to open circuit failure.

Table 8 shows the TC locations, insertion depths, and their failure status (failure date and cycle). TC-2 in Capsule 2 was damaged during fabrication of the test train and never became operational. TC-5 in Capsule 6 failed at the start of the unplanned outage of Cycle 148A. TC-1 in Capsule 2 failed ten days into Cycle 148B. Both TCs in Capsule 5 failed at the very end of Cycle 149A, a few hours before the reactor was powered down. TC-1 in Capsule 6 did not respond to the power-up phase of Cycle 151B, and it was considered failed right before the start of that cycle. TC-4 in Capsule 6 failed a few weeks later during the first unplanned outage of Cycle 151B. Three TCs failed during the power-down phase of Cycle 152B-TC-2 in Capsule 6 and both TCs in Capsule 3. Finally, TC-3 in Capsule 6 was the last TC to fail, during the unplanned outage of Cycle 154A (Pham 2014). Figure 26 shows the readings of all functioning TCs as a function of EFPD, thus the plots are discontinued at the time of TC failures. 


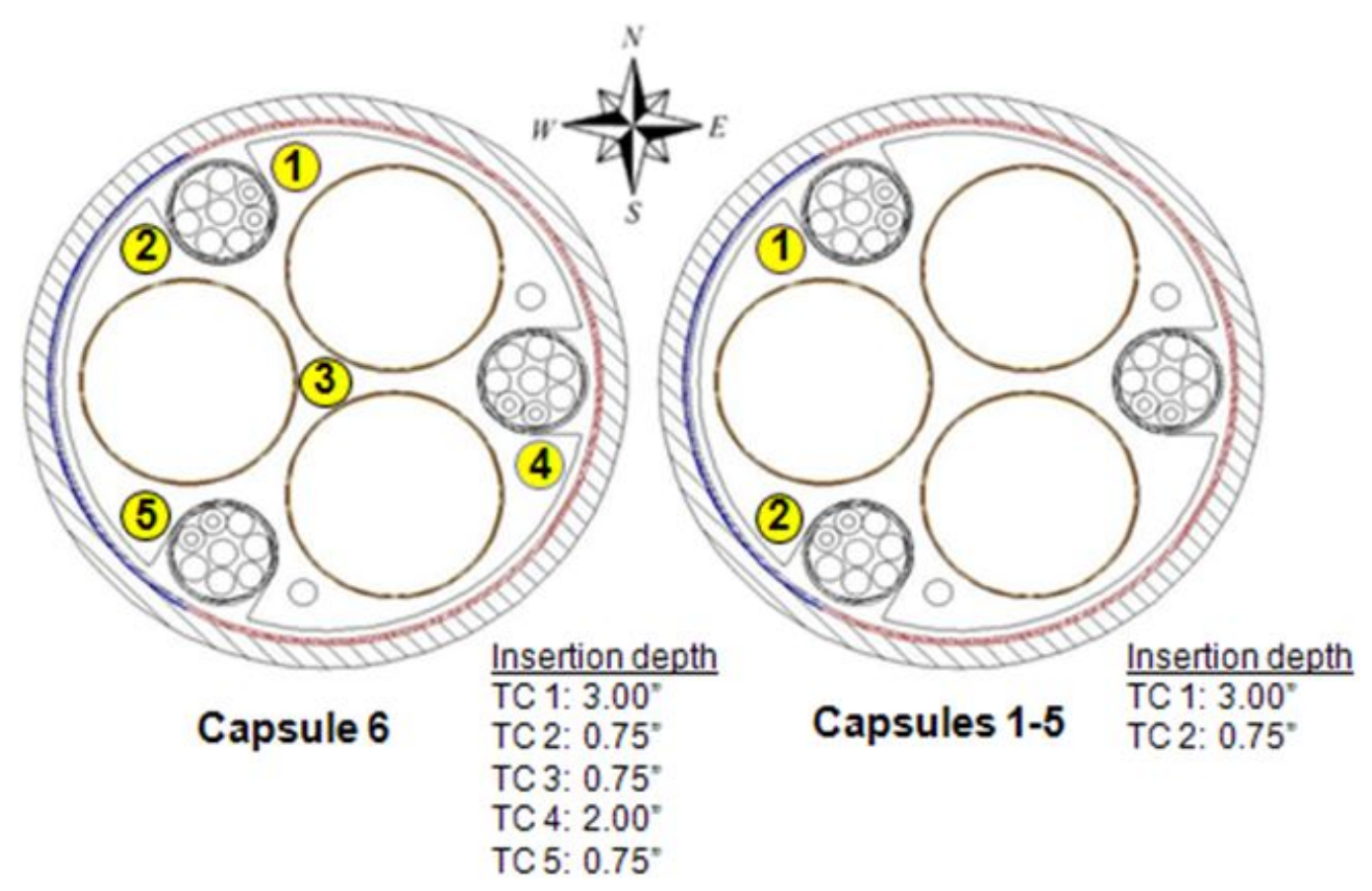

Figure 25. Cutaway view of each capsule showing type and position of TCs (ATR core center to the right).

Table 8. TC types, locations, and conditions in AGR-2 test train.

\begin{tabular}{|c|c|c|c|c|c|c|c|}
\hline Capsule & TC & $\begin{array}{l}\text { Azimuthal } \\
\text { Orientation }^{\mathrm{a}}\end{array}$ & Depth $^{\mathrm{b}}$ & TC Type ${ }^{c}$ & $\begin{array}{l}\text { Sheath/ } \\
\text { Insulation }\end{array}$ & Sleeve & Condition \\
\hline \multirow{5}{*}{6} & 1 & $353^{\circ}$ & 3.00 & Type N & $\mathrm{Nb} / \mathrm{MgO}$ & None & $\begin{array}{l}\text { Failed on 02/29/2012 } \\
\text { Before Cycle 151B }\end{array}$ \\
\hline & 2 & $307^{\circ}$ & 0.75 & Type N & $\mathrm{Nb} / \mathrm{MgO}$ & None & $\begin{array}{l}\text { Failed on } 01 / 18 / 2013 \\
\text { End of Cycle } 152 \mathrm{~B}\end{array}$ \\
\hline & 3 & $0^{\circ}$ & 0.75 & Type N & $\mathrm{Nb} / \mathrm{MgO}$ & None & $\begin{array}{l}\text { Failed on } 05 / 21 / 2013 \\
\text { Scram during Cycle } 154 \mathrm{~A}\end{array}$ \\
\hline & 4 & $113^{\circ}$ & 2.00 & Type N & $\mathrm{Nb} / \mathrm{MgO}$ & None & $\begin{array}{l}\text { Failed on } 03 / 22 / 2012 \\
\text { Scram during Cycle } 151 \mathrm{~B}\end{array}$ \\
\hline & 5 & $233^{\circ}$ & 0.75 & Type N & $\mathrm{Nb} / \mathrm{MgO}$ & None & $\begin{array}{l}\text { Failed on } 10 / 12 / 2010 \\
\text { Scram during Cycle } 148 \mathrm{~A}\end{array}$ \\
\hline \multirow{2}{*}{5} & 1 & $307^{\circ}$ & 3.00 & Type N & $\mathrm{Nb} / \mathrm{MgO}$ & None & $\begin{array}{l}\text { Failed on } 05 / 21 / 2011 \\
\text { End of Cycle } 149 \mathrm{~A}\end{array}$ \\
\hline & 2 & $233^{\circ}$ & 0.75 & Type N & $\mathrm{Nb} / \mathrm{MgO}$ & None & $\begin{array}{l}\text { Failed on } 05 / 21 / 2011 \\
\text { End of Cycle 149A }\end{array}$ \\
\hline \multirow{2}{*}{3} & 1 & $307^{\circ}$ & 3.00 & Type N & $\mathrm{Nb} / \mathrm{MgO}$ & None & $\begin{array}{l}\text { Failed on } 01 / 18 / 2013 \\
\text { End of Cycle 152B }\end{array}$ \\
\hline & 2 & $233^{\circ}$ & 0.75 & Type N & $\mathrm{Nb} / \mathrm{MgO}$ & None & $\begin{array}{l}\text { Failed on } 01 / 18 / 2013 \\
\text { End of Cycle 152B }\end{array}$ \\
\hline \multirow[t]{2}{*}{2} & 1 & $307^{\circ}$ & 3.00 & Type N & $\mathrm{Nb} / \mathrm{MgO}$ & None & $\begin{array}{l}\text { Failed on } 11 / 27 / 2010 \\
\text { During Cycle } 148 \mathrm{~B}\end{array}$ \\
\hline & 2 & $233^{\circ}$ & 0.75 & Type $\mathrm{N}$ & $\mathrm{Nb} / \mathrm{MgO}$ & None & Failed at fabrication \\
\hline
\end{tabular}

a. Azimuthal orientation given in degrees rotated clockwise as viewed from above (as in Figure 3 ) with North being $0^{\circ}$.

b. Depth (in $\mathrm{cm}$ ) of insertion into graphite sleeve.

c. All TCs are $2.03 \mathrm{~mm}(0.08$ in. $)$ in diameter. 
The temperature difference between TCs in the same capsule should remain fairly constant over time. Any other trend or discontinuity in the data suggests that one of the TCs is drifting (Pham 2014). A control chart was used to monitor the temperature difference between two TCs in each capsule. The control chart uses an initial "baseline" period of data to calculate typical operating conditions. Then, it evaluates a subsequent "monitoring period" of data relative to the baseline conditions. A control chart centerline is calculated for a given TC pair in one capsule using the mean of the temperature difference between two TCs in that same capsule during the baseline period. Upper and lower control limits for the TC differences are then calculated as three standard deviations above and below the control chart mean difference. If, during the monitoring period, one TC indicates significantly higher or lower temperatures relative to another TC in that capsule, then one of the TCs may be drifting. However, a key control chart assumption is that there is a constant mean and standard deviation of the temperature differences between TC pairs within a capsule over both the baseline and monitoring periods. This assumption may not always be valid because of differential heating across TC pairs that may occur as the experiment progresses. Using this control chart, it was suggested that TC-3 in Capsule 6 might be drifting upward from Cycle 149B to 152B, and that TC-4 in Capsule 6 might be drifting upward, although the apparent drift could be due to changes in capsule thermal condition (e.g., neutron-induced change in conductivity of the graphite holder). No drift could be identified in Capsules 3 and 5. Capsule 2 had only one operational TC so TC drift could not be monitored using that procedure.

Figure 27 shows the differences between the measured and the calculated TC temperatures. Except for TC-3 in Capsule 6, there is a good agreement between the measured and calculated TC temperatures, with differences within $\pm 100^{\circ} \mathrm{C}$ and, in many cases, within $\pm 20-50^{\circ} \mathrm{C}$. In Capsule 6 , it shows large TC residuals for TC-3, and to a lesser extent for TC-2. The inconsistency between measured and calculated temperatures at TC locations in Capsule 6 suggests that TCs might have been mislabeled during assembly, but there is no clear evidence to support the assumption (Pham 2014). Therefore, the TCs in Capsule 6 were considered to be correctly labeled. This labeling issue did not affect the experiment temperature control because the location of the control TC generally does not impact the temperature control procedure as long as TC readings are maintained at a predefined set point. 


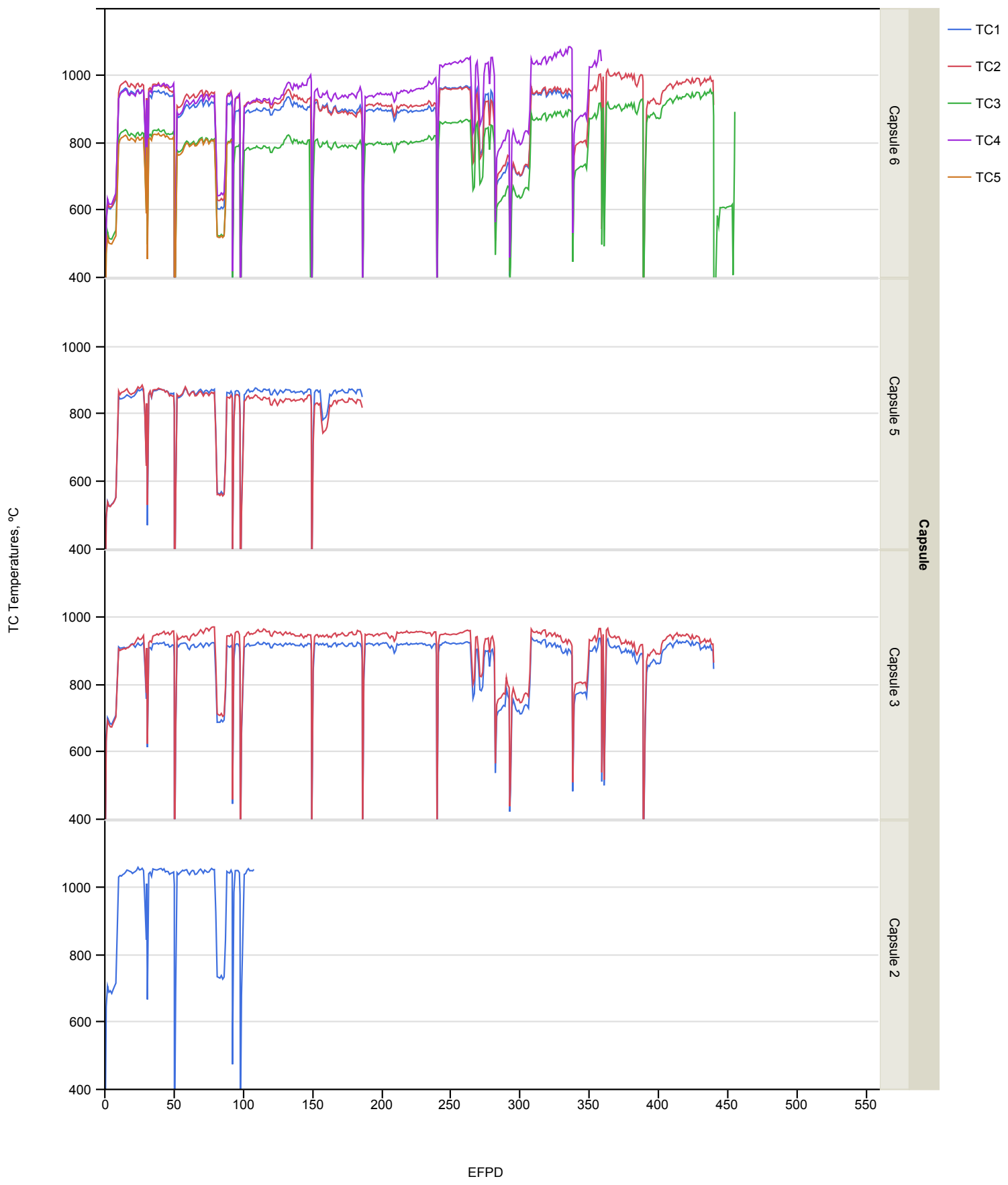

Figure 26. Measured TC temperatures versus EFPD. 


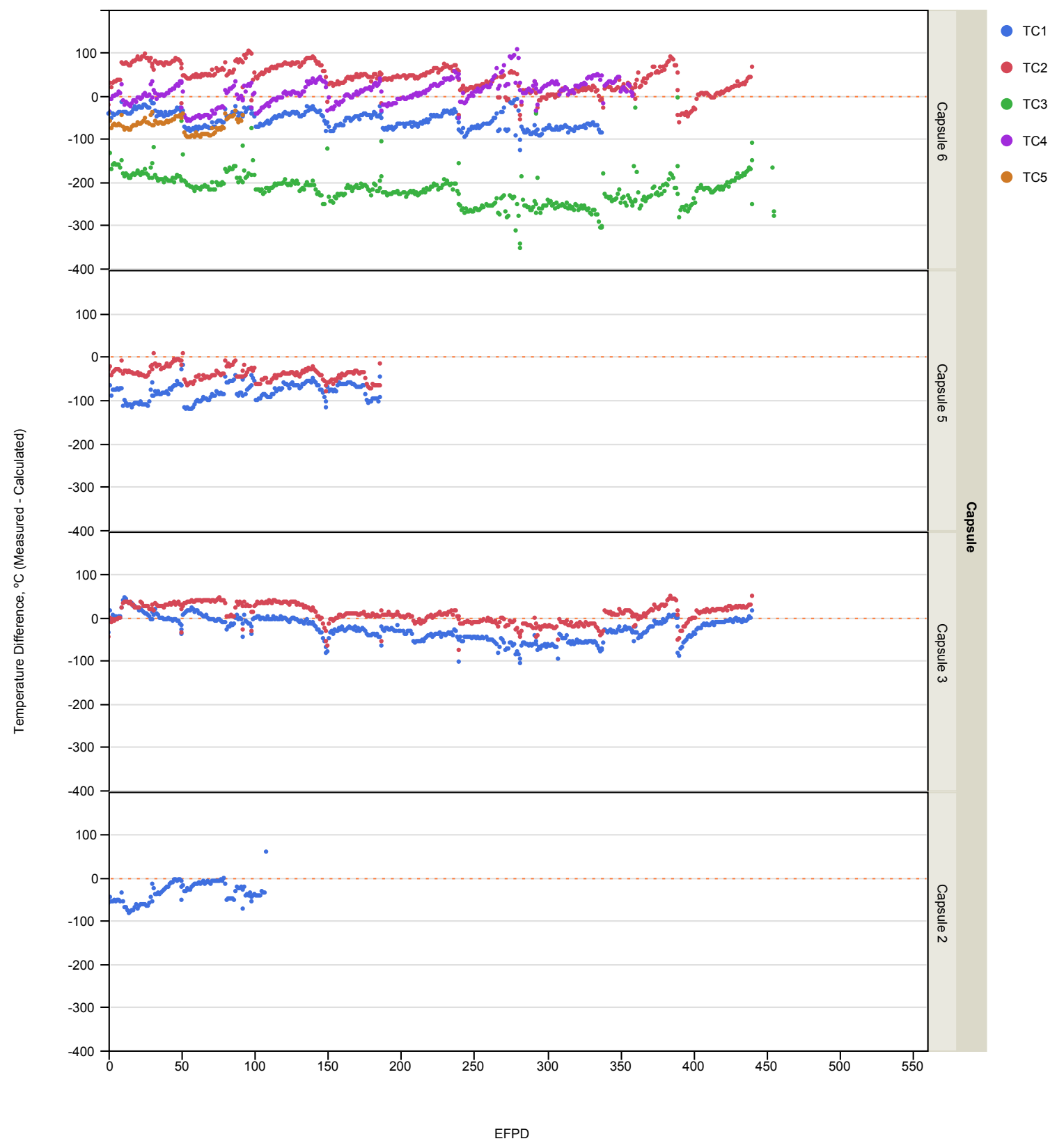

Figure 27. Difference between measured and calculated TC temperatures versus EFPD. 


\section{FISSION PRODUCT GAS RELEASE ANALYSIS}

As previously mentioned, no evidence of fuel particle failure was observed during the AGR-2 irradiation. The rate of release of fission product gases by intact TRISO fuel particles is also important in assessing fuel performance. Fission product gas release rate to birth rate $(\mathrm{R} / \mathrm{B})$ ratio values provide indicators of initial fuel quality and fuel performance during irradiation. AGR-2 reactor physics personnel provided as-run fission product birthrates for $\mathrm{Kr}-85 \mathrm{~m}, \mathrm{Kr}-87, \mathrm{Kr}-88, \mathrm{Kr}-89, \mathrm{Kr}-90, \mathrm{Xe}-131 \mathrm{~m}, \mathrm{Xe}-133$, Xe-135, Xe-135m, Xe-137, Xe-138, and Xe-139. These nuclides were selected because they are chemically inert fission product gases with relatively short half-lives, allowing each isotope to reach equilibrium concentration in the fuel during each cycle. The FPMS system described in Section 1.2 was used to quantify release rates during irradiation giving the $\mathrm{R} / \mathrm{B}$ ratios for the radionuclides of interest.

\subsection{Birth Rate Calculations Methodology}

The birth rates of noble gas fission products of interest were calculated using ORIGEN2 version 2.2 (Croff 1983). These calculations used compact flux and reaction rates from MCNP (LANL 2004). The ORIGEN2 libraries used in the calculation were modified to remove the isotope depletion methods (transmutation and decay) for the isotopes of interest for birthrates. The increase in the concentration of the isotope during the irradiation time interval divided by the irradiation time interval was determined to be the isotope birthrate of the isotope during the time interval. This was performed by two separate physics calculations with different time resolutions. One calculation used a four-point subdivision of each ATR cycle - once at the beginning of each cycle, once at the end, and two times during each cycle. The second high-resolution calculation estimated birthrates on a daily basis. The data provided by the four-point interpolation method supplied the experiment team with information pertaining to fuel integrity during the multiyear irradiation. At the conclusion of the AGR-2 experiment, the high-resolution daily depletion calculations were performed to provide daily compact and component heat rates for highresolution thermal analyses. The daily physics analysis also increased the number of tracked fission product isotopes in the TRISO particle compacts in order to assist in PIE measurements and to better characterize the irradiated compacts.

\subsection{Release Rate Calculations Methodology}

As mentioned in Section 1.2, spectrometer detector systems measure the concentrations of various krypton and xenon isotopes in the sweep gas from each capsule. Eight-hour counting intervals are used to measure the concentrations of Kr-85m, Kr-87, Kr-88, Kr-89, Kr-90, Xe-131m, Xe-133, Xe-135, $\mathrm{Xe}-135 \mathrm{~m}, \mathrm{Xe}-137, \mathrm{Xe}-138$, and Xe-139.

The radionuclides of interest decay in transit from the capsule to the counters. Given a certain measured activity, $\mathrm{A}(\mu \mathrm{Ci})$, the radionuclide release rate, $\mathrm{R}(\mathrm{at} / \mathrm{s})$, of a particular nuclide can be calculated as (Scates 2014):

$$
R=3.7 \times 10^{4} \frac{A e^{\lambda V_{T} / \mathrm{f}}}{\left(1-e^{-\lambda V_{\mathrm{S}} / \mathrm{f}}\right)}
$$

where $V_{S}$ is the sample volume $(\mathrm{mL}), \lambda$ is the nuclide decay constant $\left(\mathrm{s}^{-1}\right), \mathrm{f}$ is the capsule volumetric flow rate $(\mathrm{mL} / \mathrm{s})$, and $\mathrm{V}_{\mathrm{T}}$ is the transport volume from the capsule to the sample volume $(\mathrm{mL})$. The transport volumes were determined during a lead-out flow experiment performed at the beginning of the AGR-2 irradiation (Scates 2014). The method used to determine the transport volumes is similar to the one used for AGR-1, and it is described in Hartwell (2007). The ratio of the experimentally determined release rates to the calculated birth rates is then computed. The Scates (2014) report contains information about the software and hardware used to take and process these release rate measurements along with detailed $\mathrm{R} / \mathrm{B}$ results, which are summarized in the following section. 


\subsection{R/B Results}

Figure 28 shows R/B versus time for $\mathrm{Kr}-85 \mathrm{~m}, \mathrm{Kr}-88$, and Xe-138 plotted using NDMAS. The R/B values for this figure were computed using the high-resolution daily depletion method. These nuclides were selected for plotting because they have relatively short half-lives allowing them to come into equilibrium in each cycle. These are daily-average values filtered such that data with uncertainty higher than 50\% and sometimes data from short acquisition intervals (e.g., 20-minute intervals for neon testing at the beginning of each cycles) are removed. Appendix C contains a figure equivalent to Figure 28 only without any filtering.

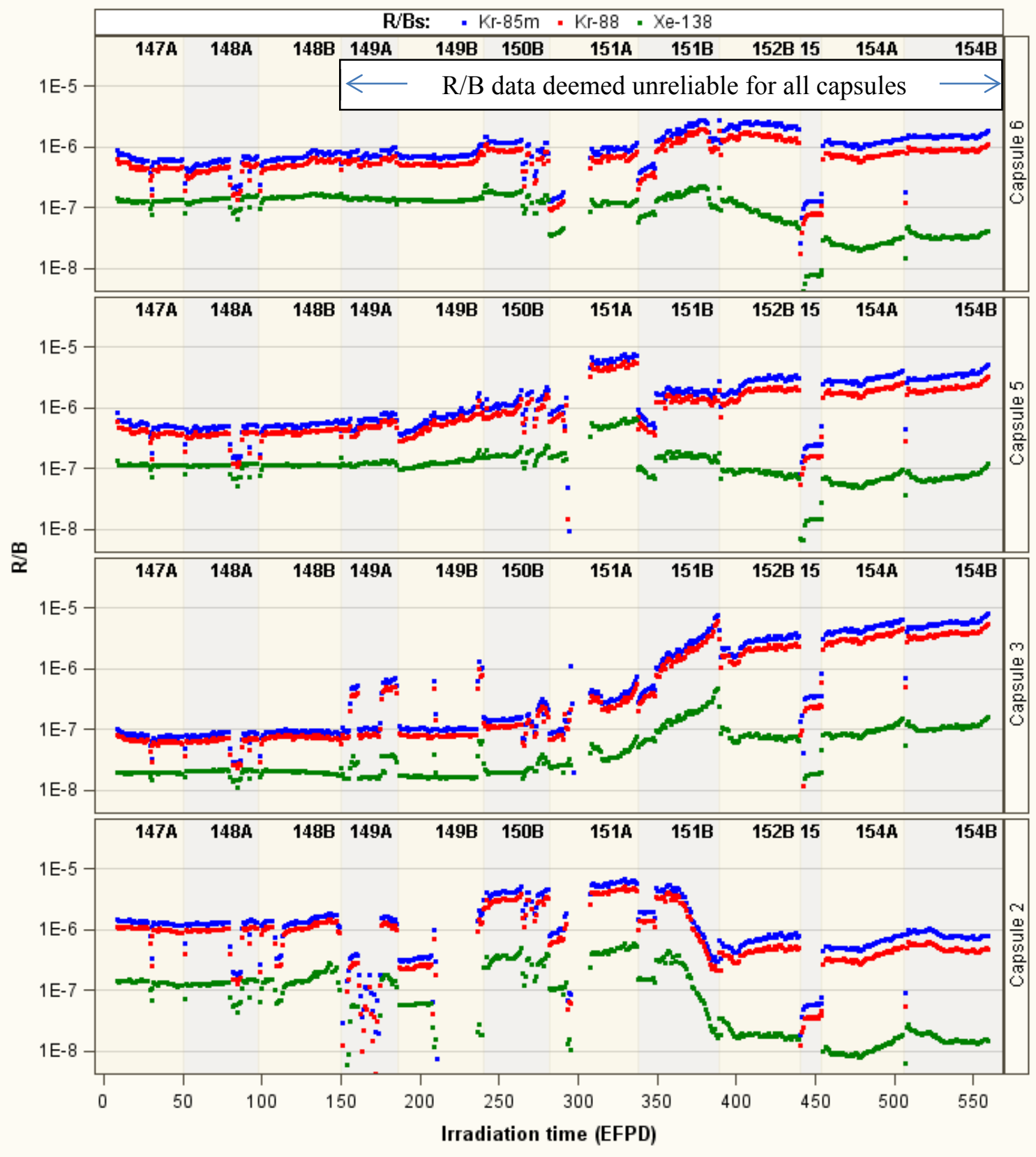

Nuclear Data Management and Analysis System (NDMAS)

Figure 28. $\mathrm{R} / \mathrm{B}$ ratios from daily birthrates for $\mathrm{Kr}-85 \mathrm{~m}, \mathrm{Kr}-88$, and $\mathrm{Xe}-138$ versus time in EFPD. Data from Cycle 149A and following cycles are not deemed reliable because of gas flow and cross-talk issues. 
The $\mathrm{R} / \mathrm{B}$ ratios for these nuclides are below approximately $10^{-6}$ in the UCO capsules for the first three cycles of the test with the exception of Capsule 2, which experiences higher temperatures during these cycles than the other two capsules, and reaches $\mathrm{R} / \mathrm{B}$ of approximately $2 \times 10^{-6}$. In the colder $\mathrm{UO}_{2}$ capsule (e.g., Capsule 3), the R/B ratios reach approximately $10^{-7}$. The data for the following cycles are not deemed reliable because of the gas flow and cross-talk issues that started with Cycle 149A and Cycle 150B, respectively (see Subsection 5.1). Because of the problems associated with gas flow and cross-talk, the absence of particle failure cannot be guaranteed. Definite estimates will be obtained by PIE. 


\section{AGR-2 OPERATIONAL ISSUES}

Some issues pertaining to the conduct of AGR-2 have arisen during irradiation. These include matters dealing with sweep gas flow, temperature control, and TC behavior. Each is discussed in the sections that follow.

\subsection{Sweep Gas Flow and Temperature Control}

The helium and neon gas supply systems for the AGR-2 experiment were upgraded to bring them into better compliance with the American Society of American Engineers (ASME) B31.1 Code for Over Pressure Protection, and to provide improved temperature control of the individual capsules in the AGR-2 experiment. During the April/May 2011 ATR operating cycle (e.g., Cycle 149A), it was discovered that the activity indicated in fission product Monitor 2 (dedicated to Capsule 2) was only approximately twenty percent of the value indicated during the previous operating cycles. A work-around was used to direct flow from Capsule 2 to Monitor 7 during the rest of the operating cycle. A suspect three-way valve was replaced in the June outage, but the reduced activity measurements continued. The upgraded relief valves installed as part of the system upgrade were replaced with new valves with lower seating pressure requirements, and additional troubleshooting and repairs were performed in the September/October ATR outage following PALM cycle 150A, when AGR-2 was transferred back into the ATR after spending that PALM cycle in the ATR canal. Initial testing during the outage indicated the flow issue in Monitor 2 had been corrected, which was confirmed when the ATR was restarted in October.

Unfortunately, in mid-November the capsules started to experience widely different temperatures. By adjusting gas mixtures, the ATR operators were able to maintain the desired range in four of the capsules, but were not able to keep Capsule 1 up to its desired temperature. In addition, the temperature in Capsule 4 started to exceed its desired temperature band. The experiment was placed upon full helium flow until all capsule temperatures had stabilized at low temperatures. The new control valves installed downstream of the test train but immediately upstream of the fission product monitors were utilized to balance the backpressure and outlet flow among all of the capsules. An attempt was made to bring the experiment back up to operating temperature, but the temperature in Capsule 4 continued to increase, which indicated there must be leakage between the capsules, so the experiment was taken to full helium flow and cooled down again. Leakage between the capsules may have been caused by the relief valve and other control system component replacements during the preceding outage or possible gas path failures inside the test train due to the transfer of the experiment from the reactor to the canal and back into the reactor. After balancing the capsule outlet flows, a leadout minimum flow test was performed by injecting a small amount of neon into a single capsule followed by lowering the leadout flow until activated neon was detected by the fission product monitor of another capsule in addition to the one receiving the neon injection. This process was repeated on all capsules individually to determine the minimum leadout flow that could prevent leakage (or cross-talk) between the capsules in the test train, which may have been causing the temperature anomalies. Unfortunately, there was significant leakage between the capsules at very high leadout flow rates, so it could not be conclusively determined if the leakage was in the control system (either upstream or downstream of the experiment) or internal to the test train. The thermal model of the experiment was used to calculate a uniform gas mixture that could be introduced to all capsules and the leadout to best meet all capsule desired temperatures without exceeding high-temperature limits on any single capsule. Another attempt was made to bring all capsules up to temperature using this uniform gas mixture; however, the neon content had to be reduced in some capsules to avoid excessive temperatures, and eventually the experiment was taken to full helium for the last few days of the operating cycle when the fuel fission powers are peaked due to high angular position of the outer shim control cylinders.

Additional troubleshooting of the temperature control gas system flow path did not reveal any possible causes for the leakage between the capsules. Thus, given the potential cross-talk between capsules, the experimental control strategy for AGR-2 going forward was to establish a uniform gas 
mixture for all capsules so that accurate thermal estimates of fuel temperature could be made. This uniform gas mix approach allowed four capsules to stay within their desired operating band. One capsule ran about $50^{\circ} \mathrm{C}$ hotter and one capsule ran about $100^{\circ} \mathrm{C}$ cooler than anticipated. On January 17, 2012 (e.g., the middle of Cycle 151A), AGR operational staff implemented a procedure to set all capsules to the same helium/neon gas mixture ratio (uniform neon fraction) for overall experiment temperature control. TC-2 in Capsule 4 was then used as the control TC for all six capsules. When all TCs failed during Cycle 154B, the neon fraction was held constant for two-thirds of the cycle based on the neon fraction of the previous cycle, while for the last third of the cycle, it was determined by its estimated relationship to the projected fuel fission power assessed from the position of the outer shim cylinders. Given the potential cross-talk among the capsules, the results from the fission product monitoring would be suspect since they would no long represent releases from a specific capsule. This uniform gas mix approach was initially thought to allow four capsules to stay within their desired operating band; however, it was determined later that all six capsules were within reasonable limits of their desired operating band. After several events in December, the uniform gas mix was introduced; however, only an approximate total of between one and two days of operation at temperature were achieved before December 28, 2011, when the experiment was purged with pure helium and isolated under a pure helium atmosphere. The events causing this reduction in operation at temperature included a gas line fitting leaking on fission product monitor one (for Capsule 1) releasing fission gases and contaminating the $2 \mathrm{C}$ secondary cubicle, a 3.5-day unplanned outage of ATR caused by a diesel generator problem, and finally another suspected fission gas leak into the $2 \mathrm{C}$ secondary cubicle. Flow to the experiment was terminated on December 28, 2011 , until the integrity of all gas lines in the $2 \mathrm{C}$ secondary cubicle could be verified.

The integrity of the gas lines was verified and flow was re-established to AGR-2 on January 11, 2012, with the uniform gas mixture being applied to all capsules and the leadout. The desired operating temperatures were achieved and the operators were able to maintain them for the balance of January by reducing the neon gas component to compensate for the movement of the outer shim control cylinders as the reactor driver fuel depleted during the operating cycle.

Operational issues relating to as-installed equipment failures, safety precautions, and testing to determine possible sources of leaks, cross lines, and TC failures are included in the sections that follow. Several of these incidences are described in Scates (2014) and are briefly reported as follows:

- During Cycle 147A, a leadout flow and transport time testing determined that the leadout flow would be set to $10 \mathrm{sccm}$ to prevent capsule cross-talk.

- During Cycle 148A isolation flow testing occurred because of suspect excess gas leaking into the test train. During isolation flow testing, the leadout flow gas mixture was switched to $30 \mathrm{sccm}$ helium and $0 \mathrm{sccm}$ neon to purge the experiment. The test was then isolated and pressure tested to a normal operating pressure of $25 \mathrm{psig}$ to ensure there were no leaks in the gas supply system. No leaks were found.

- During Cycle 148B, neon transport testing was performed, during which neon was held constant at $2 \mathrm{sccm}$ for all capsules, while the total flow was set to 35, 25, and $15 \mathrm{sccm}$. Measurements for each capsule were acquired. This testing was performed to accurately determine the transport volumes needed to compute the release activity for the AGR-2 experiment. Additionally, on November 27, 2010, the flow to Capsule 2 was changed to $15 \mathrm{sccm}$ helium and $0 \mathrm{sccm}$ neon. The capsule flow stayed at this rate until December 2, 2010, when the gas mix was changed to $16 \mathrm{sccm}$ helium and $14 \mathrm{sccm}$ neon. The initial change was triggered due to TC loss in Capsule 2.

- During the Cycle 149A outage, poppet check valves on the AGR-2 outlet distribution panel were replaced with actual relief valves. These new relief valves have a set pressure of only 5 psig versus the 10 psig of the original set of pressure check valves. The FPMS inlet isolation ball valves were also replaced with needle valves. These valve changes were anticipated to be transparent to the operation of the experiment; however, they had unexpected consequences for the FPMS measurements. Upon 
initial reactor startup, review of the gross gamma data revealed that something was not set up as intended. The expected activity levels were seen for all capsules except for Capsule 2, which showed only the fission product monitor (FPM) chamber background. Changes to the flow configuration were made to clarify the situation. The relief valve situation continued through to Cycle 149B because it was not possible to replace the relief valves during the Cycle 149B outage. Changes to the flow configuration were made to clarify the situation.

- During the first week of Cycle 150B, activity for Capsule 2 was increasing, leading the FPM team to think that the temperature within the test train for Capsule 2 was increasing as well. On November 9, 2011, flow for AGR-2 was taken to $30 \mathrm{sccm}$ helium until November 11, 2011, when neon was placed back into the test train. This test was performed to see if some valves may be reseated and if the FPM team could determine what fission products were making it to the FPMS traps. On November 11, 2011, the experiment team started a new leadout flow test to try and determine which capsules had cross-talk, if any, indicating damage to the AGR-2 test train. To help control capsule temperature, the program decided to inject $8 \mathrm{sccm}$ of neon into the leadout flow and then adjust the throttle valves upstream of the FPMs to balance the capsules. By adjusting the gas mixtures, the ATR operators were able to maintain the desired temperature range in the capsules. Leakage between the capsules appears to have been caused by gas path failures inside the test train, resulting from the handling required to transfer the experiment from the reactor to the ATR canal (storage pool) and back into the reactor. After using the throttle valves to balance the capsule back pressures and outlet flows, the leadout minimum flow test was performed to verify if leakage (or cross-talk) between the capsules in the test train was causing the temperature anomalies. Unfortunately, there was significant leakage between the capsules at very high (e.g., $30 \mathrm{sccm}$ versus previous $6 \mathrm{sccm}$ ) leadout flow rates. The thermal model of the experiment was then used to calculate a uniform gas mixture that could be introduced to all capsules and the leadout to best meet all capsule desired temperatures without exceeding high-temperature limits on any single capsule. Another attempt was made to bring all capsules up to temperature using this uniform gas mixture; however, the neon content had to be reduced in some capsules to avoid excessive temperatures and, eventually, the experiment was taken to full helium for the last few days of the operating cycle.

- Early during Cycle 151A, it was discovered that effluent from Capsule 1 was escaping from FPM1 and accumulating in the $2 \mathrm{C}$ secondary cubicle. Therefore, the effluent was routed instead to the spare FPM7. During the 151A outage, an effort had been made to flush cesium out of the FPM traps. This had required them to be disconnected from the effluent lines. When the traps were reconnected, the connections to FPM1 were not sufficiently tightened, resulting in the leak into the $2 \mathrm{C}$ secondary cubicle. Therefore, AGR-2 was placed in standby mode with all inlet and isolation valves closed until the krypton and xenon could decay or disperse. By December 24, 2011, the connection to the FPM trap was tightened and flow was restored to all FPMs. It was recommended that flow rebalancing of the throttle values for AGR-2 be performed again and that a gas mix ratio of $20 \mathrm{sccm}$ neon and $10 \mathrm{sccm}$ helium be used. On December 25, 2011, the reactor was scrammed due to loss of diesel; therefore, AGR-2 was brought down during the unplanned outage. The reactor was brought back to full power on December 28, 2011. Capsule 1 was placed back into its normal configuration and Capsule 6 was sent to spare because FPM count rates dropped to zero and gave an indication of a high-voltage power failure. Upon investigation, the preamp cable connected to the detector preamplifier had become disconnected during the flow adjustments. By December 30, 2011, all FPM modules were functioning and Capsule 6 was placed back into its normal configuration. On the same day, high pressure in the Capsule 6 inlet triggered an alarm, and the gas flow in AGR-2 was secured. R/B data for the time-period of December 30, 2011, through January 11, 2012, were deemed to be not valid. The FPMS detectors were monitoring residual effluent and cubicle background during this time-period. R/B values were calculated because non-zero flow data from the NDMAS database was provided for this time-period. Nominal flow for the AGR-2 experiment is on the order of $30 \mathrm{sccm}$. Flow during the isolated experiment was recorded in the NDMAS system to be on the order of 
$0.05 \mathrm{sccm}$. On January 11, 2012, AGR-2 was returned to operating status, where it remained in operation until February 11, 2012, without any further problems. It became clear during Cycle 151A that the helium/neon gas mixture within the AGR-2 capsules was ambiguous because of the damage sustained to the experiment during transport of the test train to the canal prior to PALM cycle 150A. The program decided to set all of the capsules and leadout flow mixture ratios (i.e., neon fraction) to the same value on January 17, 2012.

- During the Cycle 153A outage, seven flow meters were installed on the outlet side of the FPM warm traps. These meters were installed to help verify that the flow coming out of the AGR-2 capsules is the same flow that is leaving the FPM warm traps. If there were to be a difference in flow reading, it would indicate that something was amiss between the experiment and the warm traps, indicating a potential leak in the valves or tubing upstream of the FPMS. During installation of the flow meters, severe noise (on the order of hundreds of thousands of counts per second) was introduced into the FPMS via the sodium iodide detectors (gross gamma). The FPM team was able to work with plant operations to remove the noise that rendered the FPMS gross gamma detectors inoperable as far as measuring the count rate from the AGR-2 experiment. Because of time constraints, not all the plant noise was removed from the system and it would still show up periodically in the gross gamma spectra. The FPM team was able to work around the intermittent noise that was present in the spectra. Additionally, during the Cycle 153B outage, AGR-2 was moved to position I-24 to avoid being overheated.

- During Cycle 154B, the last operating TC failed, leaving the experiment with no control TC. The neon fraction was held constant for two-thirds of the cycle based on the neon fraction of the previous cycle, while for the last third of the cycle it was determined based on the projected fuel fission power assessed from the position of the outer shim cylinders.

\subsection{Thermocouple Behavior}

The TCs did not perform as well as in AGR-1 (see Collin (2015) for the AGR-1 TC characteristics). Fewer TCs were used in AGR-2 than in AGR-1, but the diameters were made larger to accommodate larger thermoelements, which should have provided better survivability. The sheath material was changed from Inconel 600 to niobium, and it is hypothesized that the sheaths became very brittle during irradiation and started fracturing in the later stages of irradiation due to both thermal expansion and contraction upon heat up and cool down, as well as when the test train was moved for PALM cycles, causing the TCs to fail. Of the 11 planned TCs, one failed during fabrication and the remaining ten failed during operation. The TC pairs in Capsules 3 and 5 failed at the same time, during cycles 152B and 149A, respectively. The TCs in Capsule 6 failed one after the other over almost the entire span of the irradiation between cycles $148 \mathrm{~A}$ and $154 \mathrm{~A}$.

Since no virtual junctions were observed in the TC data analysis, the TCs were thus assumed failed by open circuit failures resulting in loss of signal. The expected downward drift of TC temperature readings did occur with some exceptions. Inspection of the TCs during PIE may give more useful information about the performance of TCs during this irradiation. 


\section{CONCLUSIONS}

The AGR-2 fuel test was successful in irradiating the $\mathrm{UCO}$ and $\mathrm{UO}_{2}$ fuel compacts to their expected and specified burnup and fast fluence ranges with no definitive evidence of TRISO fuel particle failure:

- Capsule-average burnups ranged from 9.30\% FIMA in Capsule 6 to 12.17\% FIMA in Capsule 2 for UCO, and was $10.10 \%$ FIMA for $\mathrm{UO}_{2}$ in Capsule 3.

- Capsule-average fast fluences ranged from $2.39 \times 10^{25} \mathrm{n} / \mathrm{m}^{2}$ in Capsule 6 to $3.25 \times 10^{25} \mathrm{n} / \mathrm{m}^{2}$ in Capsule 2 for UCO, and was $3.35 \times 10^{25} \mathrm{n} / \mathrm{m}^{2}$ for $\mathrm{UO}_{2}$ in Capsule 3 .

- Time-average volume-average temperatures on a capsule basis at the end of irradiation ranged from $1074^{\circ} \mathrm{C}$ in Capsule 6 to $1252^{\circ} \mathrm{C}$ in Capsule 2 for UCO fuel, while the TAVA temperature for $\mathrm{UO}_{2}$ in Capsule 3 was $1032^{\circ} \mathrm{C}$.

The TCs did not perform as well as in AGR-1. Of the 11 planned TCs, one failed during fabrication and the remaining ten TCs failed during operation.

Fission product R/B ratios were quite low. In the UCO capsules, R/B values during the first three cycles were below $10^{-6}$ with the exception of the hotter Capsule 2 , in which the R/Bs reached $2 \times 10^{-6}$. In the $\mathrm{UO}_{2}$ capsule (e.g., Capsule 3), the $\mathrm{R} / \mathrm{B}$ values during the first three cycles were below $10^{-7}$. $\mathrm{R} / \mathrm{B}$ values for all following cycles are not reliable due to gas flow and cross-talk issues.

Some operational issues were encountered and resolved during irradiation. These include replacing some defective relief valves, adjusting gas flow to mitigate leakage and capsule cross-talk, and monitoring TC performance.

The results of this test will provide irradiation performance data for $\mathrm{UCO}$ and $\mathrm{UO}_{2}$ fuels (Demkowicz 2013). The PIE for this experiment focuses on: (1) Evaluating the performance of the UCO fuel in the high-temperature Capsule 2 and comparing to performance of identical fuel irradiated at lower temperature (e.g., Capsule 5); (2) Comparing the performance of UCO fuel fabricated at the industrial scale (AGR-2 fuel) with UCO fuel fabricated at the laboratory scale (AGR-1 fuel); (3) Comparing the performance of $\mathrm{UCO}$ and $\mathrm{UO}_{2}$ fuel; and (4) Exploring the causes of defective or failed particles, if any are found during PIE. Once PIE is completed, this test will provide additional AGR data that will form a link between fabrication processes, fuel product properties, and irradiation performance. 


\section{REFERENCES}

Albers, T.L., Letter from GrafTech to the Idaho National Laboratory, October 5, 2009.

Barnes, C.M., “AGR-1 Fuel Product Specification and Characterization Guidance,” EDF-4380, Rev. 8, April 25, 2006.

Barnes, C.M., “AGR-2 Fuel Specification,” SPC-923, Rev. 3, January 9, 2009.

BWXT, "Industrial Fuel Fabrication and Development Lot G73AA-10-69308," Data Certification Package, December 22, 2008.

BWXT, "Industrial Fuel Fabrication and Development Lot G73H-10-93085B," Data Certification Package, March 13, 2009.

BWXT, "Industrial Fuel Fabrication and Development Lot G73I-14-69307," Data Certification Package, July 30, 2008.

BWXT, "Industrial Fuel Fabrication and Development Lot G73J-14-93071A, G73J-14-93073A, G73J-14-93074A,” Data Certification Package, September 12, 2008.

Chang, G.S., "Preliminary Physics Analysis of the German $\mathrm{UO}_{2}$ and GA UCO Fuel Test Assembly in North and South Large B Hole Positions," Memorandum GSC-PBMR-04-2002, August 2, 2002.

Collin, B.P., “AGR-1 Irradiation Test Final As-Run Report,” INL/EXT-10-18097, Rev. 3, January 28, 2015.

Collin, B.P., “AGR-2 Irradiation Experiment Test Plan,” PLN-3798, Rev. 2, February, ?? 2018.

Croff, A.G., "ORIGEN2: A Versatile Computer Code for Calculating the Nuclide Compositions and Characteristics of Nuclear Materials, Nuclear Technology," Vol. 62, pp. 335-352, 1983.

Demkowicz, P.A., “AGR-2 Post-Irradiation Examination Plan,” PLN-4616, December 17, 2013.

Fluent Inc., "Fluent 6.3 User's Guide,” Lebanon, NH, September 2006.

General Atomics, "Conceptual Design Report - Steam Cycle Modular Helium Reactor (SC-MHR) Demonstation Plant," NGNP-RP00016, December 23, 2010.

Gontard, R. and H. Nabielek, "Performance Evaluation of Modern HTR TRISO Fuels," Forschungszentrum Jülich GmbH, HTA-IB-05/90, July 31, 1990.

Hartwell, J.K., D.M. Scates, and M.W. Drigert, "Design and Expected Performance of the AGR-1 Fission Product Monitoring System," INL/EXT-05-00073, September 2005.

Hartwell, J.K., J.B. Walter, D.M. Scates, and M.W. Drigert, "Determination of the AGR-1 capsule to FPMS Spectrometer Transport Volumes from Leadout Flow Test Data," INL/EXT-07-12494, April 2007.

Hawkes, G.L., “AGR-2 Daily As-run Thermal Analyses,” ECAR-2476, May 29, 2014.

Hull, L.C., "Nuclear Data Management and Analysis System Plan," PLN-2709 Rev. 5, January 18, 2016.

Hunn, J.D., "Data Compilation for AGR-2 B\&W UO 2 Coated Particle Batch G73H-10-93085B," ORNL/TM-2009/255, Rev. 1, July 2010.

Hunn, J.D., "Data Compilation for AGR-2 Baseline Coated Particle Batch G73J-14-93073A," ORNL/TM-2008/134, October 2008.

Hunn, J.D., F.C. Montgomery, and P.J. Pappano, "Data Compilation for AGR-2 UCO Variant Compact Lot LEU09-OP2-Z,” ORNL/TM-2010/017, Rev. 1, February 2010. 


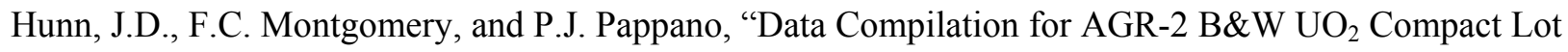
LEU11-OP2-Z,” ORNL/TM-2010/055, Rev. 1, March 2010.

J. D. Hunn, T. W. Savage, and C.M. Silva, "AGR-2 Fuel Compact Pre-Irradiation Characterization Summary Report,” ORNL/TM-2010/226, Rev. 1, November 2010.

INL, "Technical Program Plan for INL Advanced Reactor Technologies Technology Development Office/Advanced Gas Reactor Fuel Development and Qualification Program," PLN-3636, Rev. 6, June 28, 2017.

INL, "Idaho National Laboratory Advanced Reactor Technologies Technology Development Office Quality Assurance Program Plan,” PLN-2690, Rev. 16, August 23, 2017.

LANL, X-5 Monte Carlo Team, "MCNP-A General Monte Carlo N-Particle Transport Code, Version 5," Volume I, LA-UR-03-1987, Los Alamos National Laboratory, April 24, 2003 (Revised 6/30/2004) and Volume II, LA-CP-0245, Los Alamos National Laboratory, April 24, 2003 (Revised $6 / 30 / 2004)$

Maki, J.T., “AGR-2 Irradiation Test Specification,” SPC-1064, Rev. 1, June 6, 2010.

NCR-44791, "Control of Nonconforming Items, NCR Number 44791,” January 2, 2010.

Pham, B.T., and J.J. Einerson, “AGR-2 Final Data Qualification Report for U.S. Capsules - ATR Cycles 147A through 154B,” INL/EXT-14-32376, July 2014.

Scates, D.M., "Release-to-Birth Ratios for AGR-2 Operating Cycles 147A through 154B," ECAR-2420, March 3, 2014.

Snead, L.L. and T.D. Burchell, "Reduction in Thermal Conductivity Due to Neutron Irradiation," $22^{\text {nd }}$ Biennial Conference on Carbon, Extended Abstracts (1995) 774-775.

Sterbentz, J.W., "Fast Flux to DPA Multiplier,” E-mail communication to G.L. Hawkes, August 5, 2009.

Sterbentz, J.W., "JMOCUP As-Run Daily Depletion Calculation for the AGR-1 Experiment in ATR B-10 position," ECAR-958, Rev. 1, August 18, 2011.

Sterbentz, J.W., "JMOCUP As-Run Daily Depletion Calculation for the AGR-2 Experiment in ATR B-12 position,” ECAR-2066, Rev. 2, April 25, 2014.

Thompson, T.L., Letter from GrafTech to the Idaho National Laboratory, July 13, 2006. 
Appendix A

\section{As-Manufactured Fuel Data}




\section{Appendix A As-Manufactured Fuel Data}

Kernels for AGR-2 consist of LEU UCO and $\mathrm{LEU} \mathrm{UO}_{2}$ fuels. The U.S. kernels were fabricated by BWXT in accordance with the AGR-2 Fuel Product Specification (Barnes 2009). For each type of fuel, several production batches were combined into a single composite: Lot G73I-14 69307 for UCO kernels and Lot G73AA-10-69308 for $\mathrm{UO}_{2}$ kernels. Selected properties for these kernels are given in Table A-1.

The UCO and $\mathrm{UO}_{2}$ kernels were coated and characterized by BWXT (BWXT 09/2008 and 2009). In addition, ORNL characterized composite particles with anisotropy, sphericity, mass, and diameter measurements (Hunn 2008, 07/2010, 02/2010, 03/2010 \& 11/2010). Coating was performed in accordance with the AGR-2 Fuel Product Specification (Barnes 2009). Two particle composite lots comprise the fuel to be irradiated in AGR-2, one for each type of fuel: Lot G73J-14-93073A for UCO coated particles and Lot $\mathrm{G} 73 \mathrm{H}-10-93085 \mathrm{~B}$ for $\mathrm{UO}_{2}$ coated particles. A summary of selected properties, based on actual characterization data, for each of the four coated particle composites is listed in Table A-2.

After coating, AGR-2 fuel was formed into right cylindrical compacts. The compact matrix material is composed of a thermosetting carbonaceous material. Prior to compacting, the fuel particles were overcoated with approximately 215 - and 390- $\mu$ m-thick layers of the compact matrix material for UCO and $\mathrm{UO}_{2}$ fuels respectively. This overcoat is intended to prevent particle-to-particle contact and help achieve the desired packing fraction of fuel particles.

A summary of selected properties, based on actual characterization data (Hunn, 02/2010, 03/2010 \& 11/2010) and derived from these data, for each fuel type is listed in Table A-3. Data for compact mass, diameter, length, and matrix density are based on averages of those compacts sent to INL (Collin, 2017). 
Table A-1. Selected properties for kernel Lot G73I-14-69307 (UCO) and Lot G73AA-10-69308 (UO- $)_{2}$.

\begin{tabular}{|c|c|c|}
\hline UCO Kernel Property & $\begin{array}{c}\text { Specified Range for } \\
\text { Mean Value }\end{array}$ & $\begin{array}{c}\text { Actual Mean Value } \pm \\
\text { Population Standard } \\
\text { Deviation } \\
\end{array}$ \\
\hline Diameter $(\mu \mathrm{m})$ & $425 \pm 10$ & $426.7 \pm 8.8$ \\
\hline Density $\left(\mathrm{Mg} / \mathrm{m}^{3}\right)$ & $\geq 10.4$ & $10.966 \pm 0.033$ \\
\hline U-235 enrichment (wt \%) & $14.0 \pm 0.10$ & $14.029 \pm 0.026$ \\
\hline Carbon/uranium (atomic ratio) & $0.40 \pm 0.10$ & $0.392 \pm 0.002$ \\
\hline Oxygen/uranium (atomic ratio) & $1.50 \pm 0.20$ & $1.428 \pm 0.005$ \\
\hline [Carbon + oxygen]/uranium (atomic ratio) & $\leq 2.0$ & $1.818 \pm 0.005$ \\
\hline Total uranium (wt \%) & $\geq 88.5$ & $89.463 \pm 0.051$ \\
\hline Sulfur impurity $(\mathrm{ppm}-\mathrm{wt})$ & $\leq 1500$ & $365 \pm 12$ \\
\hline Phosphorus impurity $(\mathrm{ppm}-\mathrm{wt})$ & $\leq 1500$ & $\leq 50$ \\
\hline All other impurities & Various & $\begin{array}{l}\text { Below minimum detection } \\
\text { limits and within } \\
\text { specification }\end{array}$ \\
\hline $\mathrm{UO}_{2}$ Kernel Property & $\begin{array}{l}\text { Specified Range } \\
\text { for Mean Value }\end{array}$ & $\begin{array}{c}\text { Actual Mean Value } \pm \\
\text { Population Standard } \\
\text { Deviation } \\
\end{array}$ \\
\hline Diameter $(\mu \mathrm{m})$ & $500 \pm 10$ & $507.7 \pm 11.9$ \\
\hline Density $\left(\mathrm{Mg} / \mathrm{m}^{3}\right)$ & $\geq 10.4$ & $10.858 \pm 0.082$ \\
\hline U-235 enrichment (wt \%) & $9.6 \pm 0.10$ & $9.600 \pm 0.010$ \\
\hline Oxygen/uranium (atomic ratio) & $\geq 1.98$ and $\leq 2.1$ & $2.003 \pm 0.005$ \\
\hline Phosphorus, Sulfur impurities (ppm - wt) & $\leq 1500$ & $\leq 50$ \\
\hline All other impurities & Various & $\begin{array}{l}\text { Below minimum detection } \\
\text { limits and within } \\
\text { specification }\end{array}$ \\
\hline
\end{tabular}


Table A-2. Selected properties for AGR-2 coated particle composites.

\begin{tabular}{|c|c|c|c|}
\hline \multirow[b]{2}{*}{ Property } & \multirow{2}{*}{$\begin{array}{c}\text { Specified } \\
\text { Range for } \\
\text { Mean Value }\end{array}$} & \multicolumn{2}{|c|}{$\begin{array}{c}\text { Actual Mean Value } \pm \text { Population } \\
\text { Standard Deviation }\end{array}$} \\
\hline & & UCO & $\mathrm{UO}_{2}$ \\
\hline Buffer thickness $(\mu \mathrm{m})$ & $100 \pm 15$ & $98.9 \pm 8.4$ & $97.7 \pm 9.9$ \\
\hline IPyC thickness $(\mu \mathrm{m})$ & $40 \pm 4$ & $40.4 \pm 2.5$ & $41.9 \pm 3.2$ \\
\hline SiC thickness $(\mu \mathrm{m})$ & $35 \pm 3$ & $35.2 \pm 1.2$ & $37.5 \pm 1.2$ \\
\hline OPyC thickness $(\mu \mathrm{m})$ & $40 \pm 4$ & $43.4 \pm 2.9^{\text {(a) }}$ & $45.6 \pm 2.4^{\text {(a) }}$ \\
\hline Buffer density $\left(\mathrm{Mg} / \mathrm{m}^{3}\right)$ & $1.05 \pm 0.10$ & Not measured ${ }^{(b),(d)}$ & $0.99^{(\mathrm{c})}$ \\
\hline IPyC density $\left(\mathrm{Mg} / \mathrm{m}^{3}\right)$ & $1.90 \pm 0.05$ & $1.890 \pm 0.011$ & Not measured $^{(b),(d)}$ \\
\hline SiC density $\left(\mathrm{Mg} / \mathrm{m}^{3}\right)$ & $\geq 3.19$ & $3.197 \pm 0.004$ & $3.200 \pm 0.002$ \\
\hline OPyC density $\left(\mathrm{Mg} / \mathrm{m}^{3}\right)$ & $1.90 \pm 0.05$ & $1.907 \pm 0.007$ & $1.884 \pm 0.004$ \\
\hline $\begin{array}{l}\text { IPyC diattenuation } \\
\text { Optical anisotropy factor (OPTAF) }{ }^{(\mathrm{e})}\end{array}$ & $\begin{array}{l}\leq 0.0150 \\
\leq 1.030\end{array}$ & $\begin{array}{l}0.0116 \pm 0.0004 \\
1.0236 \pm 0.0008\end{array}$ & $\begin{array}{l}0.0111 \pm 0.0009 \\
1.0225 \pm 0.0019\end{array}$ \\
\hline $\begin{array}{l}\text { OPyC diattenuation } \\
\text { Optical anisotropy factor (OPTAF) }\end{array}$ & $\begin{array}{l}\leq 0.0117 \\
\leq 1.024\end{array}$ & $\begin{array}{l}0.0088 \pm 0.0004 \\
1.0177 \pm 0.0008\end{array}$ & $\begin{array}{l}0.0073 \pm 0.0004 \\
1.0147 \pm 0.0008\end{array}$ \\
\hline IPyC OPTAF post compact anneal & Not specified & $1.0315 \pm 0.0033$ & $1.0319 \pm 0.0025$ \\
\hline OPyC OPTAF post compact anneal & Not specified & $1.0290 \pm 0.0013$ & $1.0246 \pm 0.0011$ \\
\hline SiC sphericity (aspect ratio) & $\begin{array}{l}\text { Mean not } \\
\text { specified }^{(f)}\end{array}$ & $1.037 \pm 0.011$ & $1.034 \pm 0.010$ \\
\hline OPyC sphericity (aspect ratio) & Not specified & 1.052 & 1.052 \\
\hline Particle diameter $^{(\mathrm{g})}(\mu \mathrm{m})$ & $\begin{array}{l}\text { Mean not } \\
\text { specified }\end{array}$ & $873.2 \pm 23$ & $953.0 \pm 28$ \\
\hline Particle mass (mg) & $\begin{array}{l}\text { Mean not } \\
\text { specified }\end{array}$ & $1.032 \pm 0.003$ & $1.462 \pm 0.005$ \\
\hline
\end{tabular}

a. 95\% upper confidence thickness exceeds specifications. Justification of acceptance: OPyC thickness does not affect the compacting process or the fuel performance during irradiation (BWXT 09/2008 and 2009).

b. BWXT's hot sampling system does not allow both buffer and IPyC density measurements (BWXT 2009).

c. Single determination, no statistical confidence available (BWXT 2009).

d. Similar samples showed measurement results within specifications (BWXT 09/2008 and 2009).

e. The optical anisotropy factor is obtained from the diattenuation $\mathrm{N}$ as: OPTAF $=\frac{1+\mathrm{N}}{1-\mathrm{N}}$

f. Critical region is specified such that $\leq 1 \%$ of the particles shall have an aspect ratio $\geq 1.14$ for $\mathrm{UCO}$ fuel and $\geq 1.10$ for $\mathrm{UO}_{2}$ fuel.

g. Based on mean average particle measurements, not sums of mean layer thicknesses. 
Table A-3. Selected properties for AGR-2 compacts.

\begin{tabular}{|c|c|c|c|}
\hline \multirow[b]{2}{*}{ Property } & \multirow{2}{*}{$\begin{array}{l}\text { Specified Range } \\
\text { for Mean Value }\end{array}$} & \multicolumn{2}{|c|}{$\begin{array}{c}\text { Actual Mean Value } \pm \text { Population } \\
\text { Standard Deviation } \\
\end{array}$} \\
\hline & & UCO & $\mathrm{UO}_{2}$ \\
\hline Compact mass $^{(\mathrm{a})}(\mathrm{g})$ & Not specified & $6.293 \pm 0.011$ & $6.103 \pm 0.014$ \\
\hline $\begin{array}{l}\text { Mean uranium loading } \\
\text { (g U/compact) }\end{array}$ & $\begin{array}{l}1.265 \pm 0.07 \\
(\mathrm{UCO}) \\
1.00 \pm 0.05\left(\mathrm{UO}_{2}\right)\end{array}$ & $1.257 \pm 0.003$ & $0.993 \pm 0.006$ \\
\hline Diameter $^{(\mathrm{a}, \mathrm{b})}(\mathrm{mm})$ & $12.22-12.46$ & $12.286 \pm 0.005$ & $12.269 \pm 0.007$ \\
\hline Length $^{(\mathrm{a}, \mathrm{b})}(\mathrm{mm})$ & $25.02-25.40$ & $25.141 \pm 0.017$ & $25.134 \pm 0.018$ \\
\hline Average number of particles per compact ${ }^{(\mathrm{c})}$ & Not specified & 3176 & 1543 \\
\hline Particle volume packing fraction $(\%)$ & Not specified & $36.81 \pm 0.05$ & $23.46 \pm 0.04$ \\
\hline Effective overall compact density ${ }^{(\mathrm{c})}\left(\mathrm{Mg} / \mathrm{m}^{3}\right)$ & Not specified & 2.11 & 2.05 \\
\hline Compact matrix density ${ }^{(\mathrm{a})}\left(\mathrm{Mg} / \mathrm{m}^{3}\right)$ & $\geq 1.45$ & $1.589 \pm 0.005$ & $1.677 \pm 0.006$ \\
\hline Compact weight $\% \mathrm{U}^{(\mathrm{c})}$ & Not specified & 19.97 & 16.27 \\
\hline Compact weight $\% \mathrm{O}^{(\mathrm{c})}$ & Not specified & 1.92 & 2.19 \\
\hline Compact weight $\% \mathrm{Si}^{(\mathrm{c})}$ & Not specified & 6.85 & 4.54 \\
\hline Compact weight $\% \mathrm{C}^{(\mathrm{c})}$ & Not specified & 71.26 & 77.00 \\
\hline Iron content ( $\mu \mathrm{g}$ Fe outside of $\mathrm{SiC} /$ compact) & $\leq 25$ & 4.04 & 2.75 \\
\hline Chromium content ( $\mu \mathrm{g} \mathrm{Cr}$ outside of $\mathrm{SiC} /$ compact) & $\leq 50$ & 0.61 & 0.48 \\
\hline Manganese content ( $\mu \mathrm{g}$ Mn outside of SiC/compact) & $\leq 50$ & 0.136 & 0.133 \\
\hline Cobalt content ( $\mu \mathrm{g}$ Co outside of $\mathrm{SiC} /$ compact) & $\leq 50$ & 1.115 & 0.113 \\
\hline Nickel content ( $\mu \mathrm{g}$ Ni outside of SiC/compact) & $\leq 50$ & 0.96 & 0.59 \\
\hline Calcium content ( $\mu \mathrm{g}$ Ca outside of SiC/compact) & $\leq 50$ & 39.34 & 35.16 \\
\hline Aluminum content ( $\mu \mathrm{g} \mathrm{Al}$ outside of $\mathrm{SiC} /$ compact) & $\leq 50$ & 29.60 & 42.69 \\
\hline Titanium content ( $\mu \mathrm{g}$ Ti outside of SiC/compact) & Note $^{(d)}$ & 2.81 & 3.31 \\
\hline Vanadium content ( $\mu \mathrm{g} \mathrm{V}$ outside of $\mathrm{SiC} /$ compact) & Note $^{(d)}$ & 17.09 & 15.41 \\
\hline $\begin{array}{l}\mathrm{U} \text { contamination fraction } \\
{ }^{(\mathrm{e})} \\
(\mathrm{g} \text { exposed } \mathrm{U} / \mathrm{g} \mathrm{U} \text { in compact) }\end{array}$ & $\leq 2.0 \times 10^{-5}$ & $\leq 2.5 \times 10^{-5(\mathrm{f})}$ & $\leq 3.2 \times 10^{-5(\mathrm{f})}$ \\
\hline $\begin{array}{l}\text { U contamination fraction w/o exposed kernels } \\
\text { (g leached } \mathrm{U} / \mathrm{g} \mathrm{U} \text { in compact) }\end{array}$ & Not specified & $3.94 \times 10^{-6}$ & $9.66 \times 10^{-7}$ \\
\hline Defective $\mathrm{SiC}$ coating fraction ${ }^{(\mathrm{e})}$ & $\leq 1.0 \times 10^{-4}$ & $\leq 1.2 \times 10^{-5}$ & $\leq 2.5 \times 10^{-5}$ \\
\hline Defective IPyC coating fraction ${ }^{(\mathrm{e})}$ & $\leq 1.0 \times 10^{-4}$ & $\leq 4.8 \times 10^{-5}$ & $\leq 7.7 \times 10^{-5}$ \\
\hline Defective OPyC coating fraction ${ }^{(\mathrm{e})}$ & $\leq 1.0 \times 10^{-2}$ & $\leq 9.5 \times 10^{-4}$ & $\leq 2.0 \times 10^{-3}$ \\
\hline
\end{tabular}

\footnotetext{
a. Based on averages of compacts sent to INL.

b. Allowable range corresponding to upper and lower critical limits specified with no compacts exceeding the limits, which require $100 \%$ inspection of all compacts.

c. Approximate calculated value derived from other characterized properties.

d. Mean value specification of $\leq 240 \mu \mathrm{g} \mathrm{Ti}+\mathrm{V}$ outside of $\mathrm{SiC}$ per compact.

e. $95 \%$ confidence defect fraction.

f. Values exceed specifications: the non-conformances are documented in NCR-44791 with a disposition of use as is.
} 
This page intentionally left blank. 
Appendix B

\section{Graphite Holder Data}




\section{Appendix B Graphite Holder Data}

Excerpt from letter from GrafTech International Ltd. providing properties for graphite used in holders.

\section{5\% Boron (Thompson 2006)}

\section{GRAFTech}

UCAR CARBON COMPANY INC., a GrafTech International Ltd. company

Tracy L. Thompson, $\mathrm{Ph}$. D. Staff Scientist
12900 Snow Road $\bullet$ Parma, Ohio 44130

(216) $676-2307$ Facsimile (216) 676-2276 tracy.thompson@graftech.com

July 13, 2006

To Whom it May Concern:

Please find the attached chemical and physical properties of the materials shipped per PO\#00050342.

Physical Properties of Boronated Graphite*:

\begin{tabular}{|c|c|c|c|c|c|c|c|c|c|}
\hline$\overline{F O \#}$ & Density & $\begin{array}{c}\text { WG } \\
\text { Flexural } \\
\text { Strength }\end{array}$ & \begin{tabular}{c|} 
AG \\
Flexural \\
Strength \\
\end{tabular} & \begin{tabular}{|c|} 
WG \\
Youngs \\
Modulus \\
\end{tabular} & $\begin{array}{c}\text { WG } \\
\text { Specific } \\
\text { Resistance }\end{array}$ & $\begin{array}{c}\text { WG } \\
\text { CTE (1" } \\
\text { cube) } \\
\end{array}$ & $\begin{array}{c}\text { AG CTE } \\
(1 " 1 \\
\text { cube }) \\
\end{array}$ & $\begin{array}{l}\text { WG Thermal } \\
\text { Conductivity }\end{array}$ & $\begin{array}{l}\text { AG Thermal } \\
\text { Conductivity }\end{array}$ \\
\hline & g/cc & psi & psi $_{x} 10$ & 6 Psi & $\mathrm{m}$ ohm m & $\mathrm{ppm} / \mathrm{K}$ & $\mathrm{ppm} / \mathrm{K}$ & $\mathrm{w} / \mathrm{mK}$ & $w / m K$ \\
\hline $\begin{array}{c}\mathrm{P}-61-6.2 \\
-2 \\
(5.5 \% \\
\text { boron) } \\
\text { (4 cores) }\end{array}$ & 1.7 & 4470 & 4935 & 2.42 & 8.04 & 1.22 & 2.01 & 81.8 & 72.7 \\
\hline $\begin{array}{c}\text { - } 61-7.9 \\
-1(7.0 \% \\
\text { boron) } \\
\text { (4 cores) }\end{array}$ & 1.71 & 2215 & 2235 & 2.62 & 9.41 & 0.555 & 0.536 & 67.2 & 65 \\
\hline
\end{tabular}

*All testing reported in this table was carried out a room temperature.

Physical Properties at Elevated Temperature $\left(700-1300^{\circ} \mathrm{C}\right)$ :

\begin{tabular}{|c|c|c|}
\hline \multirow[b]{2}{*}{$\begin{array}{l}\text { Unirradiated Thermal } \\
\text { Conductivity (wg/ag) }\end{array}$} & \multicolumn{2}{|c|}{\begin{tabular}{|l|l} 
Core ID\# & Core ID\# \\
LP61-6.2-2 (5.5\% boron) LP61-7.9-1 (7\% boron) \\
\end{tabular}} \\
\hline & See Char & Below \\
\hline $\begin{array}{l}\text { Average Coefficient of Thermal } \\
\text { Expansion (calculated) } \mathrm{x} \text { ppm } /{ }^{\circ} \mathrm{C}\end{array}$ & $\begin{array}{l}\text { WG: } 2.26-2.70 \\
\text { AG: } 3.05-3.49\end{array}$ & $\begin{array}{l}\text { WG: } 1.60-2.03 \\
\text { AG: } 1.58-2.02\end{array}$ \\
\hline $\begin{array}{c}\text { Average Specific Heat }(700- \\
1300 \mathrm{C})(\mathrm{J} / \mathrm{kg}-\mathrm{K})- \\
\end{array}$ & $\begin{array}{l}1807 @ 700^{\circ} \mathrm{C} \\
2041 @ 1300^{\circ} \mathrm{C}\end{array}$ & $\begin{array}{l}1812 @ 700^{\circ} \mathrm{C} \\
2048 @ 1300^{\circ} \mathrm{C}\end{array}$ \\
\hline
\end{tabular}


- Unirradiated Thermal Conductivity (700-1300C)

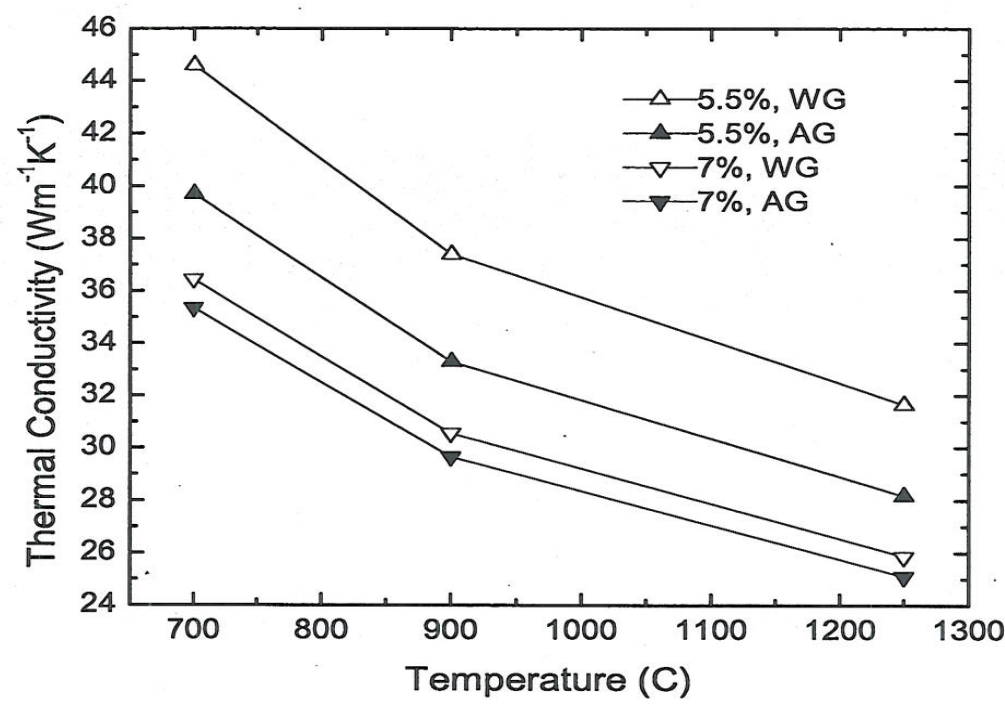

Elemental Analysis of Boronated Graphite ${ }^{\text {tw: }}$

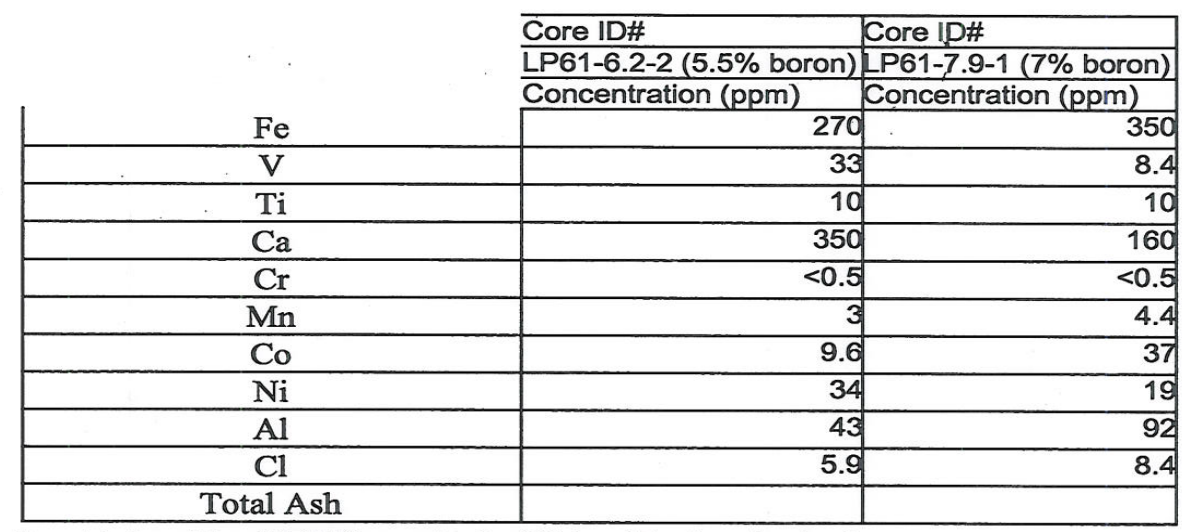

** Results obtained by GDMS analysis (Shiva Technologies). 
Tracy L. Albers, $\mathrm{Ph}$. D.

(216) 676-2307

Resoarch and Dewelopment Scientist

Nuclear Graphite Specialist

October 5, 2009

Dear Mr. Doug Stacey:

Please find the attached chemical and physical properties of the materials shipped under contract \#88582-2120. These samples have been sampled from 1 end for chemical determination of Boron Carbide and Boron. The remaining samples are included in this shipment, as specified in the order instructions.

The physical properties listed here have been reproduced from the original order processed under Purchase Order \# 00050342.

Physical Properties of Boronated Graphite*-Post Purification:

\begin{tabular}{|c|c|c|c|c|c|c|c|c|}
\hline FO\# & Density & $\begin{array}{c}\text { WG } \\
\text { Flexural } \\
\text { Strength }\end{array}$ & $\begin{array}{l}\text { WG } \\
\text { Youngs } \\
\text { Modulus }\end{array}$ & $\begin{array}{c}\text { WG } \\
\text { Specific } \\
\text { Resistance }\end{array}$ & $\begin{array}{l}\text { WG } \\
\text { CTE } \\
(1 " \\
\text { cube) }\end{array}$ & $\begin{array}{l}\text { AG } \\
\text { CTE } \\
(1 " \\
\text { cube) }\end{array}$ & $\begin{array}{c}\text { WG Thermal } \\
\text { Conductivity } \\
\text { (200C) }\end{array}$ & $\begin{array}{c}\text { AG Thermal } \\
\text { Conductivity } \\
(200 C)\end{array}$ \\
\hline & $\mathrm{g} / \mathrm{cC}$ & psi & $\times 10^{6} \mathrm{Psi}$ & mohm m & $\mathrm{ppm} / \mathrm{K}$ & $\mathrm{ppm} / \mathrm{K}$ & w/mK & w/mK \\
\hline \begin{tabular}{|c|} 
LP-61- \\
$6.2-1$ \\
$(4$ \\
cores) \\
\end{tabular} & 1.72 & $\begin{array}{c}3168 \\
(21.84 \mathrm{Mpa})\end{array}$ & $\begin{array}{c}2.10 \\
(14.47 \mathrm{Gpa})\end{array}$ & 8.38 & 1.58 & 1.98 & 89.1 & 76.4 \\
\hline $\begin{array}{c}\text { LP-61- } \\
7.9-2 \\
(4 \\
\text { cores) } \\
\end{array}$ & 1.70 & $\begin{array}{c}2036 \\
(14.03 \mathrm{Mpa})\end{array}$ & $\begin{array}{c}2.53 \\
(17.44 \mathrm{Gpa})\end{array}$ & 9.21 & 1.03 & 1.01 & 73.1 & 71.1 \\
\hline
\end{tabular}

*All testing reported in this table was carried out a room temperature.

Physical Properties at Elevated Temperature $\left(700-1300^{\circ} \mathrm{C}\right)$ :

\begin{tabular}{|c|c|c|}
\multicolumn{1}{c|}{ Core ID\# } & Core ID\# \\
\cline { 2 - 3 } \multicolumn{1}{c|}{ LP61-6.2-1 } & LP61-7.9-2 \\
\cline { 2 - 3 } Unirradiated Thermal & \multicolumn{2}{c|}{ See below. } \\
Conductivity (wg/ag) & WG: $2.62-3.08$ & WG: $2.07-2.53$ \\
\hline Average Coefficient of Thermal & AG: $3.02-3.48$ & AG: $2.05-2.51$ \\
Expansion (calculated) $x$ ppm $/{ }^{\circ} \mathrm{C}$ & $1807 @ 700^{\circ} \mathrm{C}$ & $1812 @ 700^{\circ} \mathrm{C}$ \\
\hline Average Specific Heat $(700-$ & $1807 @ 1300{ }^{\circ} \mathrm{C}$ & $2048 @ 1300^{\circ} \mathrm{C}$ \\
\hline $1300 \mathrm{C})(\mathrm{J} / \mathrm{kg}-\mathrm{K})-$ & $2041 @ 130$ \\
\end{tabular}


- Unirradiated Thermal Conductivity (200-900C)

High Temperature Thermal Conductivity Sample LP61-6.2-1

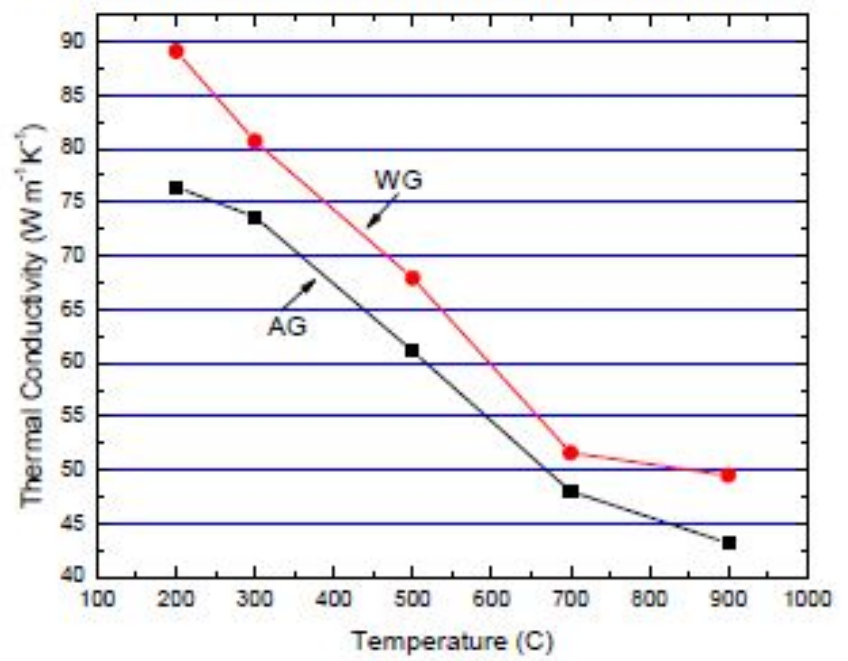

Elemental Analysis of Boronated Graphite-Post Purification*:

\begin{tabular}{|c|r|r|}
\cline { 2 - 3 } \multicolumn{1}{c|}{} & \multicolumn{1}{l|}{ Core ID\# } & Core ID\# \\
\cline { 2 - 3 } \multicolumn{1}{c|}{ LP61-6.2-1 } & LP61-7.9-2 \\
\cline { 2 - 3 } & \multicolumn{1}{c|}{ Concentration $(\mathrm{ppm})$} & Concentration $(\mathrm{ppm})$ \\
\cline { 2 - 3 } $\mathrm{Fe}$ & 0.57 & 0.55 \\
\cline { 2 - 3 } $\mathrm{V}$ & 2.5 & 3.8 \\
\cline { 2 - 3 } $\mathrm{Ti}$ & 1.8 & $<0.1$ \\
\hline $\mathrm{Ca}$ & $<0.5$ & $<0.5$ \\
\hline $\mathrm{Cr}$ & $<0.5$ & $<0.5$ \\
\hline $\mathrm{Mn}$ & $<0.05$ & $<0.05$ \\
\hline $\mathrm{Co}$ & $<0.05$ & $<0.05$ \\
\hline $\mathrm{Ni}$ & 1.5 & 9.5 \\
\hline $\mathrm{Al}$ & 0.12 & 2.2 \\
\hline $\mathrm{Cl}$ & 4.9 & 5.8 \\
\hline Total Ash & $8.0 \%$ & $13.6 \%$ \\
\hline
\end{tabular}

** Results obtained by GDMS analysis (Shiva Technologies). 
This page intentionally left blank. 
Appendix C

\section{Unfiltered Daily Average R/B Data}




\section{Appendix C Unfiltered Daily Average R/B Data}

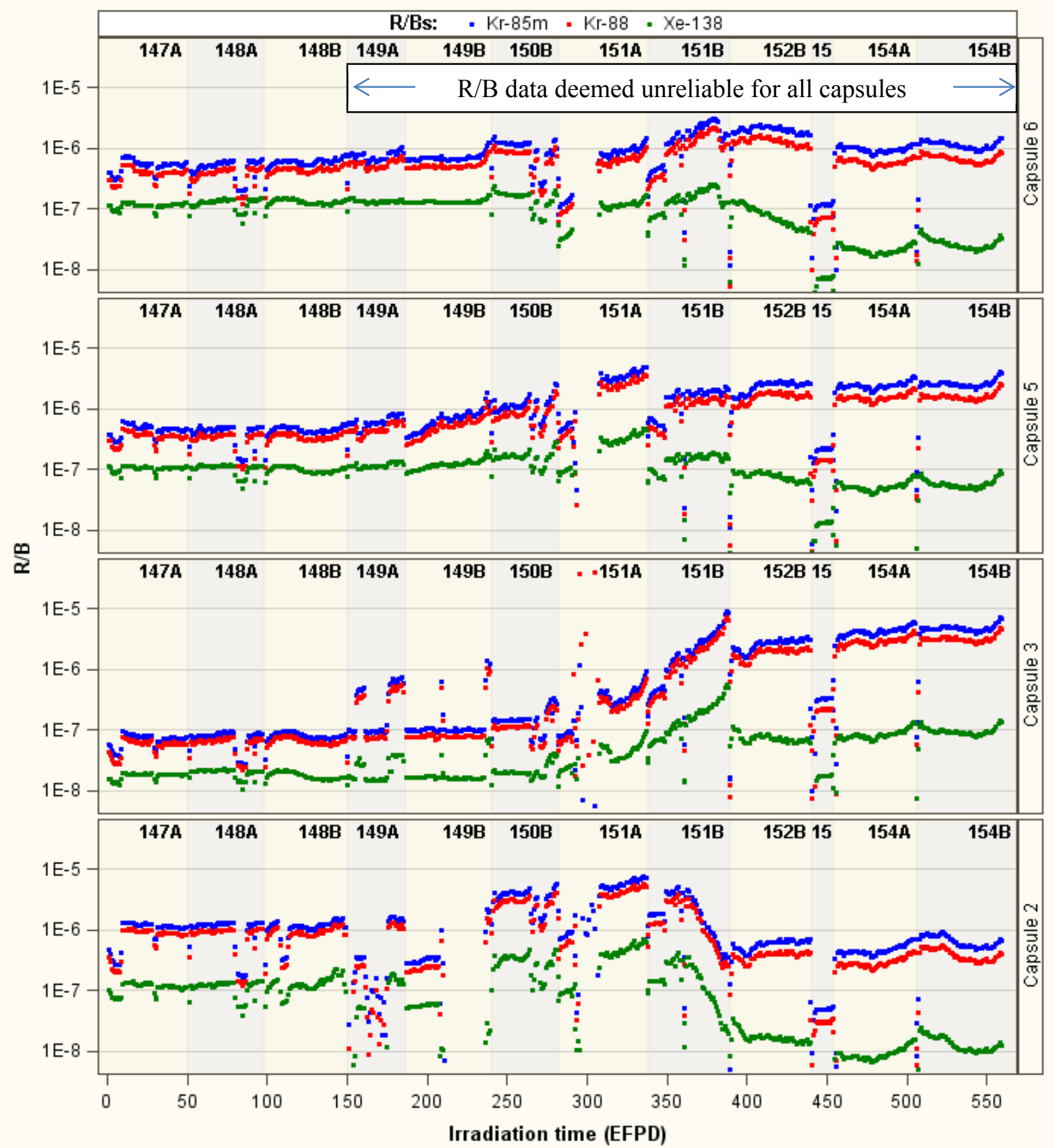

Nuclear Data Management and Analysis System (NDMAS)

Figure $\mathrm{C}-1$. Unfiltered $\mathrm{R} / \mathrm{B}$ ratios from daily birthrates for $\mathrm{Kr}-85 \mathrm{~m}, \mathrm{Kr}-88$, and $\mathrm{Xe}-138$ versus time in EFPD. Data from Cycle 149A and following cycles are not deemed reliable because of gas flow and cross-talk issues. 
Appendix D

Compact Burnup and Fast Fluence by Cycle 
Table D-1. Compact burnup and fast fluence for Capsules 6 and 5 after cycle 147A (AGR-2 cycle 1).

\begin{tabular}{|c|c|c|c|c|}
\hline Capsule & Stack & Compact & $\begin{array}{c}\text { Burnup } \\
\text { (\% FIMA) }\end{array}$ & $\begin{array}{c}\text { Fast Neutron Fluence } \\
\left(10^{25} \mathrm{n} / \mathrm{m}^{2} \mathrm{E}>0.18 \mathrm{MeV}\right)\end{array}$ \\
\hline \multirow{12}{*}{6} & \multirow{4}{*}{1} & 4 & 0.76 & 0.21 \\
\hline & & 3 & 0.72 & 0.23 \\
\hline & & 2 & 0.80 & 0.24 \\
\hline & & 1 & 0.95 & 0.26 \\
\hline & \multirow{4}{*}{2} & 4 & 0.67 & 0.20 \\
\hline & & 3 & 0.63 & 0.22 \\
\hline & & 2 & 0.71 & 0.24 \\
\hline & & 1 & 0.87 & 0.25 \\
\hline & \multirow{4}{*}{3} & 4 & 0.45 & 0.18 \\
\hline & & 3 & 0.37 & 0.19 \\
\hline & & 2 & 0.40 & 0.21 \\
\hline & & 1 & 0.60 & 0.22 \\
\hline \multicolumn{3}{|c|}{ Capsule 6 Average } & 0.66 & 0.22 \\
\hline \multirow{12}{*}{5} & \multirow{4}{*}{1} & 4 & 1.04 & 0.30 \\
\hline & & 3 & 0.92 & 0.31 \\
\hline & & 2 & 0.97 & 0.32 \\
\hline & & 1 & 1.17 & 0.32 \\
\hline & \multirow{4}{*}{2} & 4 & 0.91 & 0.29 \\
\hline & & 3 & 0.81 & 0.30 \\
\hline & & 2 & 0.85 & 0.31 \\
\hline & & 1 & 1.07 & 0.32 \\
\hline & \multirow{4}{*}{3} & 4 & 0.60 & 0.26 \\
\hline & & 3 & 0.50 & 0.26 \\
\hline & & 2 & 0.51 & 0.27 \\
\hline & & 1 & 0.67 & 0.28 \\
\hline \multicolumn{3}{|c|}{ Capsule 5 Average } & 0.83 & 0.29 \\
\hline
\end{tabular}


Table D-2. Compact burnup and fast fluence for Capsules 3 and 2 after cycle 147A (AGR-2 cycle 1).

\begin{tabular}{|c|c|c|c|c|}
\hline Capsule & Stack & Compact & $\begin{array}{c}\text { Burnup } \\
(\% \text { FIMA) }\end{array}$ & $\begin{array}{c}\text { Fast Neutron Fluence } \\
\left(10^{25} \mathrm{n} / \mathrm{m}^{2} \mathrm{E}>0.18 \mathrm{MeV}\right)\end{array}$ \\
\hline \multirow{12}{*}{3} & \multirow{4}{*}{1} & 4 & 0.96 & 0.33 \\
\hline & & 3 & 0.81 & 0.33 \\
\hline & & 2 & 0.81 & 0.33 \\
\hline & & 1 & 0.95 & 0.32 \\
\hline & \multirow{4}{*}{2} & 4 & 0.87 & 0.33 \\
\hline & & 3 & 0.74 & 0.33 \\
\hline & & 2 & 0.71 & 0.32 \\
\hline & & 1 & 0.85 & 0.32 \\
\hline & \multirow{4}{*}{3} & 4 & 0.57 & 0.29 \\
\hline & & 3 & 0.47 & 0.29 \\
\hline & & 2 & 0.46 & 0.28 \\
\hline & & 1 & 0.56 & 0.28 \\
\hline \multicolumn{3}{|c|}{ Capsule 3 Average } & 0.73 & 0.31 \\
\hline \multirow{12}{*}{2} & \multirow{4}{*}{1} & 4 & 1.18 & 0.32 \\
\hline & & 3 & 0.99 & 0.31 \\
\hline & & 2 & 0.94 & 0.31 \\
\hline & & 1 & 1.08 & 0.30 \\
\hline & \multirow{4}{*}{2} & 4 & 1.07 & 0.32 \\
\hline & & 3 & 0.88 & 0.31 \\
\hline & & 2 & 0.84 & 0.30 \\
\hline & & 1 & 0.97 & 0.30 \\
\hline & \multirow{4}{*}{3} & 4 & 0.70 & 0.29 \\
\hline & & 3 & 0.52 & 0.29 \\
\hline & & 2 & 0.51 & 0.28 \\
\hline & & 1 & 0.63 & 0.28 \\
\hline \multicolumn{3}{|c|}{ Capsule 2 Average } & 0.86 & 0.30 \\
\hline
\end{tabular}


Table D-3. Compact burnup and fast fluence for Capsules 6 and 5 after cycle 148A (AGR-2 cycle 2).

\begin{tabular}{|c|c|c|c|c|}
\hline Capsule & Stack & Compact & $\begin{array}{l}\text { Burnup } \\
\text { (\% FIMA) }\end{array}$ & $\begin{array}{c}\text { Fast Neutron Fluence } \\
\left(10^{25} \mathrm{n} / \mathrm{m}^{2} \mathrm{E}>0.18 \mathrm{MeV}\right)\end{array}$ \\
\hline \multirow{12}{*}{6} & \multirow{4}{*}{1} & 4 & 1.38 & 0.39 \\
\hline & & 3 & 1.32 & 0.42 \\
\hline & & 2 & 1.47 & 0.45 \\
\hline & & 1 & 1.77 & 0.48 \\
\hline & \multirow{4}{*}{2} & 4 & 1.30 & 0.38 \\
\hline & & 3 & 1.23 & 0.42 \\
\hline & & 2 & 1.39 & 0.45 \\
\hline & & 1 & 1.69 & 0.48 \\
\hline & \multirow{4}{*}{3} & 4 & 0.87 & 0.33 \\
\hline & & 3 & 0.74 & 0.36 \\
\hline & & 2 & 0.80 & 0.39 \\
\hline & & 1 & 1.11 & 0.42 \\
\hline \multicolumn{3}{|c|}{ Capsule 6 Average } & 1.26 & 0.41 \\
\hline \multirow{12}{*}{5} & \multirow{4}{*}{1} & 4 & 1.92 & 0.55 \\
\hline & & 3 & 1.73 & 0.57 \\
\hline & & 2 & 1.81 & 0.59 \\
\hline & & 1 & 2.19 & 0.60 \\
\hline & \multirow{4}{*}{2} & 4 & 1.80 & 0.55 \\
\hline & & 3 & 1.63 & 0.57 \\
\hline & & 2 & 1.70 & 0.58 \\
\hline & & 1 & 2.10 & 0.60 \\
\hline & \multirow{4}{*}{3} & 4 & 1.20 & 0.48 \\
\hline & & 3 & 1.01 & 0.50 \\
\hline & & 2 & 1.04 & 0.51 \\
\hline & & 1 & 1.33 & 0.53 \\
\hline \multicolumn{3}{|c|}{ Capsule 5 Average } & 1.62 & 0.55 \\
\hline
\end{tabular}


Table D-4. Compact burnup and fast fluence for Capsules 3 and 2 after cycle 148A (AGR-2 cycle 2).

\begin{tabular}{|c|c|c|c|c|}
\hline Capsule & Stack & Compact & $\begin{array}{c}\text { Burnup } \\
(\% \text { FIMA) }\end{array}$ & $\begin{array}{c}\text { Fast Neutron Fluence } \\
\left(10^{25} \mathrm{n} / \mathrm{m}^{2} \mathrm{E}>0.18 \mathrm{MeV}\right)\end{array}$ \\
\hline \multirow{12}{*}{3} & \multirow{4}{*}{1} & 4 & 1.82 & 0.62 \\
\hline & & 3 & 1.58 & 0.62 \\
\hline & & 2 & 1.57 & 0.61 \\
\hline & & 1 & 1.79 & 0.61 \\
\hline & \multirow{4}{*}{2} & 4 & 1.77 & 0.62 \\
\hline & & 3 & 1.52 & 0.62 \\
\hline & & 2 & 1.49 & 0.61 \\
\hline & & 1 & 1.72 & 0.61 \\
\hline & \multirow{4}{*}{3} & 4 & 1.19 & 0.54 \\
\hline & & 3 & 1.01 & 0.54 \\
\hline & & 2 & 0.99 & 0.54 \\
\hline & & 1 & 1.16 & 0.53 \\
\hline \multicolumn{3}{|c|}{ Capsule 3 Average } & 1.47 & 0.59 \\
\hline \multirow{12}{*}{2} & \multirow{4}{*}{1} & 4 & 2.24 & 0.61 \\
\hline & & 3 & 1.87 & 0.59 \\
\hline & & 2 & 1.80 & 0.58 \\
\hline & & 1 & 2.02 & 0.56 \\
\hline & \multirow{4}{*}{2} & 4 & 2.16 & 0.60 \\
\hline & & 3 & 1.78 & 0.59 \\
\hline & & 2 & 1.71 & 0.58 \\
\hline & & 1 & 1.94 & 0.56 \\
\hline & \multirow{4}{*}{3} & 4 & 1.41 & 0.54 \\
\hline & & 3 & 1.09 & 0.54 \\
\hline & & 2 & 1.06 & 0.54 \\
\hline & & 1 & 1.27 & 0.53 \\
\hline \multicolumn{3}{|c|}{ Capsule 2 Average } & 1.70 & 0.56 \\
\hline
\end{tabular}


Table D-5. Compact burnup and fast fluence for Capsules 6 and 5 after cycle 148B (AGR-2 cycle 3).

\begin{tabular}{|c|c|c|c|c|}
\hline Capsule & Stack & Compact & $\begin{array}{c}\text { Burnup } \\
\text { (\% FIMA) }\end{array}$ & $\begin{array}{l}\text { Fast Neutron Fluence } \\
\left(10^{25} \mathrm{n} / \mathrm{m}^{2} \mathrm{E}>0.18 \mathrm{MeV}\right)\end{array}$ \\
\hline \multirow{12}{*}{6} & \multirow{4}{*}{1} & 4 & 2.18 & 0.59 \\
\hline & & 3 & 2.10 & 0.64 \\
\hline & & 2 & 2.37 & 0.69 \\
\hline & & 1 & 2.81 & 0.73 \\
\hline & \multirow{4}{*}{2} & 4 & 2.15 & 0.58 \\
\hline & & 3 & 2.08 & 0.64 \\
\hline & & 2 & 2.35 & 0.69 \\
\hline & & 1 & 2.79 & 0.73 \\
\hline & \multirow{4}{*}{3} & 4 & 1.45 & 0.51 \\
\hline & & 3 & 1.26 & 0.55 \\
\hline & & 2 & 1.38 & 0.60 \\
\hline & & 1 & 1.87 & 0.64 \\
\hline \multicolumn{3}{|c|}{ Capsule 6 Average } & 2.07 & 0.63 \\
\hline \multirow{12}{*}{5} & \multirow{4}{*}{1} & 4 & 3.08 & 0.84 \\
\hline & & 3 & 2.83 & 0.87 \\
\hline & & 2 & 2.95 & 0.89 \\
\hline & & 1 & 3.53 & 0.91 \\
\hline & \multirow{4}{*}{2} & 4 & 3.05 & 0.83 \\
\hline & & 3 & 2.81 & 0.87 \\
\hline & & 2 & 2.94 & 0.89 \\
\hline & & 1 & 3.53 & 0.91 \\
\hline & \multirow{4}{*}{3} & 4 & 2.05 & 0.73 \\
\hline & & 3 & 1.78 & 0.76 \\
\hline & & 2 & 1.85 & 0.78 \\
\hline & & 1 & 2.31 & 0.80 \\
\hline \multicolumn{3}{|c|}{ Capsule 5 Average } & 2.73 & 0.84 \\
\hline
\end{tabular}


Table D-6. Compact burnup and fast fluence for Capsules 3 and 2 after cycle 148B (AGR-2 cycle 3).

\begin{tabular}{|c|c|c|c|c|}
\hline Capsule & Stack & Compact & $\begin{array}{l}\text { Burnup } \\
\text { (\% FIMA) }\end{array}$ & $\begin{array}{c}\text { Fast Neutron Fluence } \\
\left(10^{25} \mathrm{n} / \mathrm{m}^{2} \mathrm{E}>0.18 \mathrm{MeV}\right)\end{array}$ \\
\hline \multirow{12}{*}{3} & \multirow{4}{*}{1} & 4 & 3.01 & 0.94 \\
\hline & & 3 & 2.66 & 0.94 \\
\hline & & 2 & 2.64 & 0.93 \\
\hline & & 1 & 2.96 & 0.92 \\
\hline & \multirow{4}{*}{2} & 4 & 3.04 & 0.94 \\
\hline & & 3 & 2.70 & 0.94 \\
\hline & & 2 & 2.66 & 0.94 \\
\hline & & 1 & 2.97 & 0.93 \\
\hline & \multirow{4}{*}{3} & 4 & 2.12 & 0.83 \\
\hline & & 3 & 1.85 & 0.82 \\
\hline & & 2 & 1.83 & 0.82 \\
\hline & & 1 & 2.07 & 0.81 \\
\hline \multicolumn{3}{|c|}{ Capsule 3 Average } & 2.54 & 0.90 \\
\hline \multirow{12}{*}{2} & \multirow{4}{*}{1} & 4 & 3.66 & 0.92 \\
\hline & & 3 & 3.12 & 0.91 \\
\hline & & 2 & 3.00 & 0.88 \\
\hline & & 1 & 3.31 & 0.86 \\
\hline & \multirow{4}{*}{2} & 4 & 3.66 & 0.93 \\
\hline & & 3 & 3.11 & 0.91 \\
\hline & & 2 & 3.02 & 0.89 \\
\hline & & 1 & 3.33 & 0.87 \\
\hline & \multirow{4}{*}{3} & 4 & 2.48 & 0.83 \\
\hline & & 3 & 1.98 & 0.82 \\
\hline & & 2 & 1.91 & 0.82 \\
\hline & & 1 & 2.23 & 0.81 \\
\hline \multicolumn{3}{|c|}{ Capsule 2 Average } & 2.90 & 0.86 \\
\hline
\end{tabular}


Table D-7. Compact burnup and fast fluence for Capsules 6 and 5 after cycle 149A (AGR-2 cycle 4).

\begin{tabular}{|c|c|c|c|c|}
\hline Capsule & Stack & Compact & $\begin{array}{l}\text { Burnup } \\
\text { (\% FIMA) }\end{array}$ & $\begin{array}{c}\text { Fast Neutron Fluence } \\
\left(10^{25} \mathrm{n} / \mathrm{m}^{2} \mathrm{E}>0.18 \mathrm{MeV}\right)\end{array}$ \\
\hline \multirow{12}{*}{6} & \multirow{4}{*}{1} & 4 & 2.79 & 0.73 \\
\hline & & 3 & 2.73 & 0.80 \\
\hline & & 2 & 3.07 & 0.86 \\
\hline & & 1 & 3.58 & 0.91 \\
\hline & \multirow{4}{*}{2} & 4 & 2.76 & 0.73 \\
\hline & & 3 & 2.70 & 0.80 \\
\hline & & 2 & 3.06 & 0.86 \\
\hline & & 1 & 3.56 & 0.91 \\
\hline & \multirow{4}{*}{3} & 4 & 1.88 & 0.64 \\
\hline & & 3 & 1.67 & 0.69 \\
\hline & & 2 & 1.86 & 0.75 \\
\hline & & 1 & 2.46 & 0.80 \\
\hline \multicolumn{3}{|c|}{ Capsule 6 Average } & 2.68 & 0.79 \\
\hline \multirow{12}{*}{5} & \multirow{4}{*}{1} & 4 & 4.01 & 1.04 \\
\hline & & 3 & 3.72 & 1.09 \\
\hline & & 2 & 3.90 & 1.12 \\
\hline & & 1 & 4.57 & 1.14 \\
\hline & \multirow{4}{*}{2} & 4 & 3.96 & 1.05 \\
\hline & & 3 & 3.71 & 1.09 \\
\hline & & 2 & 3.89 & 1.12 \\
\hline & & 1 & 4.55 & 1.15 \\
\hline & \multirow{4}{*}{3} & 4 & 2.73 & 0.91 \\
\hline & & 3 & 2.42 & 0.95 \\
\hline & & 2 & 2.53 & 0.98 \\
\hline & & 1 & 3.10 & 1.01 \\
\hline \multicolumn{3}{|c|}{ Capsule 5 Average } & 3.59 & 1.05 \\
\hline
\end{tabular}


Table D-8. Compact burnup and fast fluence for Capsules 3 and 2 after cycle 149A (AGR-2 cycle 4).

\begin{tabular}{|c|c|c|c|c|}
\hline Capsule & Stack & Compact & $\begin{array}{l}\text { Burnup } \\
\text { (\% FIMA) }\end{array}$ & $\begin{array}{c}\text { Fast Neutron Fluence } \\
\left(10^{25} \mathrm{n} / \mathrm{m}^{2} \mathrm{E}>0.18 \mathrm{MeV}\right)\end{array}$ \\
\hline \multirow{12}{*}{3} & \multirow{4}{*}{1} & 4 & 3.92 & 1.17 \\
\hline & & 3 & 3.55 & 1.17 \\
\hline & & 2 & 3.52 & 1.17 \\
\hline & & 1 & 3.85 & 1.15 \\
\hline & \multirow{4}{*}{2} & 4 & 3.94 & 1.18 \\
\hline & & 3 & 3.59 & 1.18 \\
\hline & & 2 & 3.55 & 1.18 \\
\hline & & 1 & 3.87 & 1.16 \\
\hline & \multirow{4}{*}{3} & 4 & 2.85 & 1.04 \\
\hline & & 3 & 2.54 & 1.03 \\
\hline & & 2 & 2.51 & 1.03 \\
\hline & & 1 & 2.79 & 1.02 \\
\hline \multicolumn{3}{|c|}{ Capsule 3 Average } & 3.37 & 1.12 \\
\hline \multirow{12}{*}{2} & \multirow{4}{*}{1} & 4 & 4.73 & 1.16 \\
\hline & & 3 & 4.12 & 1.14 \\
\hline & & 2 & 3.98 & 1.11 \\
\hline & & 1 & 4.31 & 1.07 \\
\hline & \multirow{4}{*}{2} & 4 & 4.73 & 1.16 \\
\hline & & 3 & 4.11 & 1.15 \\
\hline & & 2 & 3.98 & 1.12 \\
\hline & & 1 & 4.33 & 1.09 \\
\hline & \multirow{4}{*}{3} & 4 & 3.35 & 1.04 \\
\hline & & 3 & 2.72 & 1.03 \\
\hline & & 2 & 2.62 & 1.03 \\
\hline & & 1 & 3.00 & 1.02 \\
\hline \multicolumn{3}{|c|}{ Capsule 2 Average } & 3.83 & 1.08 \\
\hline
\end{tabular}


Table D-9. Compact burnup and fast fluence for Capsules 6 and 5 after cycle 149B (AGR-2 cycle 5).

\begin{tabular}{|c|c|c|c|c|}
\hline Capsule & Stack & Compact & $\begin{array}{c}\text { Burnup } \\
\text { (\% FIMA) }\end{array}$ & $\begin{array}{c}\text { Fast Neutron Fluence } \\
\left(10^{25} \mathrm{n} / \mathrm{m}^{2} \mathrm{E}>0.18 \mathrm{MeV}\right)\end{array}$ \\
\hline \multirow{12}{*}{6} & \multirow{4}{*}{1} & 4 & 3.65 & 0.94 \\
\hline & & 3 & 3.65 & 1.03 \\
\hline & & 2 & 4.10 & 1.11 \\
\hline & & 1 & 4.67 & 1.17 \\
\hline & \multirow{4}{*}{2} & 4 & 3.63 & 0.94 \\
\hline & & 3 & 3.62 & 1.03 \\
\hline & & 2 & 4.10 & 1.11 \\
\hline & & 1 & 4.66 & 1.18 \\
\hline & \multirow{4}{*}{3} & 4 & 2.54 & 0.82 \\
\hline & & 3 & 2.32 & 0.90 \\
\hline & & 2 & 2.61 & 0.97 \\
\hline & & 1 & 3.34 & 1.03 \\
\hline \multicolumn{3}{|c|}{ Capsule 6 Average } & 3.57 & 1.02 \\
\hline \multirow{12}{*}{5} & \multirow{4}{*}{1} & 4 & 5.30 & 1.35 \\
\hline & & 3 & 5.02 & 1.41 \\
\hline & & 2 & 5.27 & 1.45 \\
\hline & & 1 & 5.99 & 1.48 \\
\hline & \multirow{4}{*}{2} & 4 & 5.26 & 1.35 \\
\hline & & 3 & 5.03 & 1.41 \\
\hline & & 2 & 5.28 & 1.45 \\
\hline & & 1 & 5.99 & 1.48 \\
\hline & \multirow{4}{*}{3} & 4 & 3.76 & 1.18 \\
\hline & & 3 & 3.44 & 1.23 \\
\hline & & 2 & 3.59 & 1.27 \\
\hline & & 1 & 4.29 & 1.30 \\
\hline \multicolumn{3}{|c|}{ Capsule 5 Average } & 4.85 & 1.36 \\
\hline
\end{tabular}


Table D-10. Compact burnup and fast fluence for Capsules 3 and 2 after cycle 149B (AGR-2 cycle 5).

\begin{tabular}{|c|c|c|c|c|}
\hline Capsule & Stack & Compact & $\begin{array}{l}\text { Burnup } \\
(\% \text { FIMA) }\end{array}$ & $\begin{array}{c}\text { Fast Neutron Fluence } \\
\left(10^{25} \mathrm{n} / \mathrm{m}^{2} \mathrm{E}>0.18 \mathrm{MeV}\right)\end{array}$ \\
\hline \multirow{12}{*}{3} & \multirow{4}{*}{1} & 4 & 5.13 & 1.51 \\
\hline & & 3 & 4.77 & 1.51 \\
\hline & & 2 & 4.73 & 1.50 \\
\hline & & 1 & 5.06 & 1.48 \\
\hline & \multirow{4}{*}{2} & 4 & 5.16 & 1.52 \\
\hline & & 3 & 4.83 & 1.53 \\
\hline & & 2 & 4.79 & 1.52 \\
\hline & & 1 & 5.10 & 1.50 \\
\hline & \multirow{4}{*}{3} & 4 & 3.87 & 1.34 \\
\hline & & 3 & 3.56 & 1.34 \\
\hline & & 2 & 3.53 & 1.33 \\
\hline & & 1 & 3.80 & 1.32 \\
\hline \multicolumn{3}{|c|}{ Capsule 3 Average } & 4.53 & 1.45 \\
\hline \multirow{12}{*}{2} & \multirow{4}{*}{1} & 4 & 6.21 & 1.49 \\
\hline & & 3 & 5.57 & 1.47 \\
\hline & & 2 & 5.40 & 1.44 \\
\hline & & 1 & 5.73 & 1.39 \\
\hline & \multirow{4}{*}{2} & 4 & 6.22 & 1.51 \\
\hline & & 3 & 5.57 & 1.49 \\
\hline & & 2 & 5.42 & 1.46 \\
\hline & & 1 & 5.77 & 1.41 \\
\hline & \multirow{4}{*}{3} & 4 & 4.63 & 1.34 \\
\hline & & 3 & 3.90 & 1.34 \\
\hline & & 2 & 3.75 & 1.33 \\
\hline & & 1 & 4.16 & 1.32 \\
\hline \multicolumn{3}{|c|}{ Capsule 2 Average } & 5.19 & 1.40 \\
\hline
\end{tabular}


Table D-11. Compact burnup and fast fluence for Capsules 6 and 5 after cycle 150B (AGR-2 cycle 6).

\begin{tabular}{|c|c|c|c|c|}
\hline Capsule & Stack & Compact & $\begin{array}{l}\text { Burnup } \\
\text { (\% FIMA) }\end{array}$ & $\begin{array}{c}\text { Fast Neutron Fluence } \\
\left(10^{25} \mathrm{n} / \mathrm{m}^{2} \mathrm{E}>0.18 \mathrm{MeV}\right)\end{array}$ \\
\hline \multirow{12}{*}{6} & \multirow{4}{*}{1} & 4 & 4.53 & 1.12 \\
\hline & & 3 & 4.57 & 1.23 \\
\hline & & 2 & 5.08 & 1.32 \\
\hline & & 1 & 5.73 & 1.40 \\
\hline & \multirow{4}{*}{2} & 4 & 4.50 & 1.12 \\
\hline & & 3 & 4.53 & 1.23 \\
\hline & & 2 & 5.06 & 1.33 \\
\hline & & 1 & 5.69 & 1.40 \\
\hline & \multirow{4}{*}{3} & 4 & 3.20 & 0.98 \\
\hline & & 3 & 3.02 & 1.07 \\
\hline & & 2 & 3.41 & 1.16 \\
\hline & & 1 & 4.21 & 1.23 \\
\hline \multicolumn{3}{|c|}{ Capsule 6 Average } & 4.46 & 1.22 \\
\hline \multirow{12}{*}{5} & \multirow{4}{*}{1} & 4 & 6.51 & 1.61 \\
\hline & & 3 & 6.28 & 1.68 \\
\hline & & 2 & 6.56 & 1.73 \\
\hline & & 1 & 7.29 & 1.76 \\
\hline & \multirow{4}{*}{2} & 4 & 6.46 & 1.61 \\
\hline & & 3 & 6.27 & 1.69 \\
\hline & & 2 & 6.55 & 1.74 \\
\hline & & 1 & 7.28 & 1.77 \\
\hline & \multirow{4}{*}{3} & 4 & 4.80 & 1.41 \\
\hline & & 3 & 4.51 & 1.47 \\
\hline & & 2 & 4.71 & 1.52 \\
\hline & & 1 & 5.44 & 1.55 \\
\hline \multicolumn{3}{|c|}{ Capsule 5 Average } & 6.06 & 1.63 \\
\hline
\end{tabular}


Table D-12. Compact burnup and fast fluence for Capsules 3 and 2 after cycle 150B (AGR-2 cycle 6).

\begin{tabular}{|c|c|c|c|c|}
\hline Capsule & Stack & Compact & $\begin{array}{l}\text { Burnup } \\
\text { (\% FIMA) }\end{array}$ & $\begin{array}{c}\text { Fast Neutron Fluence } \\
\left(10^{25} \mathrm{n} / \mathrm{m}^{2} \mathrm{E}>0.18 \mathrm{MeV}\right)\end{array}$ \\
\hline \multirow{12}{*}{3} & \multirow{4}{*}{1} & 4 & 6.17 & 1.79 \\
\hline & & 3 & 5.85 & 1.80 \\
\hline & & 2 & 5.81 & 1.79 \\
\hline & & 1 & 6.11 & 1.76 \\
\hline & \multirow{4}{*}{2} & 4 & 6.19 & 1.81 \\
\hline & & 3 & 5.89 & 1.82 \\
\hline & & 2 & 5.85 & 1.81 \\
\hline & & 1 & 6.13 & 1.78 \\
\hline & \multirow{4}{*}{3} & 4 & 4.85 & 1.59 \\
\hline & & 3 & 4.55 & 1.59 \\
\hline & & 2 & 4.52 & 1.58 \\
\hline & & 1 & 4.78 & 1.57 \\
\hline \multicolumn{3}{|c|}{ Capsule 3 Average } & 5.56 & 1.72 \\
\hline \multirow{12}{*}{2} & \multirow{4}{*}{1} & 4 & 7.55 & 1.78 \\
\hline & & 3 & 6.91 & 1.76 \\
\hline & & 2 & 6.72 & 1.72 \\
\hline & & 1 & 7.01 & 1.66 \\
\hline & \multirow{4}{*}{2} & 4 & 7.54 & 1.80 \\
\hline & & 3 & 6.89 & 1.78 \\
\hline & & 2 & 6.73 & 1.74 \\
\hline & & 1 & 7.03 & 1.68 \\
\hline & \multirow{4}{*}{3} & 4 & 5.84 & 1.59 \\
\hline & & 3 & 5.10 & 1.59 \\
\hline & & 2 & 4.93 & 1.58 \\
\hline & & 1 & 5.32 & 1.57 \\
\hline \multicolumn{3}{|c|}{ Capsule 2 Average } & 6.46 & 1.67 \\
\hline
\end{tabular}


Table D-13. Compact burnup and fast fluence for Capsules 6 and 5 after cycle 151A (AGR-2 cycle 7).

\begin{tabular}{|c|c|c|c|c|}
\hline Capsule & Stack & Compact & $\begin{array}{c}\text { Burnup } \\
(\% \text { FIMA) } \\
\end{array}$ & $\begin{array}{c}\text { Fast Neutron Fluence } \\
\left(10^{25} \mathrm{n} / \mathrm{m}^{2} \mathrm{E}>0.18 \mathrm{MeV}\right)\end{array}$ \\
\hline \multirow{12}{*}{6} & \multirow{4}{*}{1} & 4 & 5.63 & 1.35 \\
\hline & & 3 & 5.74 & 1.48 \\
\hline & & 2 & 6.31 & 1.60 \\
\hline & & 1 & 6.99 & 1.69 \\
\hline & \multirow{4}{*}{2} & 4 & 5.65 & 1.36 \\
\hline & & 3 & 5.75 & 1.49 \\
\hline & & 2 & 6.34 & 1.61 \\
\hline & & 1 & 7.02 & 1.69 \\
\hline & \multirow{4}{*}{3} & 4 & 4.10 & 1.19 \\
\hline & & 3 & 4.01 & 1.30 \\
\hline & & 2 & 4.52 & 1.41 \\
\hline & & 1 & 5.36 & 1.49 \\
\hline \multicolumn{3}{|c|}{ Capsule 6 Average } & 5.62 & 1.47 \\
\hline \multirow{12}{*}{5} & \multirow{4}{*}{1} & 4 & 7.96 & 1.94 \\
\hline & & 3 & 7.78 & 2.03 \\
\hline & & 2 & 8.08 & 2.09 \\
\hline & & 1 & 8.78 & 2.12 \\
\hline & \multirow{4}{*}{2} & 4 & 7.96 & 1.95 \\
\hline & & 3 & 7.85 & 2.04 \\
\hline & & 2 & 8.15 & 2.11 \\
\hline & & 1 & 8.86 & 2.14 \\
\hline & \multirow{4}{*}{3} & 4 & 6.14 & 1.71 \\
\hline & & 3 & 5.92 & 1.79 \\
\hline & & 2 & 6.18 & 1.85 \\
\hline & & 1 & 6.90 & 1.88 \\
\hline \multicolumn{3}{|c|}{ Capsule 5 Average } & 7.55 & 1.97 \\
\hline
\end{tabular}


Table D-14. Compact burnup and fast fluence for Capsules 3 and 2 after cycle 151A (AGR-2 cycle 7).

\begin{tabular}{|c|c|c|c|c|}
\hline Capsule & Stack & Compact & $\begin{array}{l}\text { Burnup } \\
\text { (\% FIMA) }\end{array}$ & $\begin{array}{c}\text { Fast Neutron Fluence } \\
\left(10^{25} \mathrm{n} / \mathrm{m}^{2} \mathrm{E}>0.18 \mathrm{MeV}\right)\end{array}$ \\
\hline \multirow{12}{*}{3} & \multirow{4}{*}{1} & 4 & 7.34 & 2.16 \\
\hline & & 3 & 7.07 & 2.17 \\
\hline & & 2 & 7.04 & 2.16 \\
\hline & & 1 & 7.29 & 2.13 \\
\hline & \multirow{4}{*}{2} & 4 & 7.42 & 2.19 \\
\hline & & 3 & 7.17 & 2.20 \\
\hline & & 2 & 7.13 & 2.19 \\
\hline & & 1 & 7.38 & 2.15 \\
\hline & \multirow{4}{*}{3} & 4 & 6.05 & 1.93 \\
\hline & & 3 & 5.78 & 1.93 \\
\hline & & 2 & 5.76 & 1.92 \\
\hline & & 1 & 5.98 & 1.90 \\
\hline \multicolumn{3}{|c|}{ Capsule 3 Average } & 6.78 & 2.09 \\
\hline \multirow{12}{*}{2} & \multirow{4}{*}{1} & 4 & 9.09 & 2.15 \\
\hline & & 3 & 8.48 & 2.13 \\
\hline & & 2 & 8.29 & 2.08 \\
\hline & & 1 & 8.52 & 2.00 \\
\hline & \multirow{4}{*}{2} & 4 & 9.16 & 2.17 \\
\hline & & 3 & 8.54 & 2.16 \\
\hline & & 2 & 8.39 & 2.11 \\
\hline & & 1 & 8.62 & 2.03 \\
\hline & \multirow{4}{*}{3} & 4 & 7.34 & 1.93 \\
\hline & & 3 & 6.66 & 1.93 \\
\hline & & 2 & 6.48 & 1.92 \\
\hline & & 1 & 6.81 & 1.90 \\
\hline \multicolumn{3}{|c|}{ Capsule 2 Average } & 8.03 & 2.02 \\
\hline
\end{tabular}


Table D-15. Compact burnup and fast fluence for Capsules 6 and 5 after cycle 151B (AGR-2 cycle 8).

\begin{tabular}{|c|c|c|c|c|}
\hline Capsule & Stack & Compact & $\begin{array}{l}\text { Burnup } \\
\text { (\% FIMA) }\end{array}$ & $\begin{array}{c}\text { Fast Neutron Fluence } \\
\left(10^{25} \mathrm{n} / \mathrm{m}^{2} \mathrm{E}>0.18 \mathrm{MeV}\right)\end{array}$ \\
\hline \multirow{12}{*}{6} & \multirow{4}{*}{1} & 4 & 6.61 & 1.57 \\
\hline & & 3 & 6.78 & 1.72 \\
\hline & & 2 & 7.37 & 1.85 \\
\hline & & 1 & 8.06 & 1.95 \\
\hline & \multirow{4}{*}{2} & 4 & 6.60 & 1.57 \\
\hline & & 3 & 6.76 & 1.72 \\
\hline & & 2 & 7.37 & 1.86 \\
\hline & & 1 & 8.06 & 1.95 \\
\hline & \multirow{4}{*}{3} & 4 & 4.90 & 1.38 \\
\hline & & 3 & 4.89 & 1.51 \\
\hline & & 2 & 5.47 & 1.63 \\
\hline & & 1 & 6.33 & 1.72 \\
\hline \multicolumn{3}{|c|}{ Capsule 6 Average } & 6.60 & 1.70 \\
\hline \multirow{12}{*}{5} & \multirow{4}{*}{1} & 4 & 9.13 & 2.24 \\
\hline & & 3 & 9.01 & 2.35 \\
\hline & & 2 & 9.30 & 2.42 \\
\hline & & 1 & 9.96 & 2.45 \\
\hline & \multirow{4}{*}{2} & 4 & 9.10 & 2.25 \\
\hline & & 3 & 9.03 & 2.36 \\
\hline & & 2 & 9.33 & 2.43 \\
\hline & & 1 & 10.01 & 2.46 \\
\hline & \multirow{4}{*}{3} & 4 & 7.22 & 1.98 \\
\hline & & 3 & 7.06 & 2.07 \\
\hline & & 2 & 7.35 & 2.14 \\
\hline & & 1 & 8.06 & 2.17 \\
\hline \multicolumn{3}{|c|}{ Capsule 5 Average } & 8.71 & 2.28 \\
\hline
\end{tabular}


Table D-16. Compact burnup and fast fluence for Capsules 3 and 2 after cycle 151B (AGR-2 cycle 8).

\begin{tabular}{|c|c|c|c|c|}
\hline Capsule & Stack & Compact & $\begin{array}{l}\text { Burnup } \\
\text { (\% FIMA) }\end{array}$ & $\begin{array}{c}\text { Fast Neutron Fluence } \\
\left(10^{25} \mathrm{n} / \mathrm{m}^{2} \mathrm{E}>0.18 \mathrm{MeV}\right)\end{array}$ \\
\hline \multirow{12}{*}{3} & \multirow{4}{*}{1} & 4 & 8.26 & 2.49 \\
\hline & & 3 & 8.03 & 2.50 \\
\hline & & 2 & 8.00 & 2.49 \\
\hline & & 1 & 8.22 & 2.45 \\
\hline & \multirow{4}{*}{2} & 4 & 8.32 & 2.51 \\
\hline & & 3 & 8.10 & 2.53 \\
\hline & & 2 & 8.06 & 2.52 \\
\hline & & 1 & 8.28 & 2.48 \\
\hline & \multirow{4}{*}{3} & 4 & 6.96 & 2.22 \\
\hline & & 3 & 6.70 & 2.23 \\
\hline & & 2 & 6.65 & 2.21 \\
\hline & & 1 & 6.89 & 2.18 \\
\hline \multicolumn{3}{|c|}{ Capsule 3 Average } & 7.71 & 2.40 \\
\hline \multirow{12}{*}{2} & \multirow{4}{*}{1} & 4 & 10.29 & 2.47 \\
\hline & & 3 & 9.70 & 2.46 \\
\hline & & 2 & 9.51 & 2.40 \\
\hline & & 1 & 9.68 & 2.31 \\
\hline & \multirow{4}{*}{2} & 4 & 10.30 & 2.50 \\
\hline & & 3 & 9.72 & 2.49 \\
\hline & & 2 & 9.57 & 2.43 \\
\hline & & 1 & 9.75 & 2.34 \\
\hline & \multirow{4}{*}{3} & 4 & 8.50 & 2.22 \\
\hline & & 3 & 7.87 & 2.23 \\
\hline & & 2 & 7.69 & 2.21 \\
\hline & & 1 & 7.97 & 2.18 \\
\hline \multicolumn{3}{|c|}{ Capsule 2 Average } & 9.21 & 2.33 \\
\hline
\end{tabular}


Table D-17. Compact burnup and fast fluence for Capsules 6 and 5 after cycle 152B (AGR-2 cycle 9).

\begin{tabular}{|c|c|c|c|c|}
\hline Capsule & Stack & Compact & $\begin{array}{l}\text { Burnup } \\
\text { (\% FIMA) }\end{array}$ & $\begin{array}{c}\text { Fast Neutron Fluence } \\
\left(10^{25} \mathrm{n} / \mathrm{m}^{2} \mathrm{E}>0.18 \mathrm{MeV}\right)\end{array}$ \\
\hline \multirow{12}{*}{6} & \multirow{4}{*}{1} & 4 & 7.49 & 1.78 \\
\hline & & 3 & 7.72 & 1.96 \\
\hline & & 2 & 8.32 & 2.11 \\
\hline & & 1 & 8.99 & 2.21 \\
\hline & \multirow{4}{*}{2} & 4 & 7.46 & 1.78 \\
\hline & & 3 & 7.70 & 1.96 \\
\hline & & 2 & 8.31 & 2.11 \\
\hline & & 1 & 8.99 & 2.22 \\
\hline & \multirow{4}{*}{3} & 4 & 5.65 & 1.56 \\
\hline & & 3 & 5.71 & 1.72 \\
\hline & & 2 & 6.36 & 1.85 \\
\hline & & 1 & 7.24 & 1.96 \\
\hline \multicolumn{3}{|c|}{ Capsule 6 Average } & 7.49 & 1.94 \\
\hline \multirow{12}{*}{5} & \multirow{4}{*}{1} & 4 & 10.15 & 2.54 \\
\hline & & 3 & 10.08 & 2.66 \\
\hline & & 2 & 10.36 & 2.74 \\
\hline & & 1 & 10.97 & 2.77 \\
\hline & \multirow{4}{*}{2} & 4 & 10.11 & 2.55 \\
\hline & & 3 & 10.09 & 2.67 \\
\hline & & 2 & 10.38 & 2.76 \\
\hline & & 1 & 11.01 & 2.79 \\
\hline & \multirow{4}{*}{3} & 4 & 8.18 & 2.25 \\
\hline & & 3 & 8.08 & 2.36 \\
\hline & & 2 & 8.40 & 2.43 \\
\hline & & 1 & 9.10 & 2.46 \\
\hline \multicolumn{3}{|c|}{ Capsule 5 Average } & 9.74 & 2.58 \\
\hline
\end{tabular}


Table D-18. Compact burnup and fast fluence for Capsules 3 and 2 after cycle 152B (AGR-2 cycle 9).

\begin{tabular}{|c|c|c|c|c|}
\hline Capsule & Stack & Compact & $\begin{array}{l}\text { Burnup } \\
\text { (\% FIMA) }\end{array}$ & $\begin{array}{c}\text { Fast Neutron Fluence } \\
\left(10^{25} \mathrm{n} / \mathrm{m}^{2} \mathrm{E}>0.18 \mathrm{MeV}\right)\end{array}$ \\
\hline \multirow{12}{*}{3} & \multirow{4}{*}{1} & 4 & 9.07 & 2.82 \\
\hline & & 3 & 8.88 & 2.83 \\
\hline & & 2 & 8.84 & 2.82 \\
\hline & & 1 & 9.04 & 2.77 \\
\hline & \multirow{4}{*}{2} & 4 & 9.13 & 2.85 \\
\hline & & 3 & 8.93 & 2.87 \\
\hline & & 2 & 8.90 & 2.85 \\
\hline & & 1 & 9.09 & 2.80 \\
\hline & \multirow{4}{*}{3} & 4 & 7.76 & 2.52 \\
\hline & & 3 & 7.50 & 2.52 \\
\hline & & 2 & 7.45 & 2.51 \\
\hline & & 1 & 7.69 & 2.48 \\
\hline \multicolumn{3}{|c|}{ Capsule 3 Average } & 8.52 & 2.72 \\
\hline \multirow{12}{*}{2} & \multirow{4}{*}{1} & 4 & 11.30 & 2.80 \\
\hline & & 3 & 10.75 & 2.79 \\
\hline & & 2 & 10.56 & 2.72 \\
\hline & & 1 & 10.68 & 2.62 \\
\hline & \multirow{4}{*}{2} & 4 & 11.29 & 2.83 \\
\hline & & 3 & 10.76 & 2.82 \\
\hline & & 2 & 10.61 & 2.75 \\
\hline & & 1 & 10.74 & 2.65 \\
\hline & \multirow{4}{*}{3} & 4 & 9.53 & 2.52 \\
\hline & & 3 & 8.95 & 2.52 \\
\hline & & 2 & 8.76 & 2.51 \\
\hline & & 1 & 8.98 & 2.48 \\
\hline \multicolumn{3}{|c|}{ Capsule 2 Average } & 10.24 & 2.64 \\
\hline
\end{tabular}


Table D-19. Compact burnup and fast fluence for Capsules 6 and 5 after cycle 153B (AGR-2 cycle 10).

\begin{tabular}{|c|c|c|c|c|}
\hline Capsule & Stack & Compact & $\begin{array}{l}\text { Burnup } \\
\text { (\% FIMA) }\end{array}$ & $\begin{array}{c}\text { Fast Neutron Fluence } \\
\left(10^{25} \mathrm{n} / \mathrm{m}^{2} \mathrm{E}>0.18 \mathrm{MeV}\right)\end{array}$ \\
\hline \multirow{12}{*}{6} & \multirow{4}{*}{1} & 4 & 7.64 & 1.79 \\
\hline & & 3 & 7.87 & 1.97 \\
\hline & & 2 & 8.47 & 2.12 \\
\hline & & 1 & 9.14 & 2.22 \\
\hline & \multirow{4}{*}{2} & 4 & 7.64 & 1.80 \\
\hline & & 3 & 7.87 & 1.97 \\
\hline & & 2 & 8.49 & 2.13 \\
\hline & & 1 & 9.16 & 2.23 \\
\hline & \multirow{4}{*}{3} & 4 & 5.82 & 1.58 \\
\hline & & 3 & 5.89 & 1.73 \\
\hline & & 2 & 6.54 & 1.87 \\
\hline & & 1 & 7.42 & 1.97 \\
\hline \multicolumn{3}{|c|}{ Capsule 6 Average } & 7.66 & 1.95 \\
\hline \multirow{12}{*}{5} & \multirow{4}{*}{1} & 4 & 10.30 & 2.55 \\
\hline & & 3 & 10.22 & 2.68 \\
\hline & & 2 & 10.50 & 2.76 \\
\hline & & 1 & 11.10 & 2.79 \\
\hline & \multirow{4}{*}{2} & 4 & 10.28 & 2.56 \\
\hline & & 3 & 10.26 & 2.69 \\
\hline & & 2 & 10.55 & 2.77 \\
\hline & & 1 & 11.16 & 2.80 \\
\hline & \multirow{4}{*}{3} & 4 & 8.36 & 2.26 \\
\hline & & 3 & 8.27 & 2.37 \\
\hline & & 2 & 8.59 & 2.44 \\
\hline & & 1 & 9.27 & 2.48 \\
\hline \multicolumn{3}{|c|}{ Capsule 5 Average } & 9.91 & 2.60 \\
\hline
\end{tabular}


Table D-20. Compact burnup and fast fluence for Capsules 3 and 2 after cycle 153B (AGR-2 cycle 10).

\begin{tabular}{|c|c|c|c|c|}
\hline Capsule & Stack & Compact & $\begin{array}{l}\text { Burnup } \\
\text { (\% FIMA) }\end{array}$ & $\begin{array}{c}\text { Fast Neutron Fluence } \\
\left(10^{25} \mathrm{n} / \mathrm{m}^{2} \mathrm{E}>0.18 \mathrm{MeV}\right)\end{array}$ \\
\hline \multirow{12}{*}{3} & \multirow{4}{*}{1} & 4 & 9.18 & 2.83 \\
\hline & & 3 & 8.99 & 2.85 \\
\hline & & 2 & 8.95 & 2.83 \\
\hline & & 1 & 9.15 & 2.78 \\
\hline & \multirow{4}{*}{2} & 4 & 9.25 & 2.86 \\
\hline & & 3 & 9.05 & 2.88 \\
\hline & & 2 & 9.02 & 2.87 \\
\hline & & 1 & 9.21 & 2.82 \\
\hline & \multirow{4}{*}{3} & 4 & 7.89 & 2.53 \\
\hline & & 3 & 7.64 & 2.54 \\
\hline & & 2 & 7.58 & 2.52 \\
\hline & & 1 & 7.82 & 2.49 \\
\hline \multicolumn{3}{|c|}{ Capsule 3 Average } & 8.64 & 2.73 \\
\hline \multirow{12}{*}{2} & \multirow{4}{*}{1} & 4 & 11.43 & 2.82 \\
\hline & & 3 & 10.88 & 2.80 \\
\hline & & 2 & 10.69 & 2.74 \\
\hline & & 1 & 10.82 & 2.63 \\
\hline & \multirow{4}{*}{2} & 4 & 11.43 & 2.85 \\
\hline & & 3 & 10.91 & 2.83 \\
\hline & & 2 & 10.76 & 2.77 \\
\hline & & 1 & 10.89 & 2.66 \\
\hline & \multirow{4}{*}{3} & 4 & 9.70 & 2.53 \\
\hline & & 3 & 9.12 & 2.54 \\
\hline & & 2 & 8.93 & 2.52 \\
\hline & & 1 & 9.15 & 2.49 \\
\hline \multicolumn{3}{|c|}{ Capsule 2 Average } & 10.39 & 2.66 \\
\hline
\end{tabular}


Table D-21. Compact burnup and fast fluence for Capsules 6 and 5 after cycle 154A (AGR-2 cycle 11).

\begin{tabular}{|c|c|c|c|c|}
\hline Capsule & Stack & Compact & $\begin{array}{l}\text { Burnup } \\
\text { (\% FIMA) }\end{array}$ & $\begin{array}{c}\text { Fast Neutron Fluence } \\
\left(10^{25} \mathrm{n} / \mathrm{m}^{2} \mathrm{E}>0.18 \mathrm{MeV}\right)\end{array}$ \\
\hline \multirow{12}{*}{6} & \multirow{4}{*}{1} & 4 & 8.44 & 1.99 \\
\hline & & 3 & 8.75 & 2.19 \\
\hline & & 2 & 9.34 & 2.36 \\
\hline & & 1 & 9.98 & 2.47 \\
\hline & \multirow{4}{*}{2} & 4 & 8.44 & 2.00 \\
\hline & & 3 & 8.74 & 2.19 \\
\hline & & 2 & 9.34 & 2.36 \\
\hline & & 1 & 9.98 & 2.47 \\
\hline & \multirow{4}{*}{3} & 4 & 6.54 & 1.75 \\
\hline & & 3 & 6.66 & 1.93 \\
\hline & & 2 & 7.37 & 2.08 \\
\hline & & 1 & 8.26 & 2.19 \\
\hline \multicolumn{3}{|c|}{ Capsule 6 Average } & 8.49 & 2.17 \\
\hline \multirow{12}{*}{5} & \multirow{4}{*}{1} & 4 & 11.20 & 2.83 \\
\hline & & 3 & 11.16 & 2.97 \\
\hline & & 2 & 11.43 & 3.06 \\
\hline & & 1 & 11.97 & 3.09 \\
\hline & \multirow{4}{*}{2} & 4 & 11.17 & 2.84 \\
\hline & & 3 & 11.19 & 2.98 \\
\hline & & 2 & 11.46 & 3.07 \\
\hline & & 1 & 12.02 & 3.10 \\
\hline & \multirow{4}{*}{3} & 4 & 9.22 & 2.51 \\
\hline & & 3 & 9.18 & 2.63 \\
\hline & & 2 & 9.51 & 2.71 \\
\hline & & 1 & 10.19 & 2.75 \\
\hline \multicolumn{3}{|c|}{ Capsule 5 Average } & 10.81 & 2.88 \\
\hline
\end{tabular}


Table D-22. Compact burnup and fast fluence for Capsules 3 and 2 after cycle 154A (AGR-2 cycle 11).

\begin{tabular}{|c|c|c|c|c|}
\hline Capsule & Stack & Compact & $\begin{array}{l}\text { Burnup } \\
\text { (\% FIMA) }\end{array}$ & $\begin{array}{c}\text { Fast Neutron Fluence } \\
\left(10^{25} \mathrm{n} / \mathrm{m}^{2} \mathrm{E}>0.18 \mathrm{MeV}\right)\end{array}$ \\
\hline \multirow{12}{*}{3} & \multirow{4}{*}{1} & 4 & 9.92 & 3.14 \\
\hline & & 3 & 9.74 & 3.16 \\
\hline & & 2 & 9.70 & 3.14 \\
\hline & & 1 & 9.89 & 3.09 \\
\hline & \multirow{4}{*}{2} & 4 & 9.97 & 3.17 \\
\hline & & 3 & 9.80 & 3.19 \\
\hline & & 2 & 9.78 & 3.17 \\
\hline & & 1 & 9.94 & 3.12 \\
\hline & \multirow{4}{*}{3} & 4 & 8.58 & 2.80 \\
\hline & & 3 & 8.35 & 2.81 \\
\hline & & 2 & 8.29 & 2.80 \\
\hline & & 1 & 8.51 & 2.76 \\
\hline \multicolumn{3}{|c|}{ Capsule 3 Average } & 9.37 & 3.03 \\
\hline \multirow{12}{*}{2} & \multirow{4}{*}{1} & 4 & 12.28 & 3.12 \\
\hline & & 3 & 11.78 & 3.10 \\
\hline & & 2 & 11.61 & 3.03 \\
\hline & & 1 & 11.70 & 2.91 \\
\hline & \multirow{4}{*}{2} & 4 & 12.28 & 3.15 \\
\hline & & 3 & 11.80 & 3.14 \\
\hline & & 2 & 11.67 & 3.07 \\
\hline & & 1 & 11.77 & 2.95 \\
\hline & \multirow{4}{*}{3} & 4 & 10.62 & 2.80 \\
\hline & & 3 & 10.06 & 2.81 \\
\hline & & 2 & 9.86 & 2.80 \\
\hline & & 1 & 10.04 & 2.76 \\
\hline \multicolumn{3}{|c|}{ Capsule 2 Average } & 11.29 & 2.95 \\
\hline
\end{tabular}


Table D-23. Compact burnup and fast fluence for Capsules 6 and 5 after cycle 154B (AGR-2 cycle 12).

\begin{tabular}{|c|c|c|c|c|}
\hline Capsule & Stack & Compact & $\begin{array}{l}\text { Burnup } \\
\text { (\% FIMA) }\end{array}$ & $\begin{array}{c}\text { Fast Neutron Fluence } \\
\left(10^{25} \mathrm{n} / \mathrm{m}^{2} \mathrm{E}>0.18 \mathrm{MeV}\right)\end{array}$ \\
\hline \multirow{12}{*}{6} & \multirow{4}{*}{1} & 4 & 9.24 & 2.20 \\
\hline & & 3 & 9.59 & 2.42 \\
\hline & & 2 & 10.16 & 2.60 \\
\hline & & 1 & 10.77 & 2.73 \\
\hline & \multirow{4}{*}{2} & 4 & 9.26 & 2.21 \\
\hline & & 3 & 9.60 & 2.43 \\
\hline & & 2 & 10.19 & 2.61 \\
\hline & & 1 & 10.81 & 2.73 \\
\hline & \multirow{4}{*}{3} & 4 & 7.26 & 1.94 \\
\hline & & 3 & 7.46 & 2.14 \\
\hline & & 2 & 8.22 & 2.30 \\
\hline & & 1 & 9.09 & 2.42 \\
\hline \multicolumn{3}{|c|}{ Capsule 6 Average } & 9.30 & 2.39 \\
\hline \multirow{12}{*}{5} & \multirow{4}{*}{1} & 4 & 12.05 & 3.12 \\
\hline & & 3 & 12.03 & 3.28 \\
\hline & & 2 & 12.28 & 3.38 \\
\hline & & 1 & 12.80 & 3.41 \\
\hline & \multirow{4}{*}{2} & 4 & 12.03 & 3.14 \\
\hline & & 3 & 12.08 & 3.29 \\
\hline & & 2 & 12.34 & 3.39 \\
\hline & & 1 & 12.88 & 3.42 \\
\hline & \multirow{4}{*}{3} & 4 & 10.08 & 2.77 \\
\hline & & 3 & 10.07 & 2.91 \\
\hline & & 2 & 10.42 & 3.00 \\
\hline & & 1 & 11.09 & 3.03 \\
\hline \multicolumn{3}{|c|}{ Capsule 5 Average } & 11.68 & 3.18 \\
\hline
\end{tabular}


Table D-24. Compact burnup and fast fluence for Capsules 3 and 2 after cycle 154B (AGR-2 cycle 12).

\begin{tabular}{|c|c|c|c|c|}
\hline Capsule & Stack & Compact & $\begin{array}{c}\text { Burnup } \\
\text { (\% FIMA) }\end{array}$ & $\begin{array}{l}\text { Fast Neutron Fluence } \\
\left(10^{25} \mathrm{n} / \mathrm{m}^{2} \mathrm{E}>0.18 \mathrm{MeV}\right)\end{array}$ \\
\hline \multirow{12}{*}{3} & \multirow{4}{*}{1} & 4 & 10.62 & 3.47 \\
\hline & & 3 & 10.46 & 3.49 \\
\hline & & 2 & 10.43 & 3.47 \\
\hline & & 1 & 10.60 & 3.41 \\
\hline & \multirow{4}{*}{2} & 4 & 10.69 & 3.50 \\
\hline & & 3 & 10.54 & 3.53 \\
\hline & & 2 & 10.51 & 3.51 \\
\hline & & 1 & 10.66 & 3.45 \\
\hline & \multirow{4}{*}{3} & 4 & 9.31 & 3.10 \\
\hline & & 3 & 9.07 & 3.11 \\
\hline & & 2 & 9.01 & 3.09 \\
\hline & & 1 & 9.25 & 3.05 \\
\hline \multicolumn{3}{|c|}{ Capsule 3 Average } & 10.10 & 3.35 \\
\hline \multirow{12}{*}{2} & \multirow{4}{*}{1} & 4 & 13.11 & 3.44 \\
\hline & & 3 & 12.63 & 3.42 \\
\hline & & 2 & 12.47 & 3.35 \\
\hline & & 1 & 12.53 & 3.21 \\
\hline & \multirow{4}{*}{2} & 4 & 13.15 & 3.47 \\
\hline & & 3 & 12.68 & 3.46 \\
\hline & & 2 & 12.55 & 3.39 \\
\hline & & 1 & 12.62 & 3.25 \\
\hline & \multirow{4}{*}{3} & 4 & 11.52 & 3.10 \\
\hline & & 3 & 11.00 & 3.11 \\
\hline & & 2 & 10.80 & 3.09 \\
\hline & & 1 & 10.95 & 3.05 \\
\hline \multicolumn{3}{|c|}{ Capsule 2 Average } & 12.17 & 3.25 \\
\hline
\end{tabular}


This page intentionally left blank. 